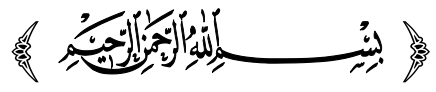

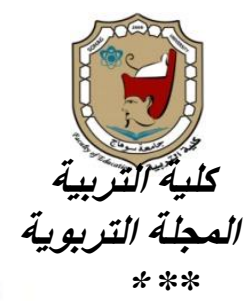

استفدام اسلوب teach live فى التنمية المهنية لمعلم الثزبية الخاصة فى هصر فى ضوى خبرة جاهمتى فلوريدا وهاريلاند بالولايات المتدة الاهمريكية

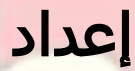

د دوفاء زكى بلدروس بشاى

أستاذ مساعد بقسم التربية المقارنة

كلية التربية - جامعة الاسكندرية

المجلة التربوية ـ العدد الثامن والستوز ـ ديسهبر 19+rم

Print:(ISSN 1687-2649) Online:(ISSN 2536-9091) 
الماخص المربي:

يؤدي معلم التربية الخاصة دورًا جوهريًا فى عملية تأهيل تلاميذه و تدريبهم، وحتى يتسنى لله القيام بهذا الدور لابد له من أن يمتلك مستوى مناسبًا من المعلومات النظرية حول ذوى الاحتياجات الخاصة مثل تعريفهم، وخصائصهم المميزة، وأسباب الإعاقة، ونظريات التدريس وغيرها من المعلومات النظرية التى يمكن أن تشكل لايه بنية معرفية تمكنه من فهم فئة التلاميذ ذوى الاحتياجات التربوية الخاصة الذين يعمل معهم، إلا أن الجانب النظرى وحده لا يكفى لتمكين معلم التربية الخاصة من تحقيق النتائج المرجوة بالنسبة له أو للطقل أو ذويه أو حتى المؤسسة التى يعمل بها، لذلك لابد له بجانب المعلومات النظرية أن يمتلك مستوى مناسبًا من المهارات العملية التطبيقية التى تمكنه من القيام بواجباته تجاه التلاميذ ذوى الاحتياجات التريوية الخاصة على الوجه الذى يليق ،حتي تواكب التطور الحادث فى النظم التعليمية فى الدول المختلفة ولتساير انتثار التكنولوجيا الحديثة واستخدامها فى التدريس لذلك تركز الدراسة الحالية على أسلوب teach liveبوصفه أحد الأساليب الحديثة للتنمية المهنية لمعلم التربية الخاصة فى ضوء خبرة المخزون التجريبي لجامعتى فلوريدا وماريلاند بالولايات المتحدة الأمريكية.

ومن هنا يحاول البحث الحالى الإجابة عن التساؤل الرئيس التالى: كيف يمكن استخدام أسلوب teach live فى التنمية المهنية لمعلم التربية الخاصة فى مصر فى ضوء خبرة جامعتى فلوريدا وماريلاند بالولايات المتحدة الأمريكية؟. ويتفرع السؤال الرئيس إلى بعضالأسئلة الفرعية التى تتمثل فيما يلي : 1. ما الأسس النظرية والمعيارية المرتبطة بمجال معلم التربية الخاصة فى الأدبيات التريوية

المعاصرة ؟.

r. ما المبررات التى دعت إلي الاهتمام بمعلم التربية الخاصة ؟ وما أبرز المشكلات التى يعانى منها معلم التربية الخاصة فى مصر ؟

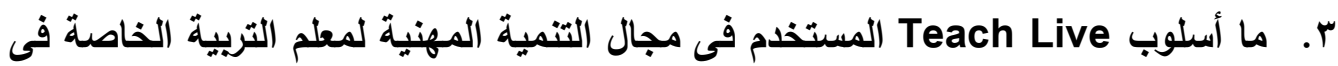
جامعتى فلوريدا وماريلاند بالولايات المتحدة الأمريكية؛. 
ء. ما أوجه الشبه والاختلاف بين خبرة كل من جامعة فلوريدا وجامعة ماريلاند بالولايات المتحدة الأمريكية فى مجال استخدام أسلوب Teach Live فى التدريس وفي تدريب

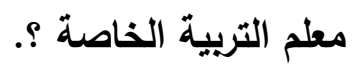

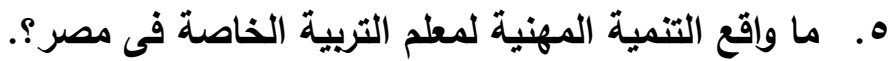
צ. ما التصور المقترح لتطبيق أسلوب(Teach Live فى التنمية المهنية لمعلم التربية الخاصة فى مصر فى ضوء خبرة جامعة فلوريدا وجامعة ماريلاند بالولايات المتحدة

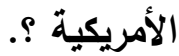

وقد اقتصرت هذه الاراسة على أسلوب Teach Live من حيث المفهوم والأهمية والأهداف ومن حيث استخدامه بوصفه أحد أساليب التنمية المهنية لمعلم التربية الخاصة فى هي الولايات المتحدة الأمريكية فى كل من جامعتى فلوريدا وماريلاند ؛ حيث إنهما من أوائل الجامعات التى بأت فى تدريب المعلمين على تطبيق Teach Live فى التدريس وحققت به نجاحات عديدة. واستخدمت الدراسة المنهج المقارن، بهذف التعرف على خبرات بعض الجامعات فى الولايات المتحدة الأمريكية وهما كل من جامعة فلوريدا وجامعة ماريلاند فى مجال استخدام أسلوبTeach Live فى التدريس وفي تدريب معلم التربية الخاصة عليه ؛ للاستفادة منه فى تطوير أساليب التنمية المهنية لمعلم التربية الخاصة فى مصر. 
استخدام اسلوب teach live فى التنمية المهنية لمعلم التربية الخاصة فى مصر

The use of teach live in the professional development of special
education teacher in Egypt in light of the experience of the universities
of Florida and Maryland, USA
Dr.. Wafaa Zaki Badrose Beshay
Assistant Professor, Department of Comparative Education
Faculty of Education - Alexandria University

Abstract:

The special education teacher plays an essential role in the process of rehabilitation and training of his students, and in order to do this role must have an appropriate level of theoretical information about people with special needs such as their definition, characteristics, causes of disability, theories of teaching and other theoretical information that can be $A$ cognitive structure that enables him to understand the class of students with special educational needs with whom he works, but the theoretical side alone is not enough to enable the special education teacher to achieve the desired results for him or the child or his parents or even the institution where he works, so it must be beside the information The theory should have an appropriate level of practical skills applied to enable him to carry out his duties towards students with special educational needs in a manner that is appropriate, as it kept pace with the development in the educational systems in different countries and the spread of modern technology and use in teaching, so the current study focuses on one of the modern methods For professional Special education teacher in

light of the experience of the University of Florida and the University of Maryland, USA.

Hence the current research attempts to answer the following key question:

How can the use of teach live in the professional development of special education teacher in Egypt in light of the experience of the universities of Florida and Maryland in the United States of America?

The main question is divided into some sub-questions:

1. What are the theoretical and normative bases associated with the field of special education teacher in contemporary educational literature?

2. What are the justifications that called for attention to the teacher of special education? What are the main problems experienced by the special education teacher in Egypt?

3. What is the method of Teach Live used in the professional development of the special education teacher at the Universities of Florida and Maryland, USA? 
استخدام اسلوب teach live فى التنمية المهنية لمعلم التربية الخاصة فى مصر

4. What are the similarities and differences between the experience of the University of Florida and the University of Maryland in the United States of America in the use of Teach Live in teaching and training of special education teacher?

5. What is the reality of the professional development of the special education teacher in Egypt?

6. What is the proposed concept of applying the Teach Live method in the professional development of the special education teacher in Egypt in the light of the experience of the University of Florida and the University of Maryland, USA?

The study was limited to style Teach Live In terms of concept and a fake and a top scorer and be used as a in both the University of Florida and the University of Maryland limit professional development for teachers of special education methods in the United States of America; where they are among the first universities, which began in the training of teachers to apply Teach Live In teaching and achieved many successes.

The study also used the comparative approach, in order to identify the experiences of some universities in the United States, namely, the University of Florida and the University of Maryland in the use of Teach Live In teaching and training the teacher of special education, in order to benefit from it in the development of methods of professional development of the teacher of special education in Egypt. 
مقدمة:

شهر مجال التربية الخاصة تطورًا هائلاً على المستوى العالمى نتيجة لاهتمام المؤسسات الدولية بحث الدول وتثجيعها على إصدار التشريعات القانونية التى تضمن حصول الأطفال ذوى الإعاقات على حقوقهم فى التعليم والصحة وفي كافة مجالات المجتمع من أجل تحسين جودة الحياة Quality of Life لهم، إضافة إلي ما شهره مجال التربية فى لإلى Assistive العقود القليلة الماضية من طقرة تكنولوجية متمثية فى التكنولوجيا المعينة Technology تعليمهم وتأهيلهم كل ذلك أدى إلى تعقد المهمة الملقاة على معلم التربية الخاصة على التى

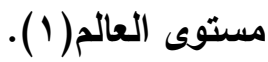

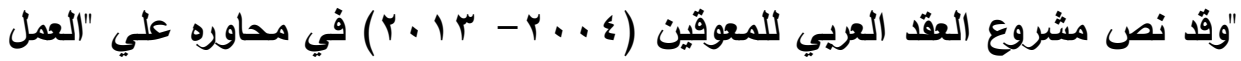
لحصول الطفل المعوق على كافة الحقوق والخدمات بالتساوي مع أقرانه من الأطفال وعلى إزالة جميع العقبات التي تحول دون تنفيذ ذلك". وقد نص مشروع العقد في مجال التعليم على "ضمان فرص متكافئة للتربية والتعليم لجميع الأشخاص المعوقين منذ الطقولة المبكرة ضمن جميع المؤسسات التربوية والتعليمية في صفوفها النظامية وفي مؤسسات خاصة، في حالة عدم قدرتهم على الاندماج أو التحصيل المناسب". (r)

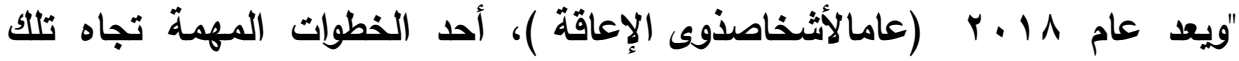
الثريحة، والتي تمثل نسبة ليست بالقليلة في المجتمع المصري، الأمر الذي يعد تقديرًا من القيادة السياسية لحقوق هذه الفئة، كي تعيش بكرامة وفقا للاستور وللاتفاقيات الدولية، كذلك لإصدار القوانين المتعلقة بهم، واقتراح حلول وواقعية. لمشكلاتهم ، بالإضافة إلى أن لن هذا العام قد أتاح للمجتمع بأكلمه وكافة فئاته زيادة الوعي بقضايا أبناء هذه الفئة، و تقبل اختلافهم ومحاولات دمجهم داخل المجتمع، والتأكيا على أنه عام "ذوى الإعاقة" من خلال الملتقى العربي الأول لأنشطة مدارس الامج ومدارس التنمية الفكرية"(r). إذشظلت نسبة ذوي الاحتياجات الخاصة حوالي بّ\% من إجمالي عدد سكان مصر، بدءاً من عمر خمس سنوات فأكثر، كما بلغت نسبة الأمية بين ذوي الاحتياجات الخاصة،

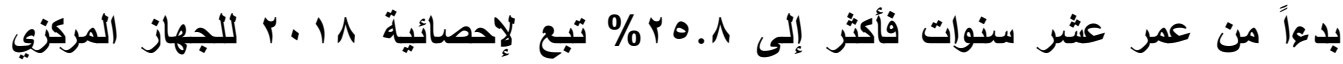


إن زيادة أعداد الطلاب ذوي الاحتياجات الخاصة أدى إلى زيادة الاهتمام بتلك المشكلات، وذلك لتتمية الإحساس بالثقة بالنفس لايهم،كذلك الثعور بالأمان والاستقرار

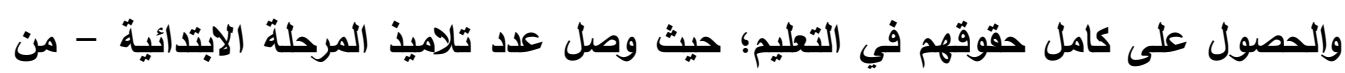

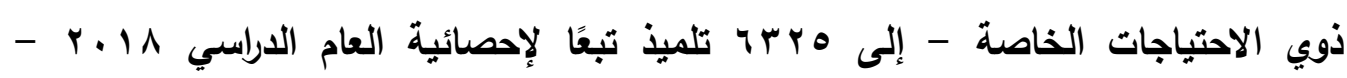
.(0) r r 19

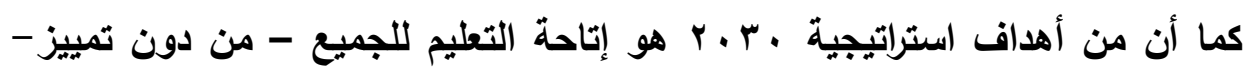

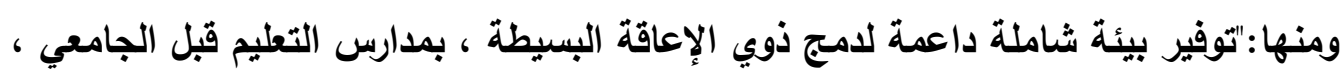
وتطوير جودة مدارس التربية الخاصة بالمتعلمين ذوي الإعاقة الحادة والمتعدّدة"( آ).

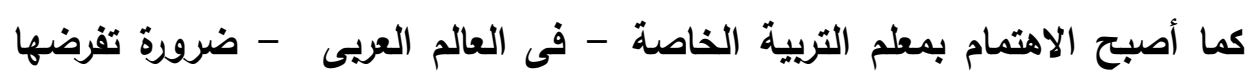

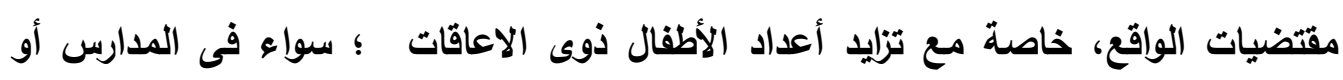

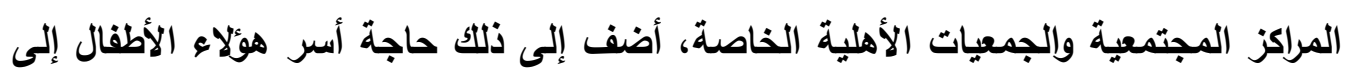

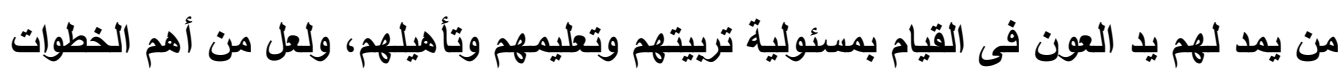
التى يجب الاهتمام بها - فى هذا الصدد - هو توافر كوادر متخصصة - في مجال التربية الخاصة - يتمتعون بالكفايات المهنية اللازمة التى تمكنهم من التعامل مع هؤلاء الأطفال

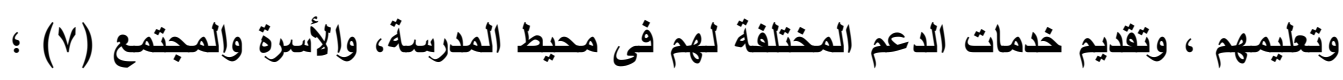
ولكن وجد أن هناك نقصًا فى أعداد هؤلاء المعلمين المتخصصين ، إلى جانب أن هناك أوجه قصور فى برامج إعداهم ، بالإضافة إلى تطور أساليب التدريس ، بوصفها نتيجة إعلاء لظهور

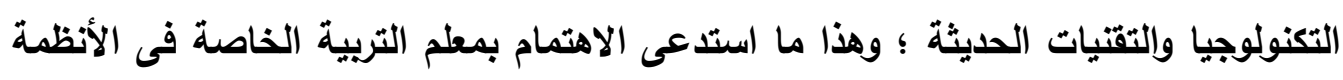

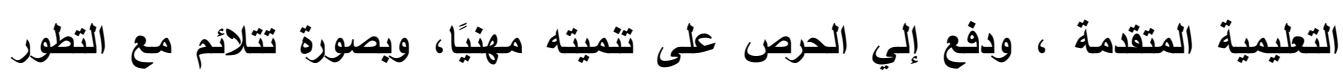
والتفيرات الحادثة. وقد تُرجم هذا الاهتمام المتزايد بمعلم التربية الخاصة وتنميته المهنية فى بعض الدول

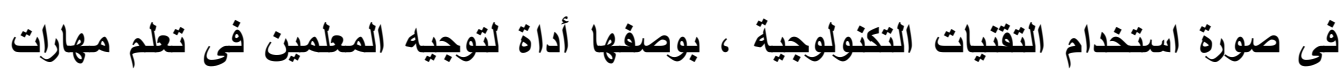
جديدة ، وإحدى هذه التقتيات هى المحاكاة ؛ والتى توفر الفرصة للمشاركة فى الممارسة الموجهة التى قد لا تكون متاحة فى الفصل الدراسى، وتسهم في تمكين التفرغ لاحتياجات

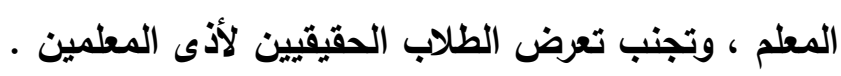


ويُعد Teach Live واحدًا من نماج المحاكاة ، حيث يوفر للمعلمين فرصة لممارسة مهارات جديدة ولتلقى ردود الفعل الفورية ، والذى طُور من قبل الباحثين فى جامعة فلوريدا وجامعة ماريلاند بالولايات المتحدة الأمريكية ؛ ليكون محاكيًا ومختلطًا (أى :جزعًا حقيقًا . جزئيًا)، حيث يتعامل المعلم مع صور تجسيدية متحركة بواسطة الكمبيوتر، وهذا ما ستركز عليه الاراسة الحالية حول كيفية استخدام أسلوب teach live فى التنمية المهنية لمعلم التربية الخاصة فى مصر ، وذلك فى ضوء خبرة الجامعتين السابقتين.

مشكلة اللدراسة:

تثنير الدراسات - فى مجال التربية الخاصة - إلى أن هناك نقصًا شديدًا فى الأفراد المؤهلين للعمل فى مجال التربية الخاصة فى معظم دول العالم ،كما تثير تلك الدراسات إلى إنى أن هناك عددًا من المعلمين - الذين يلتحقون بالعمل فى تدريس الطلاب ذوى الإعاقات - لا يلبثن أن يتركوا هذا المجال ؛ نتيجة العديد من المشكلات ، ،كما أشارت بعض الاراسات

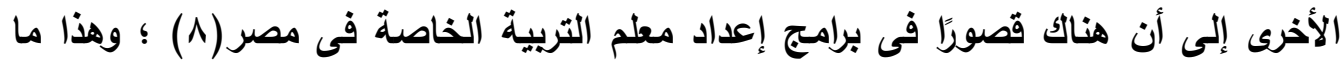
يستدعى الاهتمام بالتنمية المهنية لمعلم التربية الخاصة فى مصر لمواجهة ذلك. كما أنه - نظرًا لأن معلم التربية الخاصة يؤدي دورًا جوهريًا فى عملية تأهيل تلاميذه وتدريبهم ، وحتى يتسنى لله القيام بهذا الدور - لابد من أن يمتلك مستوى مناسبًا من المعلومات النظرية حول ذوى الاحتياجات الخاصة ، مثل تعريفهم، وخصائصهم المميزة،

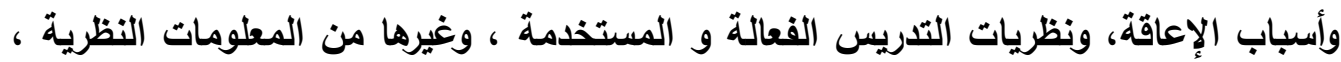
التى يمكن أن تثكل لايه بنية معرفية ، تمكنه من فهم فئة التلاميذ ذوى الاحتياجات التربوية الخاصة الذين يعمل معهم ، وتجدر الإثشارة إلي أن الجاتب النظرى - وحده - لا يكفى لتمكين

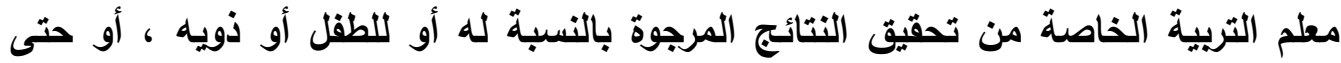

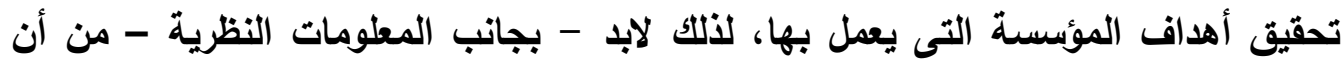
يمتلك مستوى مناسبًا من المهارات العملية التطبيقية ، التى تمكنه من القيام بواجباته تجاه لهاه التلاميذ ذوى الاحتياجات التربوية الخاصة على الوجه الذى يليق (9) ، كما ينبغي لتلك فئه المهارات أن تواكب التطور الحادث فى النظم التعليمية فى الدول المختلفة وتسهم في انتشار

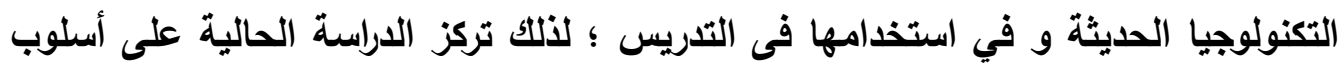

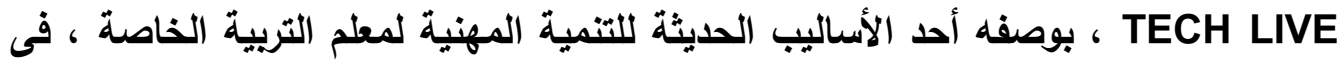


ضوء خبرة بعض جامعات الولايات المتحدة الامريكية .ومن هنا يحاول البحث الحالى الإجابة

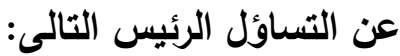

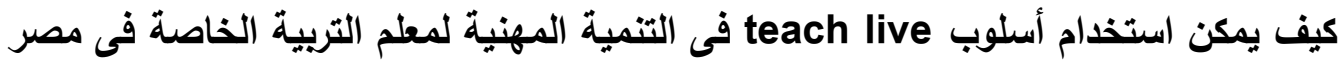

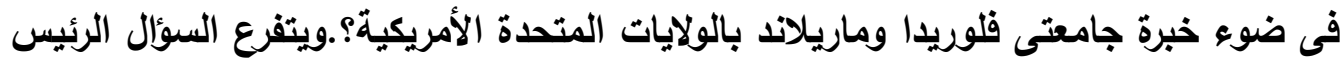
إلى بعض الأسئلة التى تتمثل فى : 1. ما الأسس النظرية والمعيارية المرتبطة بمجال معلم التربية الخاصة فى الأدبيات التريوية

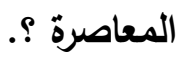

r. . ما المبررات التى تدعو إلى الاهتمام بمعلم التربية الخاصة ؟ ـ وما أبرز المشكلات التى

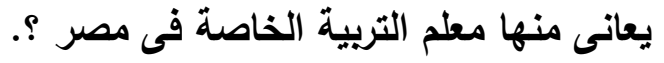

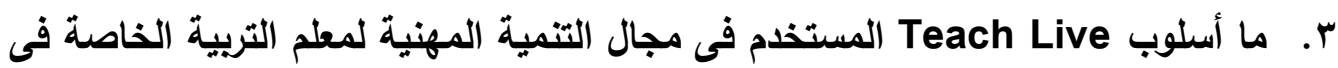
جامعتى فلوريدا وماريلاند بالولايات المتحدة الأمريكية؟. ؛. ما أوجه الثبه والاختلاف بين خبرة كل من جامعة فلوريدا وجامعة ماريلاند بالولايات المتحدة الأمريكية فى مجال استخدام أسلوب Teach Live في التدريس وفي تدريب معلم التربية الخاصة ؟

ه. ما واقع التنمية المهنية لمطلم التربية الخاصة فى مصر؟. ؟. ما التصور المقترح لتطبيق أسلوب Teach Live فى التنمية المهنية لمعلم التربية

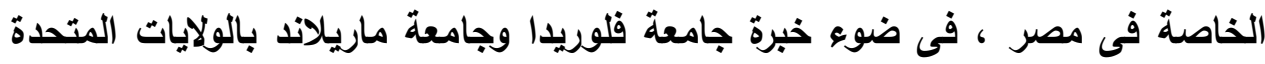

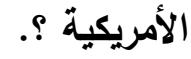
أهداف اللدراسة : تهذف الاراسة إلى : 1. التعرف على الأسس النظرية والمعيارية المرتبطة بمجال معلم التربية الخاصة فى الأدبيات

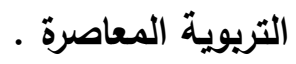
r. الكثف عن المبررات التى دعت إلى الاهتمام بمعلم التربية الخاصة ، وأبرز المشكلات

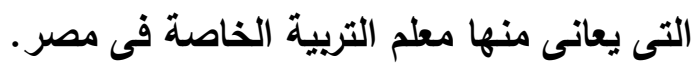
r. التعرف على أسلوب Teach Live المستخدم فى مجال التنمية المهنية لمعلم التربية الخاصة فى جامعتى فلوريدا وماريلاند بالولايات المتحدة الأمريكية. 
ع. تحديد أوجه الشبه والاختلاف بين خبرة كل من جامعة فلوريدا وجامعة ماريلاند بالولايات

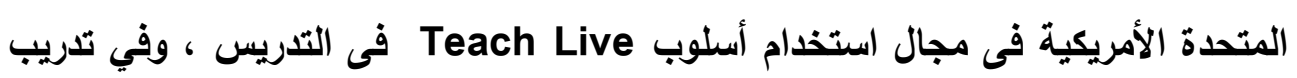

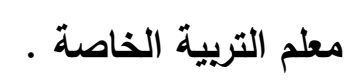

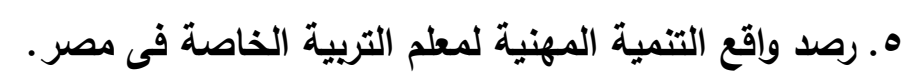

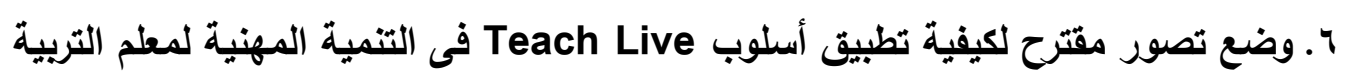
الخاصة فى مصر ، فى ضوء خبرة جامعة فلوريدا وجامعة ماريلاند بالولايات المتحدة فئرة

الأمريكية.

\section{أهمية الدراسة:}

يمكن توضيح أهمية الدراسة فيما يلى

ا ـ ترجع أهمية هذه الدراسة إلي تزايد الاتجاه العالمى والإقليمى وإلمحلى نحو الاهتمام برعاية

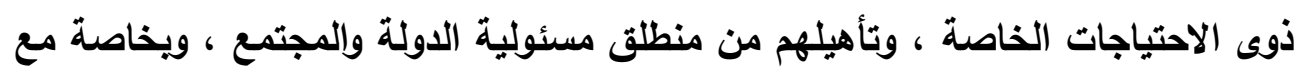

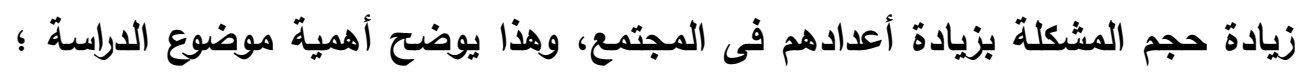

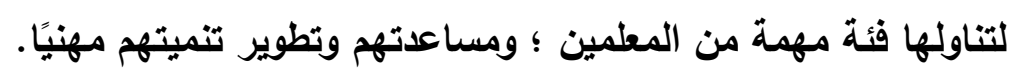

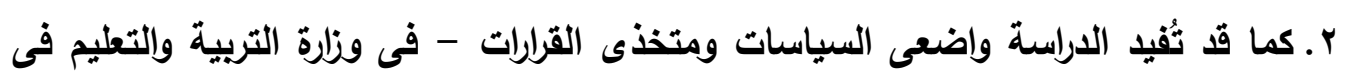
مصر - فى الاهتمام بمعلم التربية الخاصة وتنميته مهنيًا.

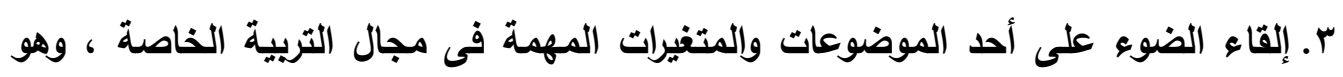

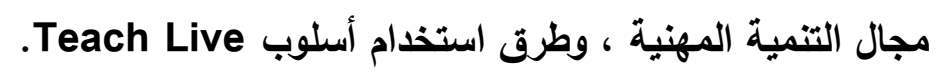
ع. تقايم وجهة نظر مقترحة لتطوير أساليب التنمية المهنية لمعلى التربية الخاصة ، وفرية ، وخاصة أسلوب Teach Live. هـ تكوين قاعدة معلومات عريضة عن كل ما يتعلق بذوى الاحتياجات الخاصة - الأعداد .

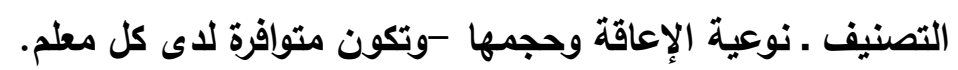
צ. تدريب معلمى التربية الخاصة ، فى موقع عمله بالفصل داخل المدرسة ؛ باستخدام

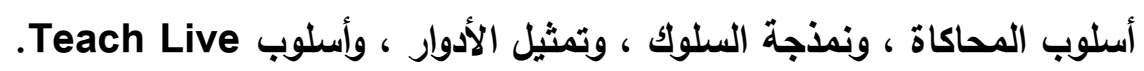

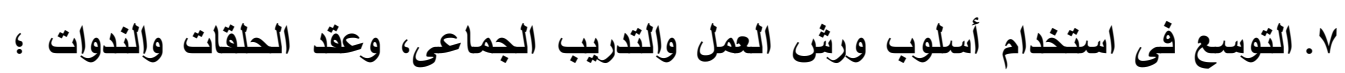

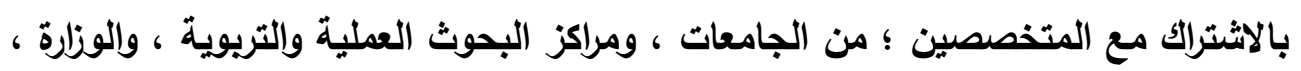


وأولياء الأمور ، فى مجال التتمية المهنية لمعلم التربية الخاصة ، وفي استخدام أسلوب

.Teach Live

حلدود اللدراسة :

اقتصرت الدراسة على أسلوب Teach Live، من حيث المفهوم والأهمية والأهداف واستخدامه ؛ بوصفه أحد أساليب التنمية المهنية لمعلم التربية الخاصة فى الولايات المتحدة

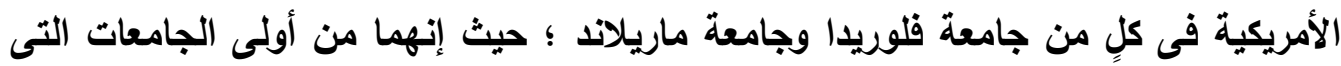
بأت فى تدريب المعلمين على تطبيق Teach Live فى التدريس ، والتي حققت به نجاحات عديدة، حيث تم استخدام Teach Live من قبل جامعة سترال فلوريدا فى عام ^ . . ب ، وتم تمويله على نطاق واسع من قبل مؤسسة "بيل غيتس" ؛ ومنذ ذلك الحين تم استخدامها من

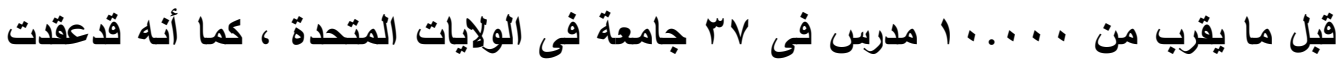
جامعة ماريلاند شراكة مع جامعة فلوريدا على استخدام Teach Live، لتمكين الطلاب من ممارسة التدريس ، أمام مساحة الواقع الافتراضى( • (1).

منهج الدراسة:

استخدمت الاراسة المنهج المقارن ، لاتساقه مع طبيعة هذه الاراسة، "حيث يقوم هذا المنهج على تحقيق أهداف الدراسة ؛ ولأنه المنهج الذي يهتم بدراسة الواقع وأبعاده ، ويسجل العوامل التي تؤثر فيه ، والعلاقات القائمة بين جوانبه.ويحدد هذا المنهج في الخطوات التالية هى:

الوصف - التفسير-المناظرة أو المقابلة - المقارنة .(1 (1)ويسير المنهج فى الخطوات التالية:

1 - الوصف: حيث يصف واقع التربية الخاصة ، ويصف الفئات ذوى الاحتياجات الخاصة ويصف معلم التربية الخاصة ويرصد المشكلات التى يعانى منها ، وواقع تنميته المهنية فى كل من مصر وجامعتى فلوريدا وماريلاند بالولايات المتحدة الأمريكية مع التركيز على أسلوب ؛Teach Live بوصفه أحدث الأساليب الحديثة للتدريس وللتنميه المهنية لمعلم التربية الخاصة بها. r - التفسير: وتتضمن هذه الخطوة تفسيرًا وييانًا للقوى وللعوامل المؤثرة فى التتمية المهنية لمعلم التربية الخاصة. ولئة 
ب- المناظرة أو المقابلة: من خلال تحديد أوجه الشبه والاختلاف بين جامعات المقارنة . ع - المقارنة: وتقودنا هذه الخطوة إلى نتائج علمية محددة ، ويمكنتا - من خلالها - وضع إجراءات مقترحة لكيفية تطبيق أسلوب Teach Live فى التنمية المهنية لمعلم التربية الخاصة فى مصر، وذلك بلراسة أبعاد هذا الأسلوب فى جامعتى المقارنة (فلوريداماريلاند ) بالولايات المتحدة الأمريكية ، وتجريب حلولها المتبعة ؛ بما يساير الإمكانات المتاحة والظروف المجتمعية لبلانا مصر.

\section{مصطلحات اللدراسة :}

تتحدد مصطلحات الدراسة على النحو التالى:

Special Education التربية الغخاصة

تعرف التربية الخاصة علي أنها : مجموع البرامج التربوية المتخصصة ، التى تقلم

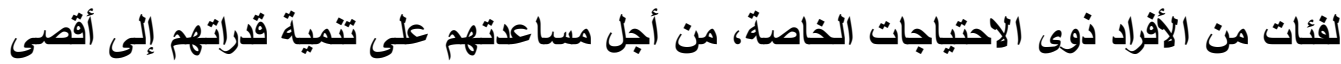

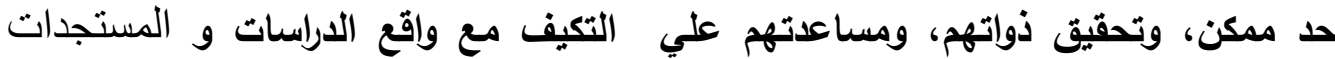
(12). التربوية همن،

\section{التعريف الإحرائى:}

تعرف التربية الخاصة في اصطلاح التريويين بأنها : مجموعة الخدمات والبرامج المنظمة التى تقلم للأفراد ذوى الإعاقة ؛ بلرجة تجعلهم بحاجة إلى خبرات أو أساليب أو مواد

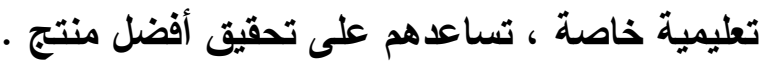

\section{Teacher of Special Education معلم التربية الخاصة}

وهو : المعلم الذى يقوم بالتدريس لفئات من الأطفال المعوقين داخل فصول الدراسة ، بمدارس التربية الخاصة التابعة لوزارة التربية والتعليم، حيث إن بعض المعلمين حاصلون على دبلوم معلمين أو ليسانس/ بكالوريوس تربية ؛ بالإضافة إلى دبلوم التربية الخاصة فى لهي

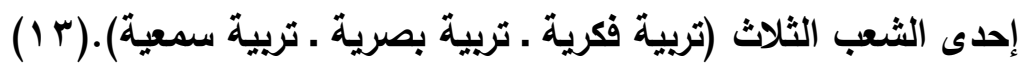

التعريف الإحرائى:

هو: الثخص المؤهل علميًا وتريويًا لتدريس الأطفال ذوى الاحتياجات الخاصة ، حسب طبيعتهم ووفقًا للمنهج الذى وضعته وزارة التربية والتعليم ؛ للارتقاء بالمستوى التحصيلى التي والتدريبى لهولاء التلاميذ. 


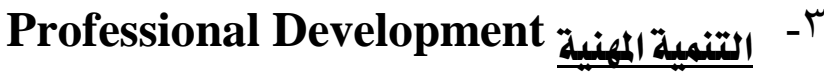

"وهى : عملية مقصودة تهاف إلى تحسين القدرات المهنية للمطلم ، وتقديم كل جديد يتصل بالمعارف والمعلومات والمهارات السلوكية اللازمة لنجاحه فى عمله ؛ فضلًا عن إثراء خبراته لرفع مستوى الأداء"( ع 1).

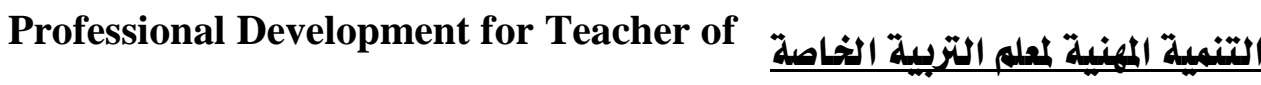

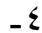
Special Education

التعريف الإجرائى: وهى : مجموعة من الخبرات التعليمية والكفايات والمهارات التى يكتسبها مطلم التربية الخاصة ، والتى ترتبط بطريقة مباشرة أو غير مباشرة بمهنته، وهى - أيضًا- عملية مخططة ومنظمة طويلة المدى ، تستهدف تزويد هذا المعلم بالخبرات الثقافية والمهنية ؛ لتحسين أدائه المهنى و، تبدأ منذ التعيين حتى نهاية الخدمة. Teach Live: $\quad$ - 0 "وهو : بيئة تعليمية افتراضية مبتكرة ، تستخدمها الجامعات - فى جميع أنحاء الولايات المتحدة - من أجل التنمية المهنية لمعلم ذوى الاحتياجات الخاصة ، ومن أجل دعم المطمين المستقبليين فى هذا المجال ، فى العديد من الجوانب (معرفة المحتوى ، سلوكيات

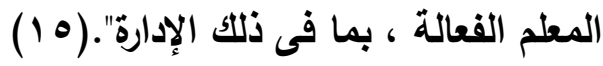

\section{الإطار النظرى لللدراسة}

إن اهتمام الدولة بتعليم ذوى الاحتياجات الخاصة يعبر عن عمق النظرة

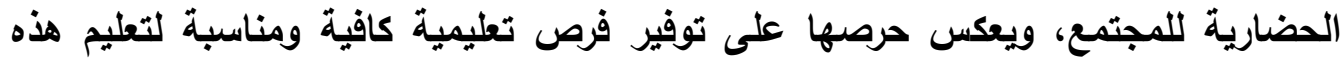

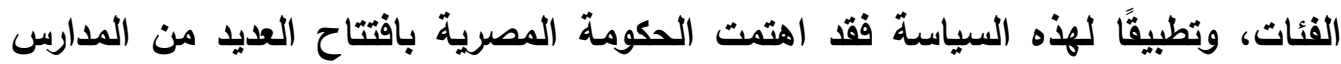

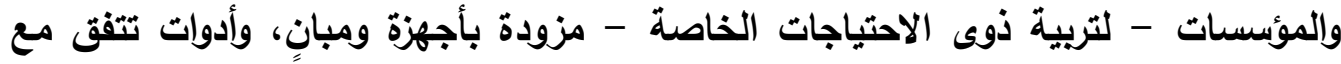
قدراتهم العقلية والجسمية والاجتماعية، وافتتحت أقسام التربية الخاصة فى كليات التربية،

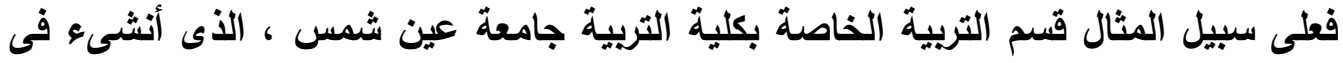

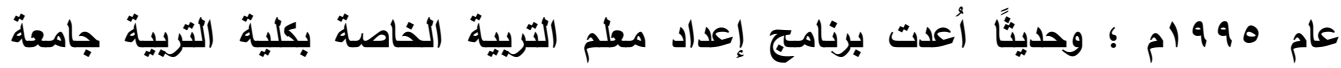
الزقازيق، والذى يهدف إلى إعداد مطلم التربية الخاصة ، بما يتفق مع احتياجاتهم التريوية - 
أي : أصحاب الاحتياجات الخاصة من المتعلمين ، خاصة مع تطور زيادة أعداد هذه الفئات

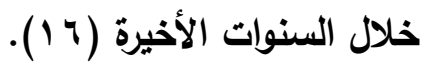
ومن هنا شغل إعداد معلم التربية الخاصة وتدريبه اهتمامًا كبيرًا من جاتب المسئولين بكليات التربية، ووزارات التربية والتعليم ، فى كثير من دول العالم، حيث أصبح المعلم المحور الأساسى فى العملية التعليمية، نتيجة لما يقوم به من أدوار ومسئوليات داخل حجرة الدراسة لهنة وخارجها، لذلك تضافرت الجهود المكثفة لتطوير برامج إعداد معلم المستقبل، وإعداد برامج التنمية المهنية المناسبة وتنفيذها حتى يستطيع المعلمون الاستفادة منها على أكمل وجه. من الجيد الإثترة إلي أن تقدم المجتمعات يرتكزعلى قدرتها علي استثمار طاقة جميع أفرادها، ووضع كل فرد من أفرادها فى مكانه الصحيح، وحيث إن ذوى الاحتياجات الخاصة من الموارد البشرية للمجتمع التى يجب استثمارها، والتي ينبغي رعايتها ووضعها فى المكان المناسب لها ، حتى تدخل ضمن نسيج المجتمع، ولا تكون عائقة فى تقدمه وفي استهلاك طاقات أخرى من أفراده، فهم عندما - يعتمدون على أنفسهم فى حياتهم - إنما يوفرون طاقات الأفراد الآخرين ، التى قد تُستهلك فى خدمتهم، وعندما يقومون بأداء بعض الأعمال البسيطة

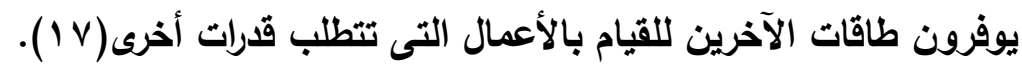
ولعل خير شاهد على هذا الاهتمام المتزايد بإعداد المعلم، هو العنوان الذى اتخذه

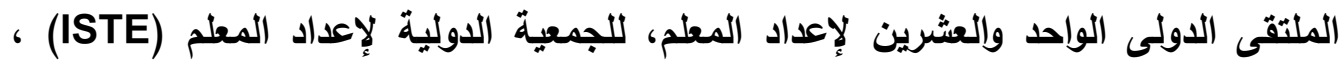

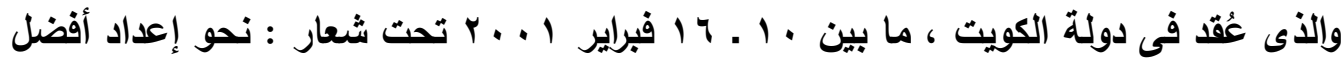
للمعلمين: روئية عالمية، والذى شارك فيه خبراء ، ومختصون ، وياحثون من مختلف أنحاء العالم، وقد تحددت محاوره فى ضوء أهداف الملتقى فى ست بنود أساسية هى( 1 ( ): 1. إعداد المعلم: نظرة مستقبلية. r. الاتجاهات الحديثة فى القياس والتقويم. r. ت تكنولوجيا المعلومات واعداد المعلم. ع. إعداد المعلم قبل وأثناء الخدمة.

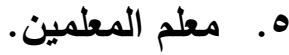
7. إعداد معلم التربية الخاصة. 
ونظرًا لأهمية مكانة معلم التربية الخاصة ، ودوره فى نجاح العملية التعليمية داخل الفصل وخارجه، والاهتمام المتنامى بتعليم هذه الفئة، وإلنقص الثديد فى إعداد المعلمين

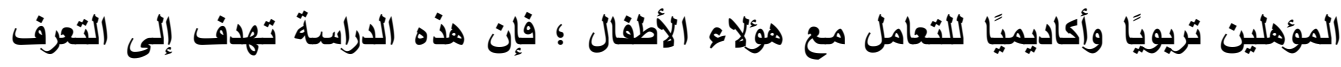
على الأساليب الحديثة للتنمية المهنية لمعلم التربية الخاصة ، حتى يقوم بالدور المنوط به. أونًا : الأسس النظرية والمعيارية المرتبطة بمجال معلم التربية الخاصة : التربية الخاصة:

إن المراجع العلمية المتخصصة - بوجه عام - تجمع على أن التربية الخاصة هى تدريس يختلف عن التدريس التقليدى ، وغايته تلبية الحاجات الفردية للطلبة ذوى الحاجات الخاصة ، بهذف مساعدتهم على بلوغ أقصى مدى ممكن من الأداء الحسن والاستقلالية

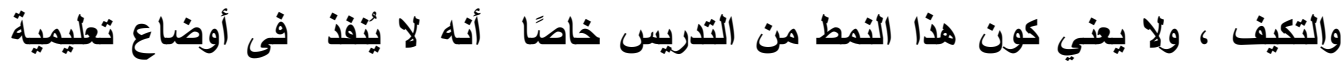

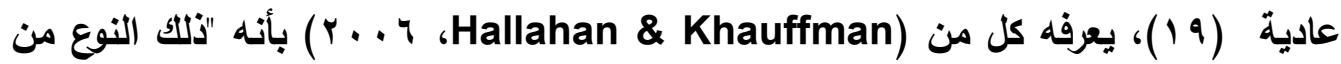
Special التعليم الذى صمم - خصيصًا - لمقابلة الاحتياجات الخاصة للتلميذ غير العادى لتهن education means specially designed instruction that meets the .( $r$. )unusual needs an exceptional student ولما كانت التربية الخاصة مهتمة بهذا المعنى، لذا فإنها تقدم - لجميع فئات ذوى الاحتياجات الخاصة ، سواء من يعانون من قصور واضح فى الأداء الوظيفى بالارجة ، التى

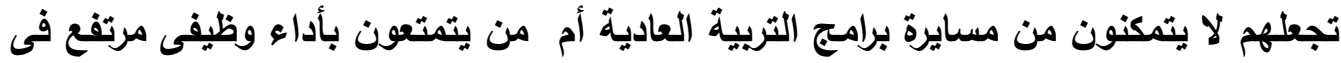

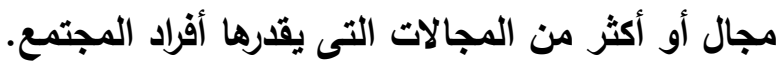

\section{Special Education تعريف التربية الخاصة}

لقد عرف تونبكين وكولانا (r . . F) التربية الخاصة بأنها : مجموعة من البرامج التريوية المتخصصة والأساليب المنظمة التى تقدم للطلاب ذوى الاحتياجات التريوية الخاصة، بهدف مساعدتهم فى تنمية قدراتهم إلى أقصى مستوى ممكن ، ومساعدتهم للتكيف العام ، وتحقيق الأات، وتهدف - أيضًا - إلي التعرف على قدرات الطلاب و ميولهم و مهاراتهم ؛ من خلال أدوات القياس والتثخيص المناسبة، وإعداد البرامج التربوية والتعليمية المناسبة، مصحوية بالوسائل التعليمية التى تساعد على التأهيل والتطور"( الت ). 


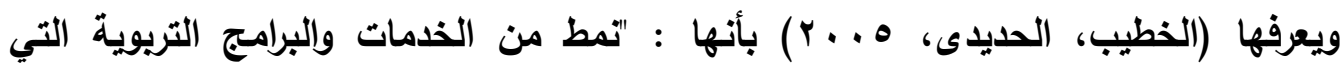

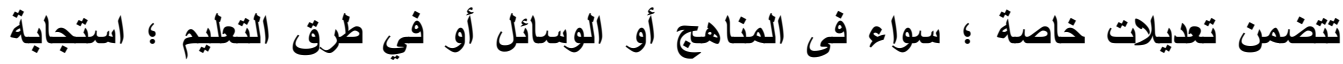
للحاجات الخاصة لمجموع الطلاب الذين لا يستطيعون مسايرة متطلبات برامج التربية العادية، وعليه فإن خدمات التربية الخاصة تقدم لجميع فئات الطلاب ، الذين يواجهون صعويات تؤئر الطئر - سلبيًا - على قدرتهم على التعلم، كما إنها تتضمن الطلاب ذوى القدرات والمواهب المتميزة"

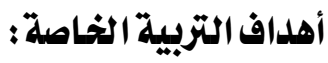

تتحدد أهداف التربية الخاصة في النقاط التالية (ب r) :

1. التعرف على الأطفال ذوى الاحتياجات الخاصة ، وذلك من خلال أدوات القياس والتثخيص المناسبة لكل فئة من فئات التربية الخاصة. r. إعاد البرامج التعليمية لكل فئة من فئات التربية الخاصة. r. إعداد طرائق التدريس لكل فئة من فئات التربية الخاصة، وذلكك لتتفيذ أهداف البرامج التربوية ، على أساس الخطة التربوية الفردية.

؛. إعداد الوسائل التعليمية والتكنولوجيا الخاصة بكل فئة من فئات التربية الخاصة.

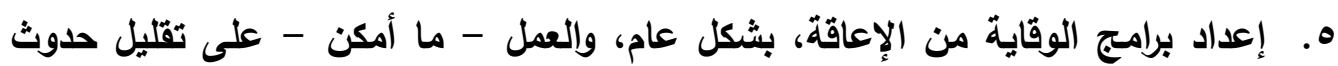
الإعاقة عن طريق البرامج الوقائية. צ. مراعاة الفروق الفردية بين الطلاب ، وذلك بحسن توجيههم ، ومساعدتهم على النمو وفق قدراتهم واستعداداتهم وميولهم. V. تهيئة وسائل البحث العلى ؛ للاستفادة من قدرات الموهوبين وتوجيهها ، وإتاحة الفرصة أمامهم فى مجال نبوغهر. ^. تأكيد كرامة الفرد ، وتوفير الفرص المناسبة لتنمية قدراته ؛ حتى يستطيع المساهمة فى في نهضة الأمة . تصنيف فئات ذوى الاحتياجات الخاصة : : : : يمكن تصنيفها علي النحو التالى 1-الكفيف Blind: وهو الثخص الذى فقد حاسة البصر ، أو كان بصره من الضعف بدرجة يحتاج معها إلى أساليب تعليمية لا تعتمد على استخام البصر ، وهولا يستطيع التعامل 


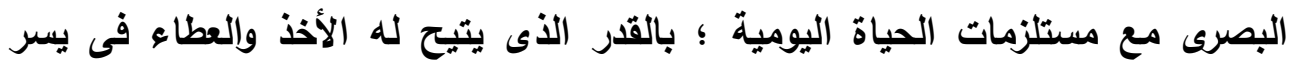

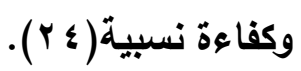

r-ضعيف البصر: و هو الثخص الأى لا يمكنه - بسبب نقص جزئي فى قوة الأبصار -

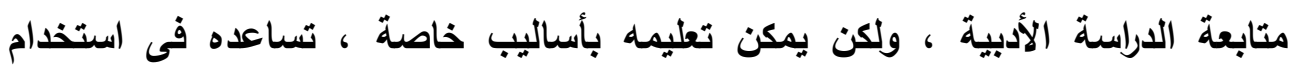

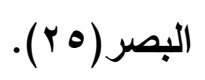

Hearing Impairment ب-الإعاقة السمعية (بإن يقصد بالإعاقة السمعية : تلك المشكلات التى تحول دون قيام الجهاز السمعى - عند الفرد - بوظائفه ، أو تقلل من قدرته على سماع الأصوات المختلفة، وتتراوح الإعاقة السمعية التئية

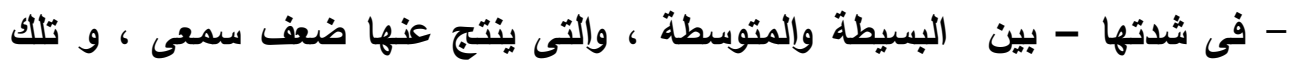

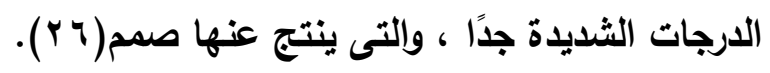
وتصنف الإعاقة السمعية إلى فئتين: الأصم: Deaf: وهو من ليس لايه القدرة على السمع أو فهم لغة الحديث ، ولو بمساعدات

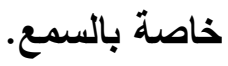
ضعيف السمع Hard of Hearing: وهو من لايه ضعف نسبى فى حاسة السمع ؛ فيتطلب بعض التكيفات الخاصة، حيث يمكنه استخدام حاسة السمع فى فهم لغة الحديث، وغالبًا ما يكون ذلك من خلال الأجهزة المساعدة على السمع.

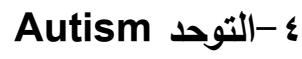

وهو : من أكثر الاضطرابات النمائية صعوية ، بالنسبة للطفل نفسه، ولوالايه، ولأفراد أسرته

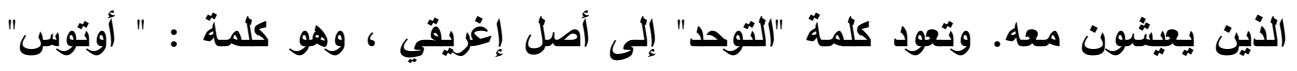

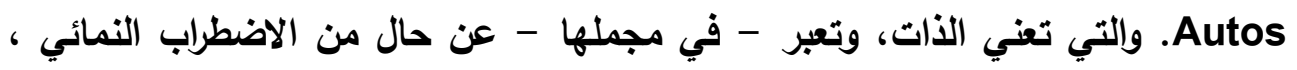

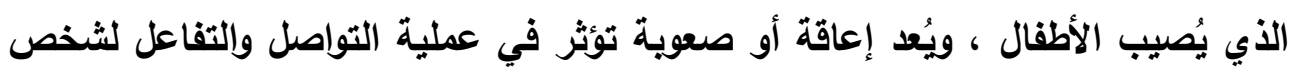
الآخرين. م ما

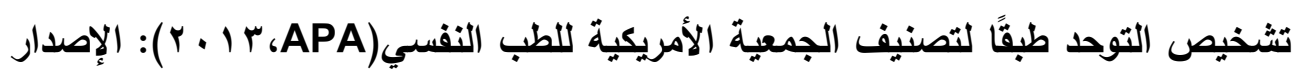

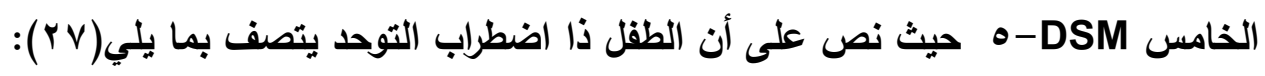

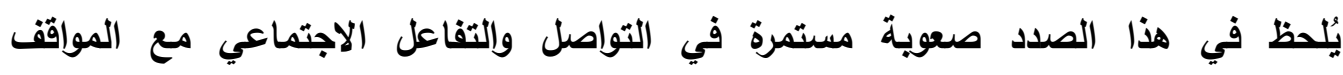
المختلفة،عوية في التبادل الاجتماعي - العاطفي: ويتراوح ما بين التعامل الاجتماعي فئي 
غير الطبيعي والفشل في تبادل حوار اعتيادي ، مثلُ : الفشل في المشاركة في الاهتمامات وإلمزاج،

والعواطف

وكذلك صعوية في سلوكيات التواصل غير اللفظي المستخدمة في التفاعل الاجتماعي: ويتراوح ما بين ضعف في تكامل التواصل اللفظي وغير اللفظي مثلُ: الخلل في التواصل البصري وفي لغة الجسد ، أو صعوية في استخدام التعبير الجسدية (الإيماعات)وفهمه،

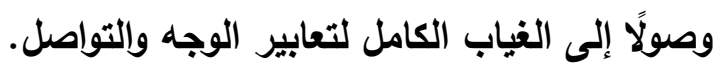
- ويُلحظ صعوية في إنشاء العلاقات أو الحفاظ عليها أو فهمها: ويتراوح من بين

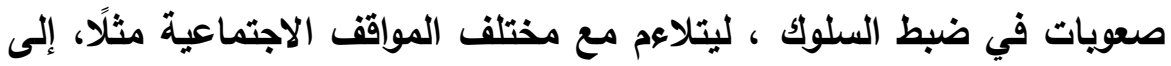
رصد صعويات في مشاركة اللعب التخيلي أو إنشاء الصداقات، وصولًا إلى فقدان الاهتمام بالأقران.

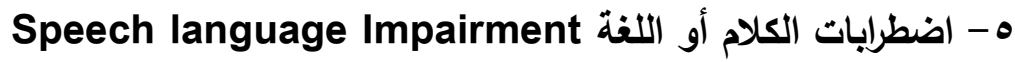
و هو : عبارة عن اضطراب فى التواصل ، نلحظه في اللجلجة أوفي اضطرابات النطق أو

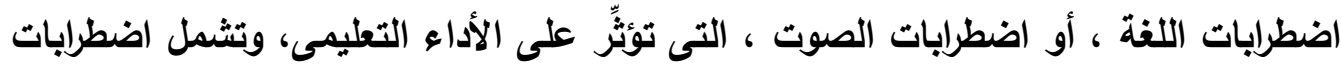
الكلام نوعية الصوت ونغمته و شدته، وفي الطلاقة الكلامية ؛ من حيث السلاسة أو المعدل

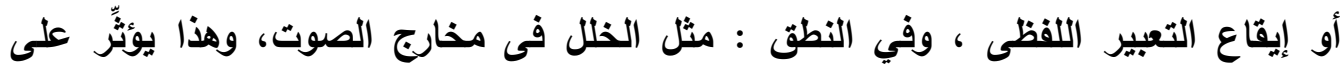

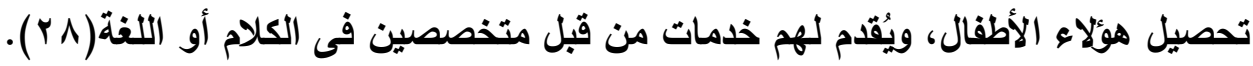

\section{צifted and Talented الموهوب}

وهو : الأى تتوافر لايه استعدادات وقدرات غير عادية ، أو أداء متميز عن بقية أقرانه فى مجال أو أكثر من المجالات التى يقدِّها المجتمع، وخاصة فى مجال التفوق العقلى، وفي التحصيل العلمى، والتفكير الابتكارى وفي المهارات الخاصة، ويحتاج هذا النمط إلى رعاية تعليمية خاصة لا تتوافر له بشكل متكامل( 9 ب) . وقد أجمع كثير من الباحثين على أن الموهوب هو الذى يمتاز بالقدرة العقلية ، التى هاتى يمكن قياسها بنوع من اختبارات الأكاء ، والتى تحاول أن تقيس المهارات و القدرات التالية

- القدرة على التفكير والاستدلال.

- القدرة على تحديد المفاهيم اللفظية. 
- القدرة على إدراك أوجه التشابه بين الأشياء والأفكار.

- القدرة على الريط بين التجارب السابقة والمواقف الراهنة.

Heath Impairment الإعاقات الصحية الأخرى - V

ويقصد بها : أن يكون لاى الفرد قدرة حيوية ومحددة ؛ أو ضعف بلنى ؛ بسبب ما

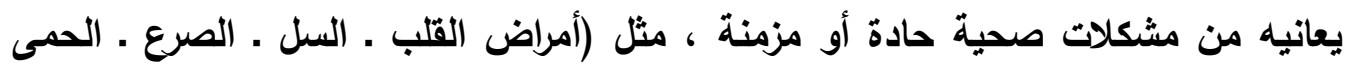

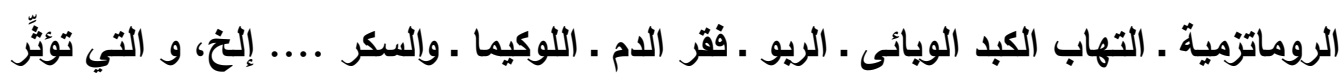
على أدائه التحصيلى( ابـ).

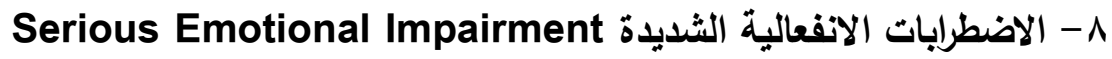

يعرف الاضطراب الانفعالى الثديد : بأنه حالة تتسم بواحدة أو أكثر من الخصائص التالية لمدة طويلة لارجة تؤثر على إنجاز الفرد التعليمى ، مثل الصفات الظاهرة التالية

-

- - ضعف القدرة على إقامة علاقات شخصية مع زملائه ومعلميه والمحافظة عليها. - - إظهار نوع من أنواع السلوك غير المناسب. - - التسام المزاج العام بالحزن وعلم السعادة. - الاستعداد للإصابة ببعض الاضطرابات العضوية والمخاوف المرضية ، والتي تكون مقرونة بمشاكل شخصية أو مدرسية.

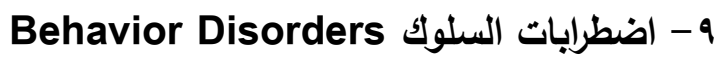
ويقصد بها : وجود صفة أو أكثر من الصفات التالية لمدة زمنية طويلة، والتي تؤثِّر على التحصيل الأكاديمى ، وهذه الصفات هى(ب وبه): - ضعف القدرة على التعلم التى لا ترتبط بعدم الكفاية فى القدرات أو الجوانب الصحية العامة أو الحسية أو العصبية.

- ضعف القدرة على إقامة علاقات شخصية مع الأقران أو المعلمين أو الاحتفاظ بها. - ظهور السلوكيات والمشاعر غير الناضجة وغير الملائمة وفقًا للظروف والأحوال العادية. - الاكتئاب و عدم الشعور بالسعادة بوجه عام • 
Communication Disorders اضطرايات التواصل 1 - 1 . تُعرف اضطرابات التواصل بأنها : عجز الفرد عن أن يكون كلامه مفهومًا للآخرين ، أو عجزه عن التعبير عن أفكاره بكلمات مناسبة، وكذلك عجزه عن فهم الأفكار أو الكلمات التى

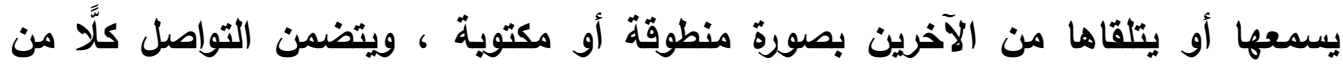
الوسائل اللفظية المتمثلة في اللفة المنظوقة ـ والمسموعة ـ والمكتوية ، والوسائل غير اللفظية ، مثل استثمارلغة الإثـارة ـ وتهجئة الأصابع ـ وقراءة الثفاه التى يستخدمها الصم، ولغة برايل التى يستخدمها المكفوفون، وكذلك الإيماءات، وتعبيرات الوجه، ولغة العيون، وحركات اليدين والرجلين وغيرها ( ؟ ب).

\section{معلم التربية الخاصة: - ميلم}

وهو : المعلم الأى يقوم بالتدريس لفئات من الطلبة المعوقين داخل فصول الدراسة بمدارس التربية الخاصة التابعة لوزارة التربية والتعليم ، وهو شخص مؤهل أكاديميًا وفنيًا ،

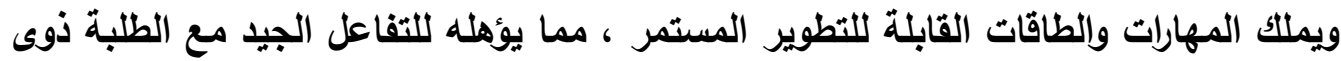
الاحتياجات الخاصة(ه) (ب).

\section{ثانيًا : أبرزالمككلات التىيعاذى منها معلم التربية الغحاصة :}

تُشير الاراسات - فى مجال التربية الخاصة - إلى أن هناك نقصًا شديدًا فى الأفراد المؤهلين للعمل فى مجال التربية الخاصة فى معظم دول العالم ،كما تثير تلك الدراسات إلى إلى أن هناك عددًا من المعلمين الذين يلتحقون بالعمل فى تدريس الطلاب ذوى الإعاقات لا

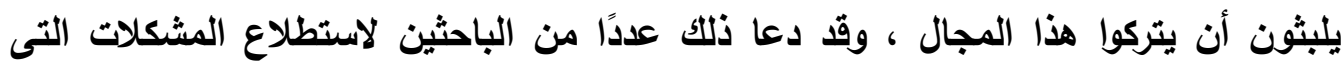

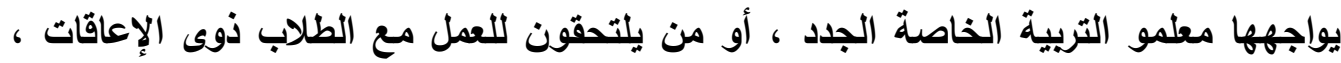

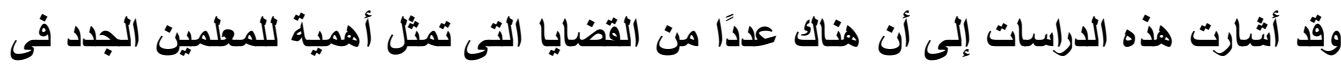

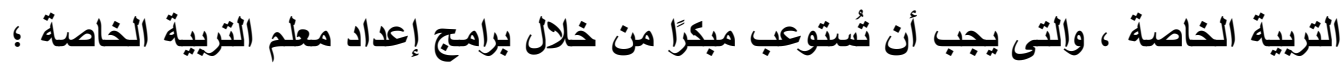
حتى لا يقع هؤلاء المعلمون لتأثير الصدمة المهنية Surprise Effect، مما يُؤدى إلى منى تركهم لمهنتهم، ويُمكن تلخيص هذه المشكلات فيما يلى هوه: ا مالأدواروالمسئوليات:

من المفيد الإثارة إلي أن معلمي التربية الخاصة قد عانوا من تعدد أدوارهم

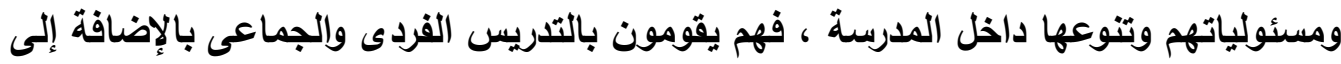


تخطيط برامج التدخل العلاجى وتنفيذها، كما تقوم المدرسة بتحميلهم أعباء إضافية، ومن ثم يجب على برامج إعداد معلم التربية الخاصة تبصير المرشح للقيام بدور معلم التربية الخاصة بتعدد أدوارهم ومسئولياتهم · والجدير بالذكر - في هذا الموضع-الإشارة إلي أن معايير

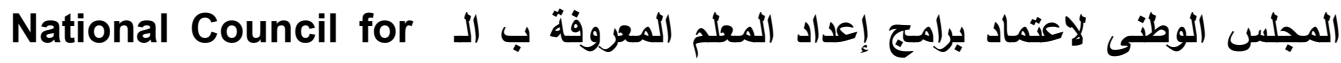
- Accreditation Education العالم للحصول على اعتمادها - تذكر بوضوح تعدد أدوار معلم التربية الخاصة ؛ ما بين فهم احتياجات الطلاب ذوى الإعاقات المختلفة، وترتيب بيئة تعلمهم، ويناء برامج التذخل العلاجى، والتدريس الفردى، والتعاون مع أسرهم ؛ من أجل تحسين أدائهم، ومساعدة معلمى التعليم العام، وهو ما يؤكد على أهمية الدور الذى يقوم به معلم التربية الخاصة، ولذلك يجب أن أن تركز برامج إعدادهم - أي معلمي التربية الخاصة - على إكسابهم الكفايات المهنية، ومهارات التفاعل البناء، وإكسابهم القدرة على الابتكار فى حالة نقص الإمكانيات وإلمصادر، كما يحتاج معلمو التربية الخاصة إلى التمتع بسمات شخصية تكسبهم قدرًا من القوة الداخلية Inter Strength

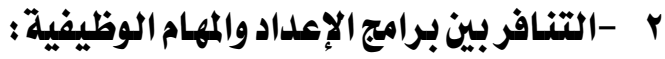
انحصرت - فى الماضى - أدوار معلم التربية الخاصة فى تلريس الطلاب ذوى الإعاقات فى مدارس منعزلة وفي مجموعات متجانسة، على سبيل المثال : تعليم الطلاب لئل الصم فى مدارس خاصة بهم ، وكذلك الحال بالنسبة للطلاب ذوى الإعاقة البصرية، والعقلية، والنمائية، غير أن هذا الأمر قد تعرض للتغيير مع التوجه نحو سياسة الدمج الثامل ، ومن ثم أصبح هناك تنافرُ بين برامج الإعداد وييئات العمل الجديدة ، وما تتطلبه من مهام وظيفية

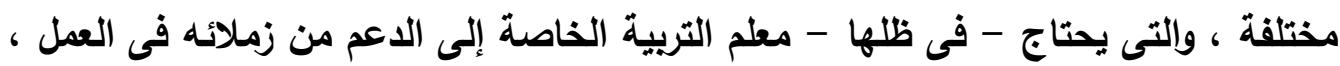
والإدارة المدرسية ، والآباء والطلاب العاديين.

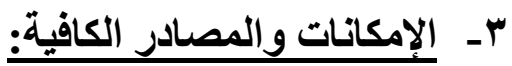

دائمًا ما يشكو معلمو التربية الخاصة من قلة الإمكانات ، ومن أنهم بحاجة إلى توافر المصادر التى تساعدهم على تعليم الطلاب ذوى الإعاقات ، ودائمًا ما يتم التركيز - فى برامتج إعداد معلم التريية الخاصة - على البيئة المثالية للعمل من دون ذكر سيناريوهات قلة الإمكانات ، وكيف يمكن أن يؤدى معلم التربية الخاصة دوره فى ظل وجود إمكانيات محدودة، ولذلك يصدم الكثير من معلمى التربية الخاصة بالواقع المرير الأى يختلف عمَّا درسوه، فتركز 
برامج إعداد معلم التربية الخاصة على كيفية استخدام التكنولوجيا - بوجه عام والتكنولوجيا المعينة - بوجه خاص - فى تكييف المنهج وتهيئة بيئة التعلم، فى حين تخلو البيئة المدرسية فى الواقع من التركيز على هذا التوجه ، بل إن الآباء لا يؤمنون إلَّا بالأساليب التقليدية فى تعليم أبنائهر من ذوى الإعاقات المناته ع- قضضايا متعلقة بالمنهج:

أدى التحول إلى تدريس المنهج الوظيفى الملائم للعمر الزمنى للطلاب ذوى الإعاقات فى ظل بيئة دامجة إلى تحديات كبيرة لمعلى التربية الخاصة ويرامج إعدادهم، فقى ظل هذه

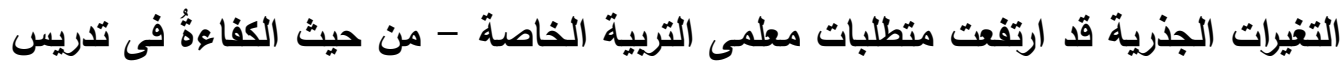
هذه المناهج ، وما تركز عليه من عمليات أكثر صعوية ، مثل : القهم القرائى ، ومهارات حل المشكلات ، ومجالات اللغة المكتوية والمنظوقة، ومهارات تنظيم الذات، ومهارات حماية الذات ، وتركز معايير الـ NCATE على أن من مهام معلم التربية الخاصة فهم الفرق بين التطور

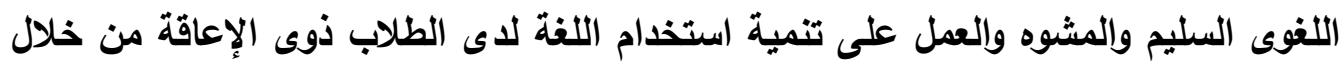
استخدام جواتب المنهج المختلف، ويتطلب المنهج الوظيفى أن يتم التركيز - فى برامج إعداد معلم التربية الخاصة - على استراتيجيات تكييف المنهج و طرق التدريس، و طرق التقويم، والتدريب على إدارة حجرة الدراسة Management Strategies.

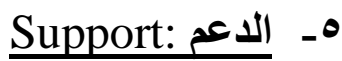
شهد مجال التربية الخاصة توسعًا فى الخدمات المقدمة للطلاب ذوى الإعاقات ، وذلك بعد دمجه مع التعليم العام ، وزيادة التكنولوجيا المتاحة لتدريس التلاميذ ، بالإضافة إلى التى

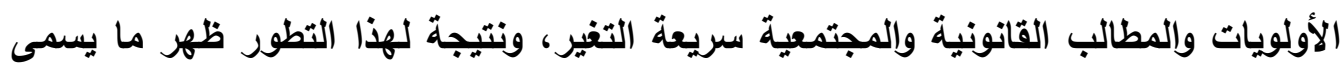

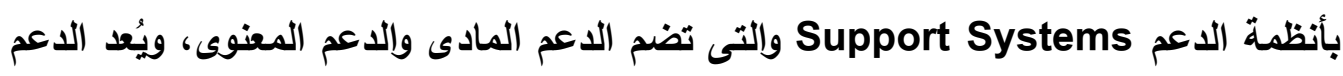
من المفاهيم التى يجب أن تركز عليه برامج تدريب معلم التربية الخاصة، ويقصد بالدعم

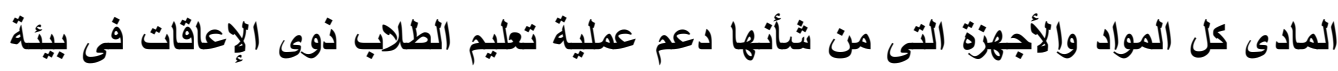

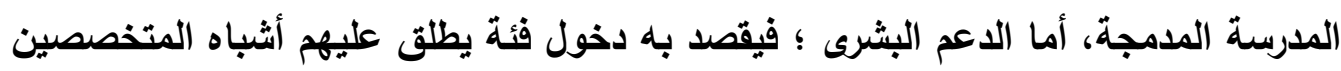
Paraprofessionals

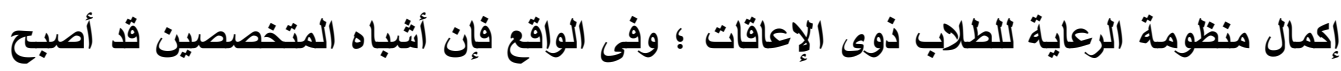

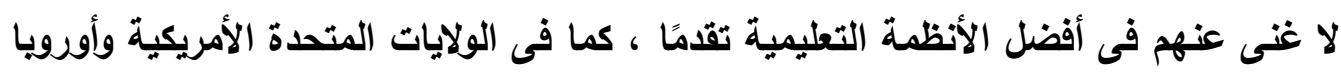

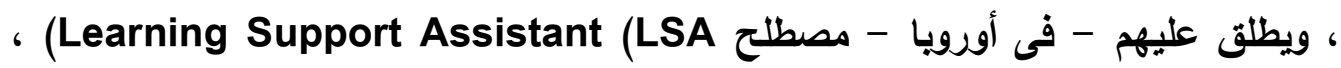


والواقع أن هذه الكوادر تكون ممن حصلوا على دورات تدريبية فى مجال معين متصل بالإعاقة

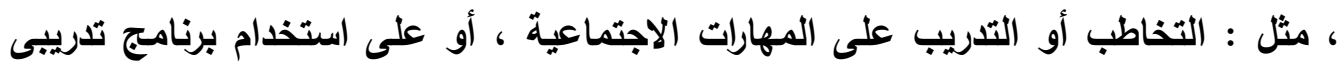
معين ، مثل برنامج:PECS أو مع تعليم الطلاب ذوى التوحد ؛ومن ثم يعتمد عليهم نظام التعليم فى العمل الفردى مع الطلاب داخل المدرسة، ويتم إقرار الخطة السنوية للاعم البشرى ، بوصفه جزيًًا من برنامج التعليم الفردى (ndividualized Education Plan

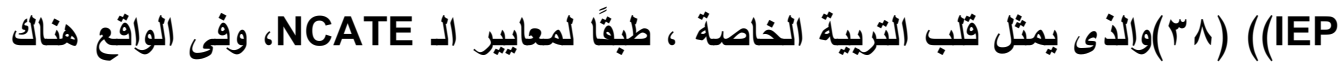
خلط بين أدوار معلمى التربية الخاصة ومعلم الدعم ؛ فى ظل عدم وضوح الروئية داخل عالمنا

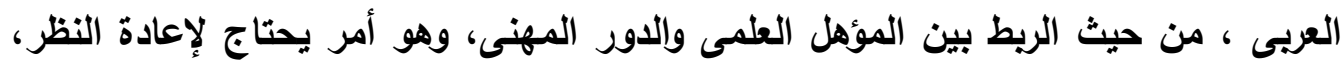

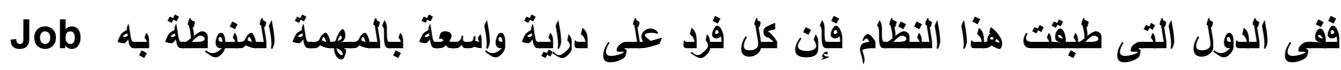
Specifications

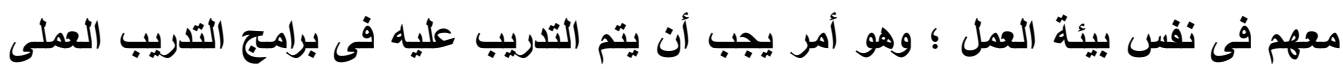

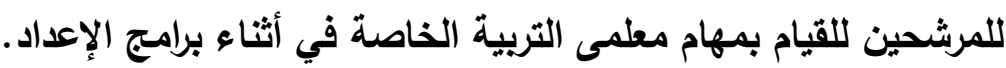

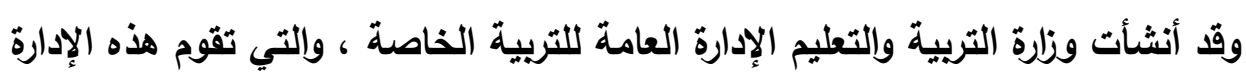

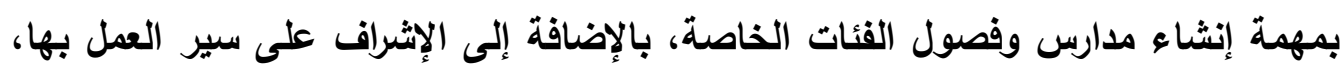

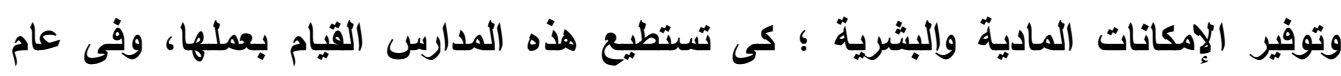

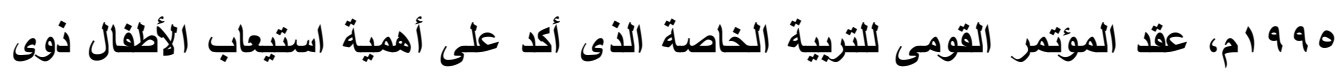
الاحتياجات الخاصة فى مؤسسات التعليم العام فى سن مبكرة ، وتوفير الرعاية التريوية

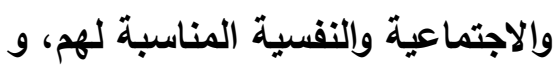
قد بدأت الفئات الخاصة تأخذ حقها الطبيعى فى الرعاية والتوجيه والتأهيل لحياة يستطيعون أن يعيشوها فى سعادة وفق إطار إمكانياتهم وقدراتهم ، التى أمكن تحويلها من فن التهات قوى وطاقات بشرية معطلة إلى قوى منتجة تسهم - بقر الإمكان - في عملية الإنتاج، ويتم تحقيق ذلك من خلال إعداد معلم مؤهل تريويَّا للتعامل مع هذه الفئات (9 ب).

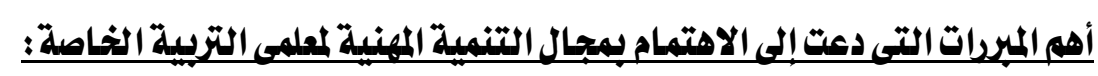
إن التمية المهنية عملية أساسية لا يمكن الاستغناء عنها ؛ لتحسين الأداء المهنى

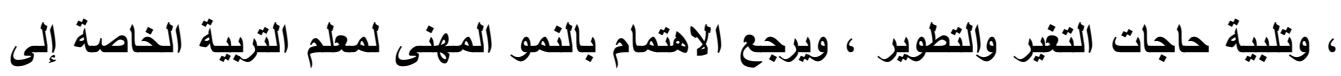


1- النقص فى أعداد المطلمين المتخصصين فى التربية الخاصة ، مما يستلزم الاستعانة بمعلمين غير متخصصين ، الأمر الذى يتطلب ضرورة تزويدهم ببرامج تدريبية تأهيلية.

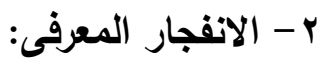

إن التغيير المستمر والمتطور فى المعرفة أدى إلى أن يكون المطلم مواكبًا لهذا التطور

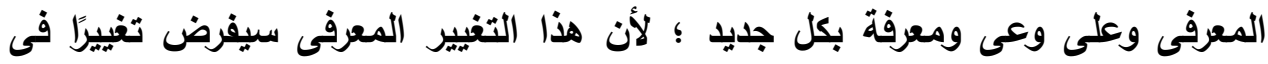

المناهج الدراسية التى يقدمها للطلاب.

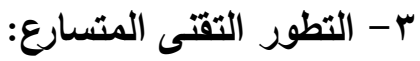

فرض ظهور التقنيات التكنولوجية الدايثة واستخدامها فى التدريس ؛ على معلم التربية الخاصة حاجة للنمو المهنى فى مجال إتقان المهارات المطلوية للقيام بدوره.

ع - تطور مفهوم التربية:

لقد تطور مفهوم التربية من مفهوم ضيق يعنى الجانب العقلى إلى مفهوم واسع يعنى بمختلف جوانب شخصية المتعلم وما يترتب عليه من حاجة المعلم للنمو المهنى فى الجى

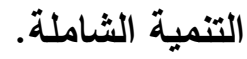

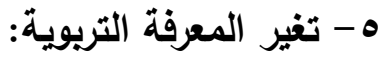

إن المعرفة التريوية تتغير نتيجة لما تتوصل إليه البحوث التريوية والنفسية من نتائج

تغير فى العملية التعليمية ، من حيث أهدافها ومحتواها وطرائقها. 4- التقتيات الجليدة فى التربية:

إن ما يُستجد - فى المجال التريوى - من تقتيات تريوية جديدة يتطلب إعادة النظر فى بنية النظام التعليمى ، وفي دور المطلم ، وفي إيجاد الحلول الناجعة للعديد من المشكلات التريوية ، التي تفرض على المعلم تطوير طرق تدريسه وخطظه، وتجديد معلوماته.

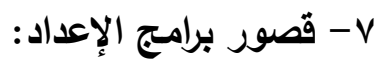
توجد بعض أوجه النقص والقصور فى برامج إعداد المعلم - قبل الخدمة - كأن يجد

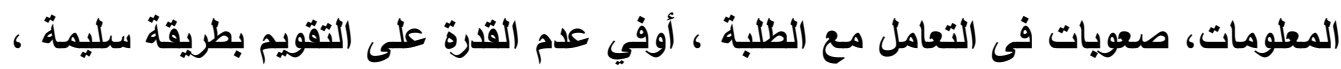

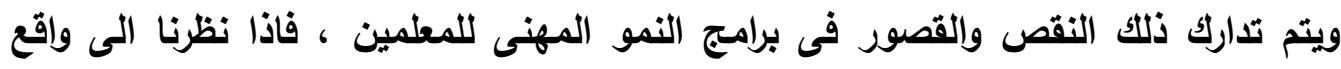
اعداد معلم التربية الخاصة فى مصر نجد انه يتمثل فى (• ؛) : 
بدأ إعداد مطلم التربية الخاصة فى أواخر الأربعينيات وأوائل الخمسينات فى قسم

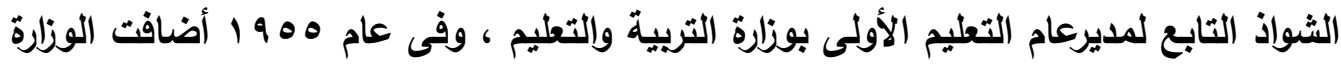

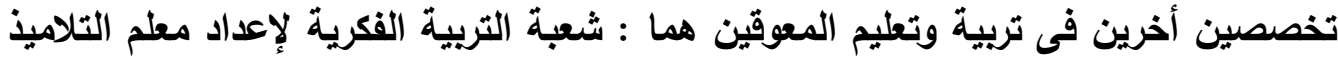

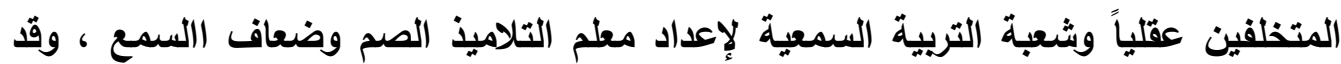

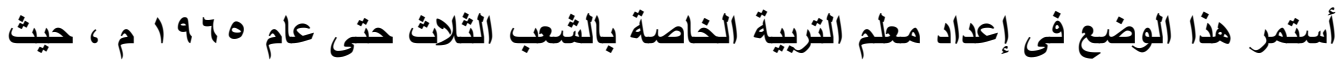
قامت وزارة التربية والتعليم بالعمل على تغيير هذا النظام ، فأنثأت البعثة الداخلية لإعداد

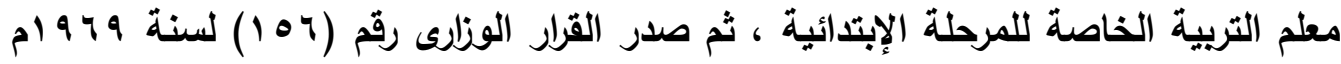
فى شأن اللائحة التظيمية لمدارس وفصول التربية الخاصة للمرحلة الإبتدائية بشعبها الثلاث ( الفكرية - السمعية - البصرية ). ووضعت وزارة التربية والتعليم مناهج دراسية خاصة بكل

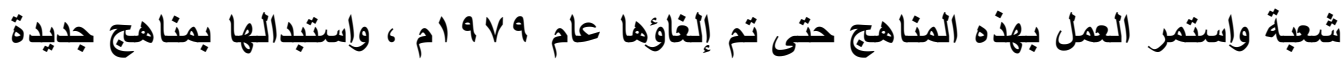
مطورة تخدم خصائص الإعاقات وتظلب الجاتب العملى على الجانب النظرى . ويدأ الاهتمام بإعداد معلمى الفئات الخاصة للمرحلتين الإعدادية والثانوية بعد صدور الجانية

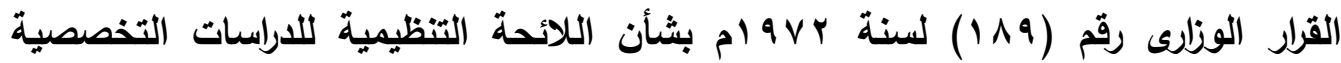
لتربية وتعليم المكفوفين وضعاف البصر ، وذلك بالاشتراك مع المركز النموذجى لرعاية

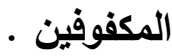
وفى إطارالاهتمام بالمعوقين ودعوة مصر لجعل عام ،99 ام عاما للطفل المعاق إعيد

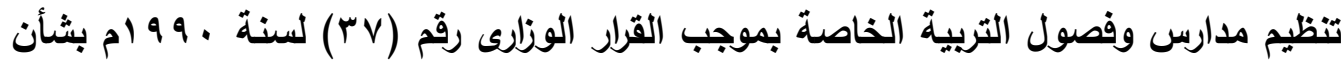
اللائحة التنظيمية لمدارس وفصول التربية الخاصة ، حيث نصت (المادة هب) على أن :

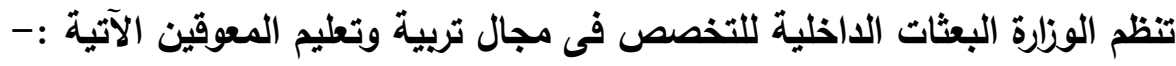
- البعثة الداخلية لإعداد معلم التربية الخاصة بالتعليم الأساسى ومدتها عام دراسى لإنى

- البعثة الداخلية لإعداد معلم الإعدادى والثثانوى وفصول المعوفين بصريا ومدتها عام دراسى واحل - كلية التربية جامعة عين شمس: تتضمن لائحة كلية التربية جامعة عين شمس نظامين لإعداد معلم التربية الخاصة وهما: 
- بكالوريوس العلوم والتربية ( شعبة التربية الخاصة) :وافق مجلس كلية التربية جامعة عين شمس بتاريخ / / 99 / 9 / على أقتراح قسم الصحة النفسية بإنشاء شعبة طلابية للتصص فى التربية الخاصة ، ومدة الدراسة بالشعبة أربع سنوات يحصل بعدها الطالب على درجة بكالوريوس فى التربية ( تخصص تربية خاصة)

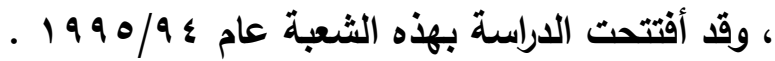
- الدبلومة المهنية فى التربية تخص (تربية خاصة):تضمنت المادة (0) (1 ) بمروع اللائحة الاخلية لكلية التربية جامعة عين شمس هو/999 99 على التخصصات التى تمنح فيها درجة الدبلوم المهنية فى التربية ومن بينها مجال التربية الخاصة ، على أن تكون مدة الدراسة لنيل الدبلومه المهنية سنة جامعية واحدة .

معهد الدراسات والبحوث التريوية (جامعة القاهرة) : استحداث شعبة لإعداد معلم التربية الخاصة تمنح فيها درجة الدبلومة العامة واللابلومة الخاصة ودرجتى الماجستير والدكتوراه فى فلسفة التربية الخاصة ، وقد تم التعاون لتنفيذ الدراسة بهذة الشعبة بين كل من معهر الاراسات والبحوث التربوية ومدرسة التربية

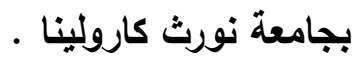

- كلية رياض الاطقال بالاقى :أنشئت كلية رياض الأطفال بالقاهرة بالقرار الوزارى رقم VAV لسنة 9A^ ام وتمنح الكلية درجة بكالوريوس التربية فى الطقولة المبكرة شعبة رياض الأطفال و شعبة الأطفال المتفوقين ، وشعبة الأطفال المعوقين .

- كلية التربية جامعة الزقازيق:انشئت برنامج لاعداد معلم التربية الخاصة حديثا

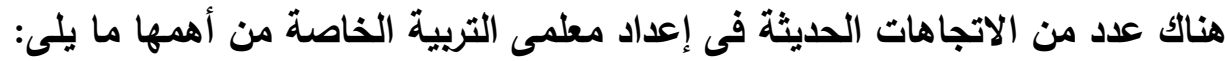
- الاتجاه نحو دمج التربية الخاصة والتربية العادية :وهو تدريب معلمى التربية الخاصة على تأدية أدوار جديدة أكثر تتوعاً ، من خلال إعداد برنامجا لتهيئة

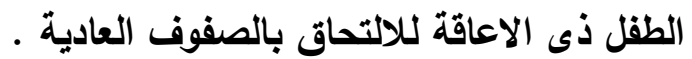


- الأتجاه نحو التدريب النعتمد على الكفايات :تتمثل فى وجود اتجاهات إيجابية لاى معلم التربية الخاصة نحو ذوى الإعاقة ، وتتمثل فى الدراية بخصائص

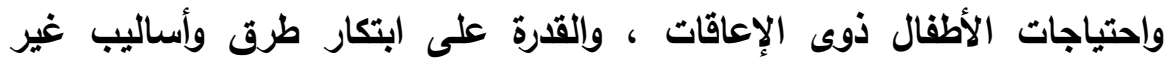
تقليدية فى التعامل مع هؤلاء المتعلمين، والقدرة على الاستفادة من المبتكرات التكنولوجية فى تعليم الأفراد ذوى الإعاقات.

- الأتجاه نحو التدريب غير التصنيفى فى التربية الخاصة :وهو تدريب يعتمد على الخصائص السلوكية للأطفال ذوى الإعاقة بشكل عام ، بهدف التظلب على

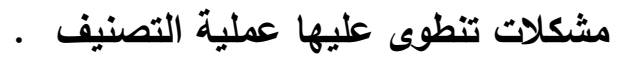
ونظرا لما سبق من واقع اعداد معلم التربية الخاصة وإختلاف برامجه وعدم توحيدها على كافة جامعات مصر مثل اعداد معلم العاديين فقد ظهرت العديد من المشكلات الخاصة بإعداد معلم التربية الخاصة فى مصر وهى على النحو التالى :

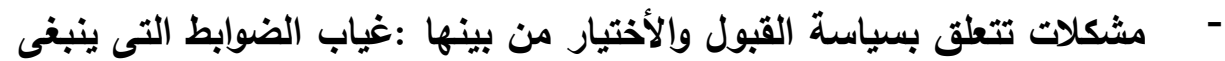
أن تتسم بها عملية القبول للبعثات ، وشكلية الأختيارات الثخصية التى تُعقد للمتقدمين للاراسة بمؤسسات الإعداد.

- مشكلات تتعلق بأهداف الإعداد :عمومية الأهداف ببرامج إعداد معلم التربية الخاصة ، الأمر الذى جعل معظم كليات التربية تحقى أهدافهابدرجة ملائمة فيما يتعلق بإعداد المعلمين فى مجال التربية العامة لتعليم العاديين غير المعاقين ،إلا هلابه

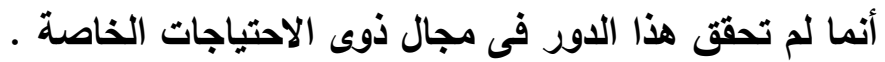
- مشكلات تتعلق بالبرامج الدراسية :ضعف برامج الإعداد التى تُقدم وافتقار برنامج

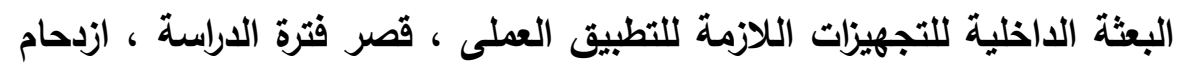
خطة الاراسة الأكاديمية بالمقررات النظرية ،عدم وجود برنامج لإعداد معلم

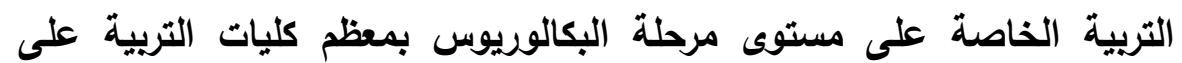
مستوى الجمهورية ، إلا فى كلية التربية بعين شمس والتربية النوعية بعين شمس ، وكلية التربية بحلوان وكلية التربية بالزقازيق ،اعتماد باقى المحافظات بلهي

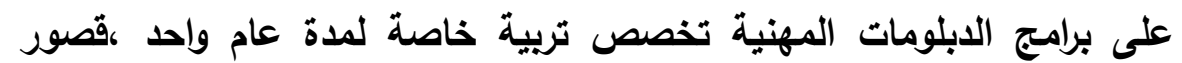

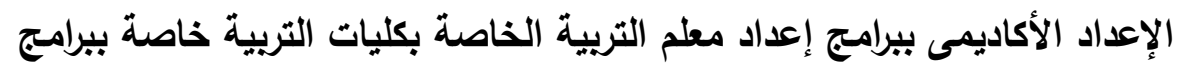


الدبلومات المهنية تخصص التربية الخاصة ،غلبة المقررات الدراسية النظرية على حساب المقررات التطبيقية العملية ببرامج الدبلوم المهنية بكليات التربية . - مشكلات تتعلق بمدة الدراسة :فترة الإعداد بالبعثة الداخلية ثمان أشهر فقط فهى غير كافية لإعداد معلم الفئات الخاصة ، مدة الاراسة ببرنامج الابلوم المهنى فى بلى التربية الخاصة بالعديد من كليات التربية عام جامعى يُقسم فصلين دراسيين لا يؤهل فى مجمله التخرج لأن يكون معلماً أو حتى أخصائياً، حيث مدة الدراسة غير كافية لإعداده .

- مشكلات تتعلق بنظام الإعداد :نظام إعداد معلم الطقل المتخلف دراسياً ( بطئ

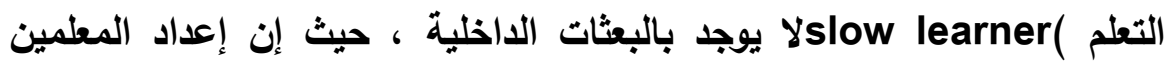

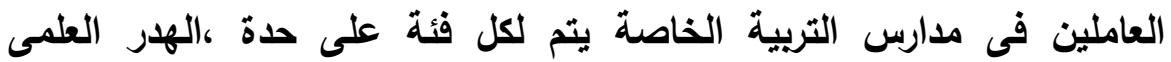
والمهنى فى نظام إعداد معلم التربية الخاصة نظراً لتوجيه الكثير من خريجى الابلوم المهنى لاستكمال دراستهم فى تخصصات أخرى .

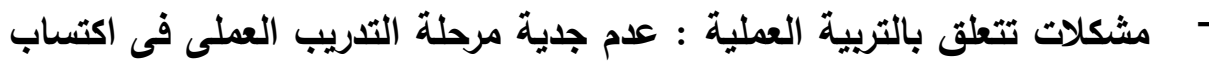
المهارات الأساسية ، ضعف فاعلية برنامج التربية العملية فى الدبلومات المهنية نظراً لنقص الفترة التدريبية .

\section{أهم التتفيرات العالمية التى دعت إلى تطوير أساليب التنمبية المهنية لمعلم التربية الخاصة} تثير الدراسات - المعنية ببرامج إعداد معلم التربية الخاصة - إلى وجود عدد من المتغيرات العالمية التى فرضت نفسها، وأصبح من الصعب تجاهلها على المستوى المحلى، ويمكن تلخيص هذه المتغيرات فيما يلى:

\section{I -القوانينوالتشريعات اللدولية:}

لقد أدى الاهتمام الدولى برعاية الأطفال ذوى الإعاقات إلى إصدار الأمم المتحدة لعدد من المواثيق الاولية ، التى تضمن حصول هؤلاء الأطفال على حقوقهم المختلفة فى الحياة ،

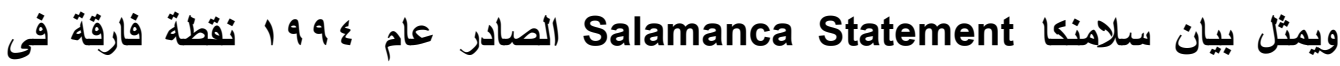
التحول من التركيز على النموذج الطبى ، فى تقديم خدمات التربية الخاصة إلى تبنى النموذج الاجتماعى ، الأى يعنى بتبنى المنحى الحقوقى ، فى حصول هؤلاء الأطفال على خدمات

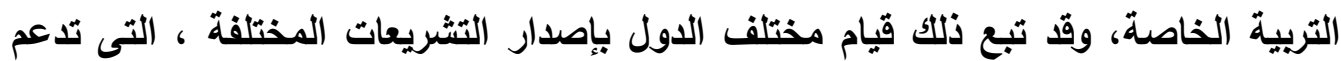


هذا النموذج الاجتماعى، وتنص المادة ؟؟ - من هذا القانون - على ضرورة أن يتلقى

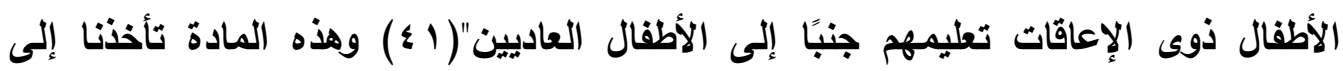

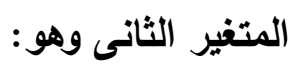

أدم:

أدى تطور نظريات بناء المنهج الحديثة إلى إعادة النظر فى بناء مناهج تعليم الطلاب ذوى الإعاقات، فبعد أن كان تركيز مخططى المناهج - فى الماضى - منصبًا علي تصميم مناهج تتضمن أنشطة تتناسب والعمر العقلى والعمر الاجتماعى للطقل ، أصبح التركيز منصبًا على ملى فئي تدريس المنهج الوظيفى Functional Curriculum، الأى يتماشى مع العمر الزمنى للطقل، أى أن يتلقى الطقل نفس المنهج الذى يلرسده أقرانه ، ولكن بعد إجراء عمليات التعديل والموائمة اللازمتين Accommodation and Modification (ب ؟ ). وتُعد هذه المتغيرات السابق ذكرها من أهم المستجدات التى يتم - فى ضوئها - تحديث

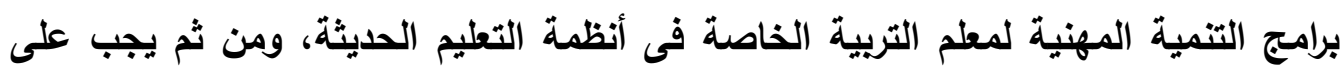
المعنين بالتعليم النظر إلي هذه المحددات بعين الاعتبار.

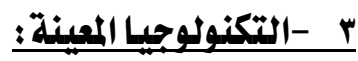
فرض التقدم التكنولوجى نفسه على جميع المجالات المجتمعية - بما فى ذلك مجال تعليم

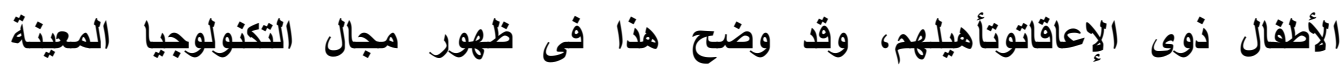
Assistive Technology

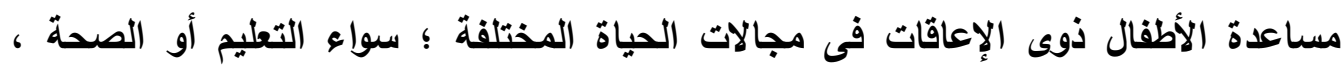

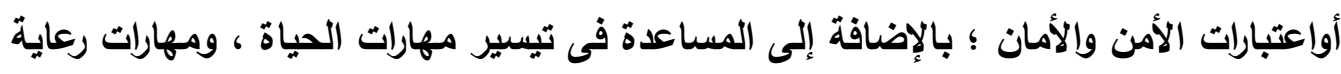
الذات ؛ من تواصل لفظى وغير لفظى، وفي تحسين المهارات الحركية الكبيرة وإلاقيقة Gross and Fine Motor Skills

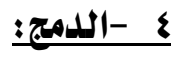
لقد شهر مفهوم الدمج تطورًا سريعًا ومتلاحقًا فى المفهوم والتطبيق ؛ حيث تطور من مجرد

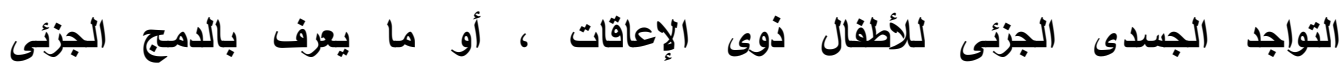
Mainstreaming 
- Inclusive Education على أهداف برامج إعداد معلم التربية الخاصة ومحتوها ونواتجها(ب ؛ ).

استراتجيسات اللدمج:

أصبح مجال التربية الخاصة جزعًا لا يتجزأ من نظام التعليم العام ؛ بعد أن ظل - لفترات -

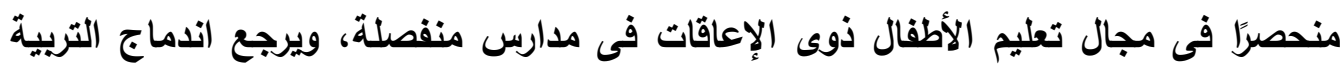

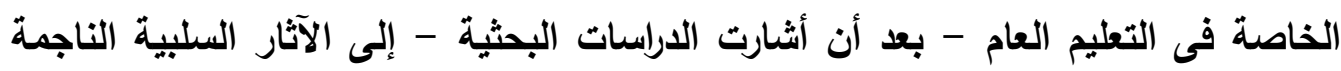

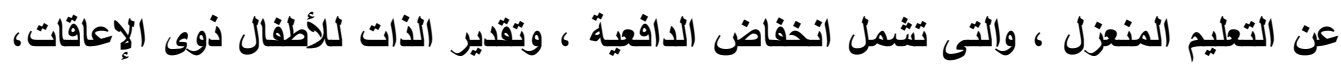
وانخفاض فرص تعليمهر عن طريق الملاحظة observational learning من خلال نمذجة الأقران، أضف إلى ذلك انخفاض توقعات الوالدين والمعلمين للتحصيل الدراسى لهوّلاء الأطفال فى بيئات التعليم المنعزلة، ولذلك أصبح هناك اتجاهُّالّي تعليم الطلاب ذوى الإعاقات في إطار تعليمي ؛ لم يعد فيه معلم التربية هو المعلم الوحيد الذى يدرس لهم فى بيئة منعزلة،

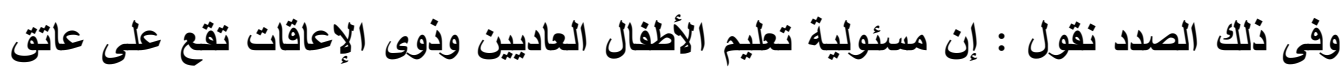
كل المعلمين ، بما فيهم معلمى التربية الخاصة" (ع ع ). وقد أصبح المنهج المقدم للتلاميذ ذوى الإعاقات - فى ظل نظام الدمج فى مدارس التعليم العام - هو نفسه المقدم للأطفال الأسوياء ؛ مما أدى إلى توحيد الأهداف التعليمية ، على الرغم من الاختلافات والفروق الفردية الموجودة بينهم ، ولهذا تبقى الأهداف من مثل : "أن يصبح أكثر ثقة، وأن يكون قادرًا على التفاعل - بإيجابية - مع أقرانه، وأن يكتسب عددًا

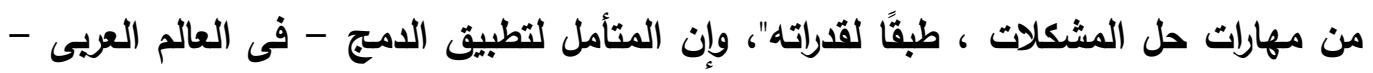

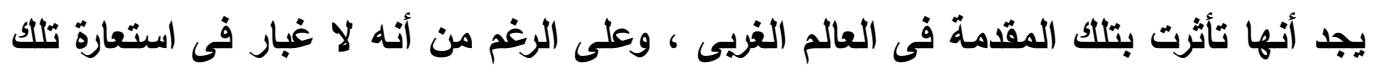

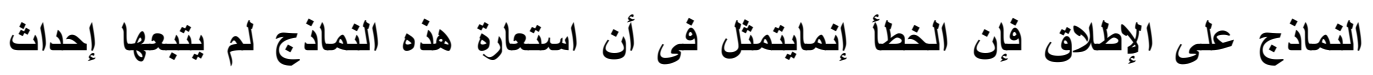

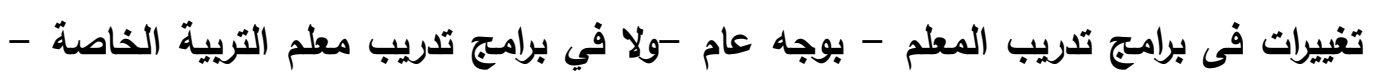

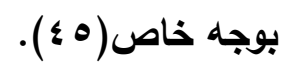

حيث إن الامج - عمليًا = يعنى : تقديم برامج تعليمية ملائمة لكل الطلاب ، بحيث

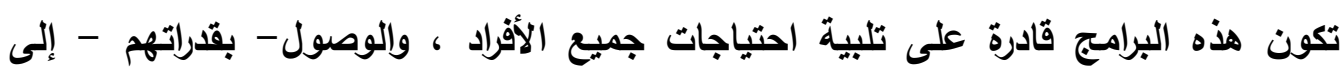
أقصى ما تسمح به تلك القدرات والمهارات ، مع تقديم الدعم اللازم من تدريس خاص الدابل

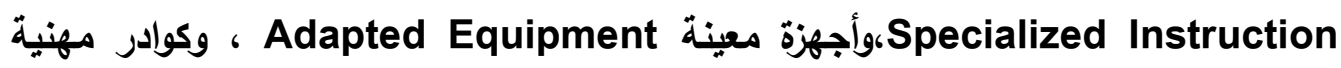


قادرة على تقديم الرعاية Specialized Personnel، وفى الواقع فإن مدارسنا فى العالم العربى تفتقد لهذه المنظمة ،على الرغم من توافر حسن النية وسلامة القصد.

\section{ثالثا :التنمية المهنبة لمعلم التربية الخاصة}

تُعد التنمية المهنية عملية أساسية لا يمكن الاستفناء عنها ؛ لتحسين الأداء المهنى، ولتلبية حاجات التغير والتطوير ، ويرجع الاهتمام بالنمو المهنى لمعلم التربية الخاصة إلي نقص أعداد المعلمين المتخصصين فى مجال التربية الخاصة ، وإلي وجود العديد من أوجه النقص والقصور فى برامج إعداد المعلم قبل الخدمة ؛ كأن يجد المعلم صعويات فى التعامل مع الطلبة، أو أن يعجز عن إدراك التطورات التى لحقت بأدوار المعلم ومسئولياته؛ نتيجة التغيرات المتسارعة فى مجال التعليم. وتهاف التنمية المهنية - فى الأساس - إلي إضافة معارف جديدة إلي الطلاب ،

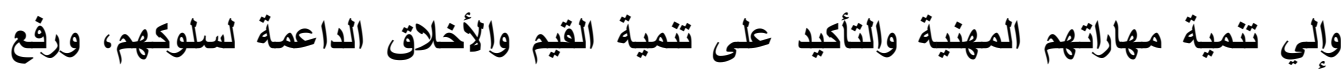
مستوى أداء معلمى التربية الخاصة ، بتحسين اتجاهاتهم ، وتطوير مهاراتهم التعليمية

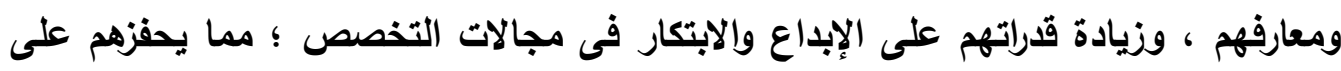

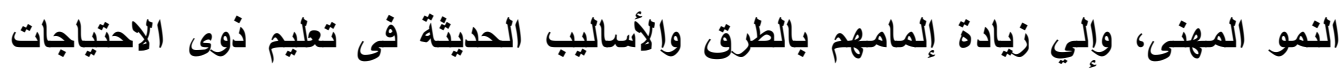

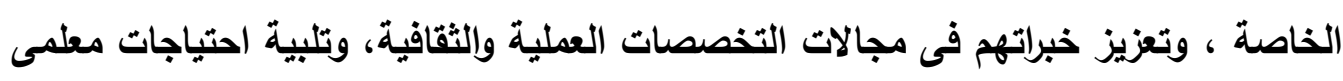

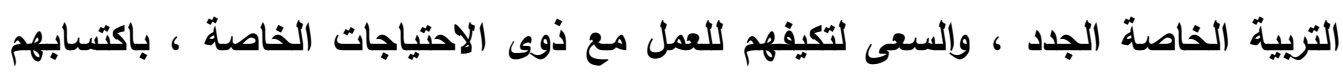
الكثير من المهارات المهنية(7 ؛ ).

\section{أهداف التنمية المهنبة لمعلمى التربية الخحاصة:}

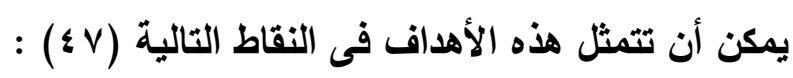

1. رفع مستوى أداء معلمى التربية الخاصة ، بتحسين اتجاهاتهم وتطوير مهاراتهم التعليمية

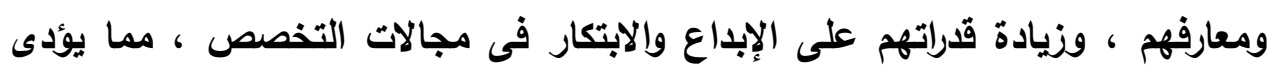
يحفزهم على النمو المهنى. r. تلبية احتياجات معلمى التربية الخاصة الجدد ، والسعى لتكيفهم للعمل مع ذوى التئ الاحتياجات الخاصة ؛ باكتسابهم الكثير من المهارات المهنية.

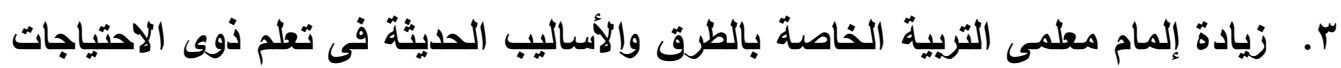
الخاصة ، وتعزيز خبراتهم فى مجالات التخصصات العلمية وإلثقافية. 
؛. تأهيل المطمين غير المتخصصين ، بتزويدهم بمؤهلات تكميلية لممارسة مجال عمل فئل يختلف عن المجال الأول ، وهذا ما يحدث فى برامج تدريب معلمى التربية الخاصة

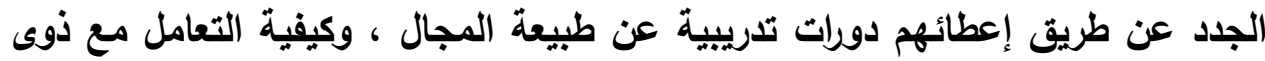
الاحتياجات الخاصة.

ه. الإسهام فى زيادة فهم معلمى التربية الخاصة لخصائص نمو طلابهم وهواياتهم وحاجاتهم وطرق إثباعها.

I. تبصير معلى التربية الخاصة بمثكلات التربية الخاصة ووسائل طلها ، وتعريفهم بأدوارهم ومسئولياتهم نحو ذلك وتعريفهم بفلسفة التربية الخاصة وأهدافها. V. تنمية مهارات معلى التربية الخاصة على استخام تكنولوجيا التعلم والاتصال والمطلومات الحديثة ، وتوظيفها فى إثراء بيئة التعلم داخل الفصل وخارجه.

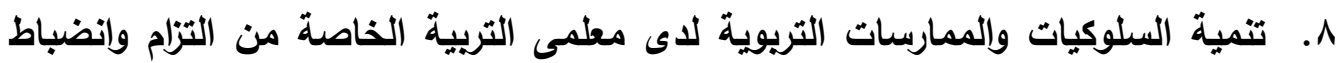

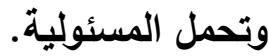

9. إتاحة الفرصة لمعلمى التربية الخاصة لممارسة البحث العلمى ، وتجريب أنماط تدريسية جديدة وممارستها ، بطريقة تساعدهم على الابتكار والإبداع ، وتؤدى لنموهم المهنى.

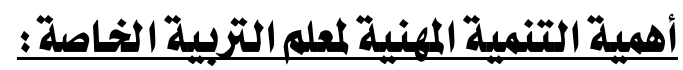

يعد معلم التربية الخاصة - خصيصًا - ليقوم بالتدريس للطلبة غير العاديين ، أو غير الأسوياء ؛ ممن يتطلب تعليمهم حاجات خاصة تميزهم عن غيرهم من الطلبة العاديين ،

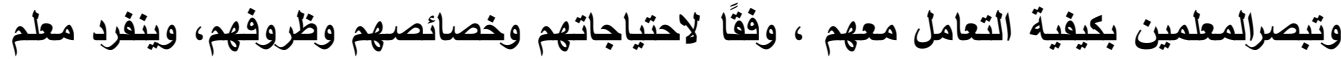
التربية الخاصة بتريس المنهج الإضافى ، والذى يشتمل على مجموعة من المهارات التعويضية ، التى دعت الحاجة إلى تدريسها ؛ نتيجة لظروف الطلاب ذوى الاحتياجات الخاصة.ولقد تزايد اهتمام المؤسسات التعليمية بالتنمية المهنية لمعلي التربية ، نظرًا لقدرتها

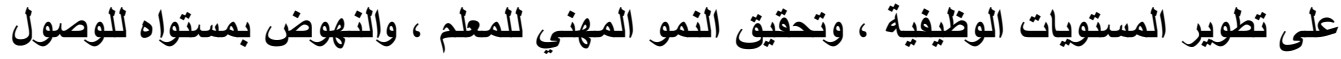
لأفضل أداء ، ويمكن توضيح أهمية التنمية المهنية فى النقاط التالية(^ ؛ ) :

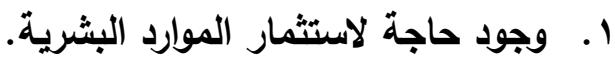

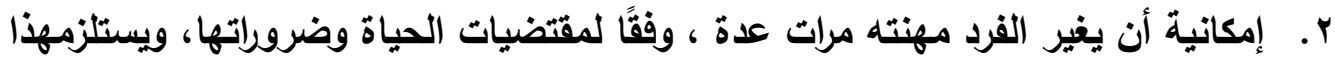

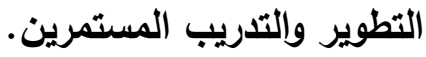


r. تعد التمية المهنية من الاستراتيجيات المطلوية لخروج النظم التعليمية من أزمتها

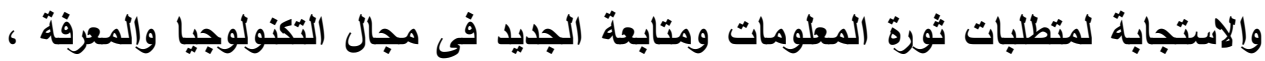
حيث تم تحديث معارف المعلمين ، وصقل خبراتهم ومهاراتهم المهنية ، ومواجهة أوجه القصور فى برامج الإعداد بكليات التربية ؛ ويالتالى رفع مستوى الأداء ، بما يسهم فى ، تطوير العملية التعليمية. ء. تؤدى التنمية المهنية إلي تحسين القدرات المهنية للمعلمين ، وتقدم كل جديد يتصل بالمعارف والمعلومات والمهارات السلوكية اللازمة للنجاح فى العمل فى الحقل التعليمى ، فضلًا عن إثراء خبراتهم لرفع مستوى الأداء.

\section{أساليب التنمية المهنية لمعلم التربية الخاصة}

من الجيد الإثارة إلي أن هناك العديد من أساليب التنمية المهنية التى تدعم المعلم ،

ويمكنتا عرض تلك الأساليب فى النقاط التالية (9 ؛): ا 1

يعتبر التدريب من أكثر أساليب التنمية المهنية شيوعًا ، مما يُحسن الأداء ويجوده ، ويؤهل الأفراد إلى مستويات مختلفة ، لتولى مسئوليات متعددة ؛ وقد تتفاوت مدة التدريب حسب نوعية التدريب واللهدف منه ، حيث يوجد تدريب قصير المدى وآخر طويل المدى.وقد يتم التريب ؛ إما داخل المنظمة أو خارجها ، من خلال العديد من المراكز المتخصصة بتظوير الأداء ، حيث تشمل مراكز التطوير والتدريب الخاصة ، أو يقع عبء تطوير الأداء علي الحكومة العامة ، ويحقق التدريب أهدافًا كثيرة فى العديد من المجالات الاقتصادية والاجتماعية والنفسية. r

يُعدأسلوب المحاضرات من أقدم أساليب التنمية المهنية ، فهو أسلوب قيم حديث وواسع الاستخدام ؛ لا يمكن الاستفناء عنه ؛ فهو عبارة عن اتصال المحاضر بمجموعة من الأفراد ؛ بهذف تقديم أفكار ومعلومات حول موضوع معين ، قد سبق الترتيب له وأُعد ، كما لهاء يتميز هذا الأسلوب بتقديم مبادئ موضوع معين ؛ لتغطية كمية كبيرة من المطلومات لعدد كبير من المتلقين فى وقت وجيز. 
r - ب المؤتقرات والندوات وورش العمل: تُعد تلك الآلية من أهم وأكثر الأساليب التى يمكن اتباعها فى التتمية المهنية ؛ لرفع كفاءة الموظفين فى الوقت الراهن ، حيث يجتمع الخبراء فى المجالات موضع المناقشة ؛ من الن الاهن الأفراد أو المنظمات لمناقشة اتجاهات متعددة ، وتتنشر - من خلال تلك المؤتمرات - أفكارهم لاكتساب أكبر قدر من الخبرات والمهارات ، التى تساعد المشاركين على تحسين العملية التعليميةوتطويرها.

ك - الحوار:

يُعد الحوار من أكثر الأساليب الثائعة ، حيث يقسم المشاركون - فى الحوار - أنمار

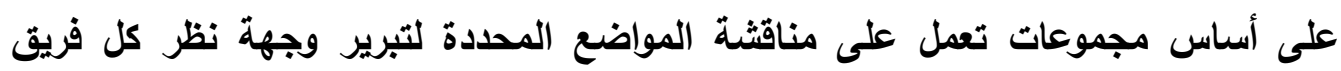
وتوضيحها، وتتمثل فى حلقات النقاش الجماعى والحوار المفتوح.ويمكن الاستفادة من هذا الأسلوب في التقريب بين التيارات المختلفة على الصعيد الخارجى، أما على الصعيد الداخلى ؛ فيمكن تبنى هذا الأسلوب للتطوير من مهارات المحاور فى عرض أسلويه ومهاراته فى الإقناع

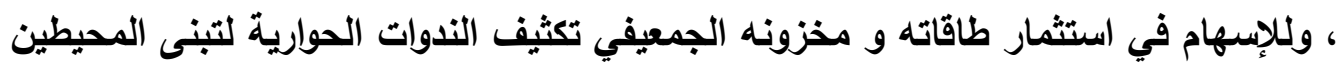
به لأفكاره ولتوجهاته ؛ مما قد يساعد الجميع على المشاركة فى تبنى روئة مشتركة يعمل الجميع على إنجازها. 0 - التوجيه والإرشاد:

يُعد التوجيه والإرشاد من الأولويات المهمة فى التعليم العام لعدد من العقود ؛ حيث يعد معونة ناجعة من معونات تمكين العاملين فى التعليم للعمل بوصفهم مرشدين ، و لعل هذا

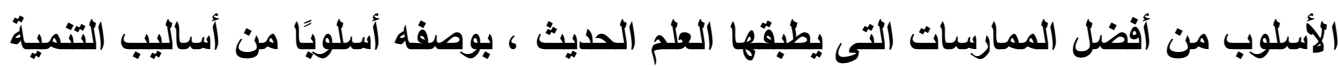

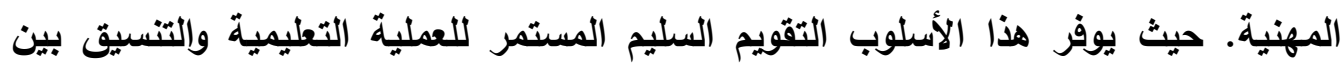
عناصر ها ، بما يكفل نمو العاملين وزيادة فعاليتهم ، و نمو الأبهاد الثقافية و العياتية للمحيطين بهم وتنمية قدراتهم. I - التعلم عن بُعلد:

ويتم - من خلاله - توظيف تقتيات الاتصال المتطورة ؛ بما يُمكن أطراف العملية التعليمية من التحرر من قيود المكان والزمان وتعظم من استخدام التعلم عن بعد أو التعليم

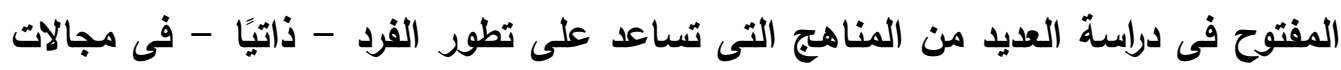


مختلفة تعود بالفائدة عليه وعلى نظام العمل المؤسسى.وهو يشمل المؤتمرات المرئية والاتصالات البيانية المسموعة ويرامج الأقمار الصناعية.

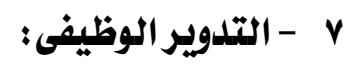

يُعد التدوير الوظيفى من أساليب التنمية المهنية ، حيث يتطلب من الموظف أن يُعلّق مهام عمله الحالية من أجل اكتساب مهارات العمل الجديد ، وقد يؤدى الموظف مهامًا

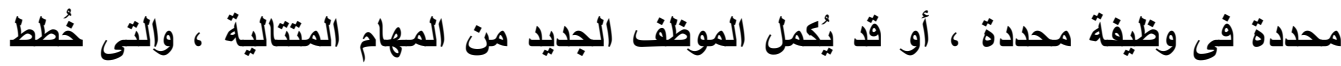
لها، وأُعدت لتحديد الموظفين ، ولتوسيع مفاهيمهر ، من خلال ممارسة مهام مختلفة لوظائف متعددة وتطبيقهابالمنظمة. ويشتمل التدوير الوظيفى على نوعين ، هما ( • ه):

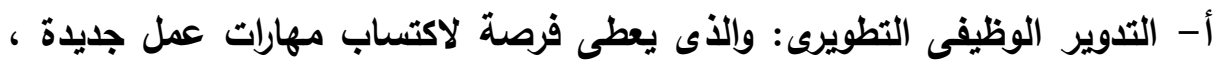

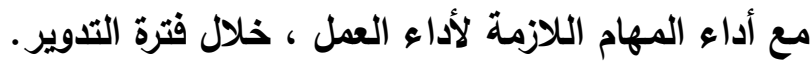
ب- التدوير الوظيفى الإثرائى: وهو نمط يعطى الموظف الفرصة ، لاستخدام مهاراته المكتسبة فى بيئات عمل مختلفة ، حيث يُتوقع من الموظف أداء المهام كاملة ، خلال فترة التدوير · 1 - التعلم اللذاتى: يُعد أسلوب التعلم الأتى من الأساليب التى تساعد فى تحسين العملية التعليمية ،

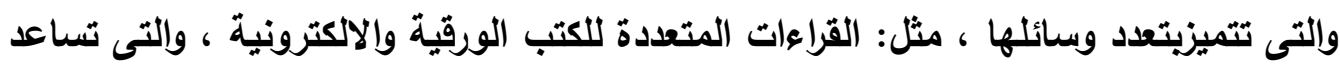
الفرد على تطوير معارفه ومعلوماته، كما يشمل العديد من وسائل التواصل الالكترونى لجميع قتوات (المدونات ـ البريد الالكترونى ـ قنوات التواصل الاجتماعى) . حيث تستخدم - جميعها - فى تبادل العلوم والمعارف والمعلومات والوثائق، حيث إن الاهتمام بعملية الترجمة للكتب المتخصصة والتأليف ، والنشر فى المجالات العلمية أو من خلال دور النشر ؛ مما يُسهم من عملية تطوير الأتات.

The Simulation 9

تُظهر العديد من التجارب أن عمليات المحاكاة يمكن أن تدعم فرص التنمية المهنية ، وتدعم ممارسة مهارات التدريس وإدارة الفصول الدراسية ، حيث تتزايد إمكاناتها ، انعكاسًا للتقدم التكنولوجى الأى يوفر قدرًا كبيرًا من الواقعية والتطبيقات الموزعة للنفاذ والمحاكاة

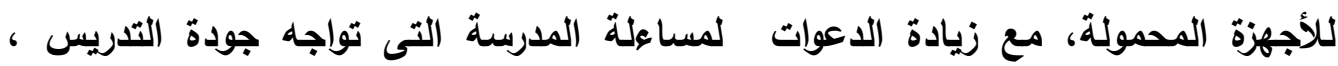


وإخضاعها لفص دقيق ولذلك كثيرًا ما يحتاج المعلمون لمجموعة دائمة من المعرفة والمهارات والمواقف والسلوكيات ، لتوجيه الطلاب وتحفيزهم لتحقيق أهداف تعليمية قابلة للقياس. مفهوم المحاكاة: والمحاكاة هى : نموذج مبسط ودقيق وديناميكى للواقع ، يسمح للمستخدمين بمواجهة المشكلات ويعينهم علي اتخاذ القرارات ويمدهم بآليات متنوعة عن الإجراعات اللازمة ، ويزيد من معيار الصدق و الثبات نتيجة تجرية النتائج وتعديل السلوك من دون

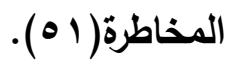

المحاكاة لتعلم الممارسة المهنية : استخدمت المحاكاة - على نطاق واسع - لسنوات عليدة فى أوضاع مثل : الطيران أو الطب ، حيث تُعد ممارسة تلك الوظائف فى الواقع تحديًا من الناحية اللوجيستية أو خطرة أو مكلفة، وقد يتم استخدام عمليات المحاكاة وتتفيذهاباستخدام التقتيات الرقمية ، ويمكن الاستفادة منها لتوفير مزيد من الواقعية والمرونة والوصول لردود الفعل المفصلة. وتتمتع المحاكاة بالعديد من المزيا للتعلم والممارسة ؛ بما فى ذللك القدرة على تكرار السيناريوهات مع أهداف تعليمية محددة ، حيث إن الممارسة لفترات أطول من تلكت المتوفرة

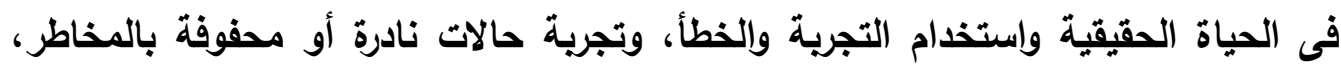
وقياس النتائج بوضوح من خلال أنظمة تسجيل معتمدة ؛ كل هذا مما يسهم في تطوير المهارات.

لذا صارت المحاكاة أكثر شيوعًا فى تعليم المعلمين ، مما يسمح بخبرة الممارسة والتغذية المرتدة لمهارات ، مثل : تخطيط الدروس وتنفيذه، وإدارة الفصل الدراسى ، وتعليم الطلاب ذوى الاحتياجات ، وحسن التعامل مع التحديات التعليمية المختلفة ، حيث يمكن للمعلمين الانتقال من النظرية للتطبيق. ويعتمد التعلم من المحاكاة فى التدريس على التفكير والممارسة المتكررة، إذ أشارت بعض الأبحاث إلي إن الطلاب الذين استخدموا Teach live أصبحوا أكثر وعيًا للبيانات ، وأكثر دقة فى استخدام اللغة. 
أنواعالمحاكاة:

صُنفت عمليات المحاكاة بطرق عديدة ، بناءً على أوضاعها ومهامها وتخصصاتها والتقتيات الداعمة لها إلي الأنواع التالية (ro). المحاكاة الظرفية ؛ ( الحالية ) :

وهى : تلك النماذج التى تمثل جواتب بيئات العمل والتفاعلات بين الأشخاص ؛ مما يجعلها تنطبق - بشكل خاص - على تدريب المعلمين وتقييمهم، فقد تكون تلكك المحاكاة سيناريو أو حالة طارئة ، حيث يتخذ المعلم قرارات للاستجابة للوضع الراهن ، ويطور الاستراتيجيات ؛ وذللك لتصحيح الوضع ، كما يفعلون فى سياق الحياة الواقعية.وتقيد تلك المحاكاة فى التأكيا علي أن توفير وضع واقعى حقيقى يمنح المتعلمين شعورًا بالظهور والمشاركة ، حيث يكون

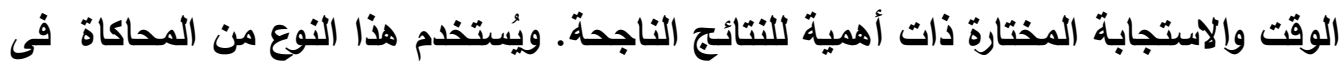
المجال الطبى والصحة ، مثل مقابلات المرضى ، والاستجابة للأزمات ، وإدارة الطوارئ ؛

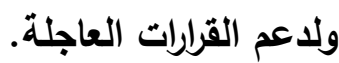

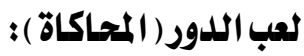

تُعد المحاكاة /السيناريو / لعب الأدوارأنماطًا تعليمية ليست بالجديدة فى تنشيط المعلمين من مختلف الأبعاد ، لكنها اكتسبت أهمية كبيرة ، حين تم التأكيل على الحاجة إلى له الممارسة ، فهى بمثابة بيئة تعلم على شبكة الانترنت باستخدام منهج منظم ؛ لمساعدة الطلاب على تطوير مهاراتهم وإبتكارالحلول اللازمة لحل مشكلات الفصول الدارية - بيئة التنظيم - كما لو كانت في فى العالم الحقيقى. وتطلب مجموعة تعليم من أجل أمريكا - ومن المرشحين للتدريس - دروسًا للمحاكاة ، بوصفها جزعًا من المقابلات النهائية قبل التعيين، حيث تعمل على فحص المعلمين المرشحين لشغل وظائف هيئة التعليم ، من أجل تحسين الأداء ، من خلال تمارين لعب الأدوار وأنشطة المحاكاة.

\section{المحاكاة مع الطلاب:}

وفي هذا النمط يُستخدم الطلاب وأعضاء المجتمع لتدريب المعلمين وقادة المدارس علي مهارات الاتصال والإدارة ،حيث تركز هذه المحاكاة على القضايا التى يواجهها المعلمون والقادة - عادة - مثل : الطلاب المعاقين والمشكلات الأخلاقية. 
المحاكاة المستندة للكمبيوتر :

و تلك المحاكاة أدوات التكنولوجيا لنمذجة الناس/ أو بيئات التعلم ، ويذلك تكون أكثر واقعية للممارسة فى تلك البيئات. وتستخدم فى تعليم المعلمين ، حيث تُستخدم محاكاة الفصول الاراسية بنجاح متزايد، وتقدم وضعًا للتدريب مع الطلاب المحاكين الذين يعتمدون على طلاب حقيقيين، ففى بيئة المحاكاة يستطيع المستخدمون تكرار استراتيجياتهم وخطظهم التعليمية وتعديلها جميعًافى مجموعة متنوعة من المستويات والمراحل. المحاكاة عبر الانترنت:

تركز "Class sim" وهى محاكاة عبر الاتترنت يتم فيها تدريب معلمين ذوى

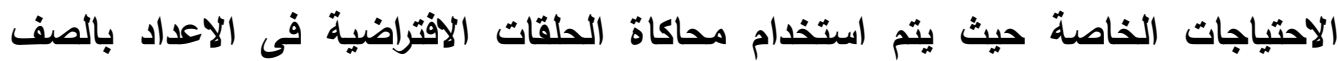
الدراسى ويتم دعم التعلم بمواد وروابط على الانترنت. تقدّم شركة (AtenIntc) واحدة من عمليات المحاكاة القليلة المتوفرة تجاريًّا لتدريب المعلمين نمطًا من محاكاة ثلاثية الأبعاد قائمة بذاتها ، أو مستتدة إلى ويب "التعلم عبر الويب" ، والتى تحتوى على سيناريوهات متفرعة ؛ يقوم فيها المدرسون باتخاذ القرارات

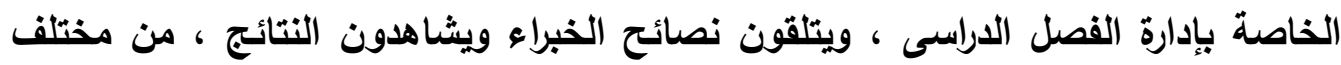
مواقف الفصول الدراسية ، مثل خبرات التدريب على الويب للمعلمين. وتحاول برامج Sim Schoolنقل خبرات التدريب على الويب للمعلمين ، وإعادة إنتاج تجرية العمل فى الفصول الدراسية بدقة أكبر، حيث تُستخدم لقطات الثاشة للفصل

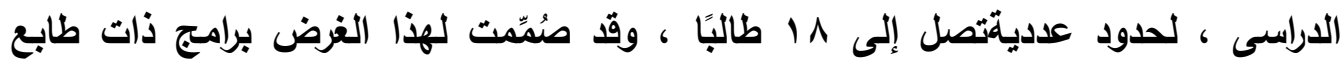
كرتونى ، تم إنشاؤه عشوائيًا، ويكون موقع المعلم - فيه - فى الجزيء الأمامى من الغرفة،

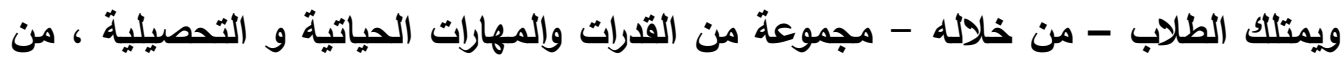
حلال التجرية ومناظرة الخبرة السابقة و المشاهدة ، ويذلك تضمن المحاكاة استجابة المتعلم لإجراءات المعلم، وعلى الرغم من كون المستخدمين قد شككوا فى Sim School؛ فإن هناك مجموعة من نتائج التعلم الإيجابية للمعلمين ، الأين تدريوا على تلك المهارة. 
وتتمثل مزايـا المحاكاة لمعلمى التربية الخاصة في النقاط التالية ( به ) : ا ـ تواجه الزيادة فى أعداد الأطفال فى الفصول. r. تساعد الأطفال على الاستقلال ، وعلي تحسين مشاركتهم ، وعلي التواصل ، بشكل ذات فعالية ، وروئية وسماع أفضل.

r. مساعدة الطفل على القيام بأنشطة التعلم واللعب ؛ للوصول اللى حقوقهم والتمتع بها. ـ ـ تواجه الاختلافات بين الأطقال ذوى الإعاقة وغيرهم من الأسوياء.

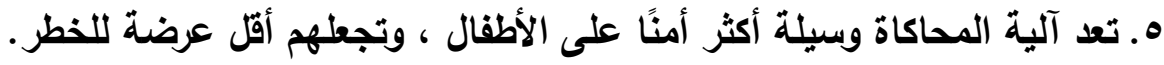
צ. تعين هؤلاء الأطفال فى عمليات التواصل والاتصال والتتقل والرعاية الذاتية والمهام المنزلية والتعليم وإللعب والترفيه .

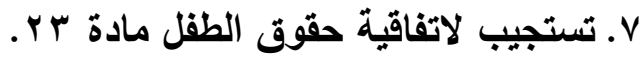

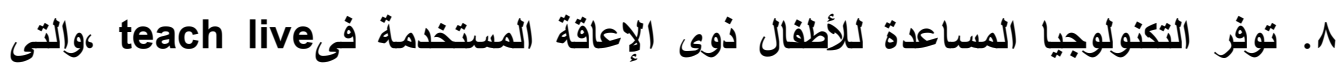
يتعامل بيها معلم التربية الخاصة.

رابعًا : خبرات استخدام أسلوب Teach Live كأحلد أساليب التنمية المهنية لمعلم التزبية الخاصة فى كل من جامعتى فلوريلا وماريلاند بـالولايات التتحدة الأمريكية : اذا نظرنا الى معلم التربية الخاصة بالولايات المتحدة الامريكية نجد انه يطلق على الأفراد

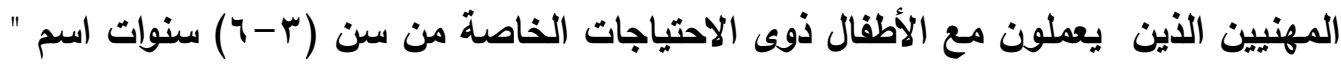
معلمى التربية الخاصة فى مرحلة الطقولة المبكرة " وقد يقوم هؤلاء المعلمون بزيارة منازل

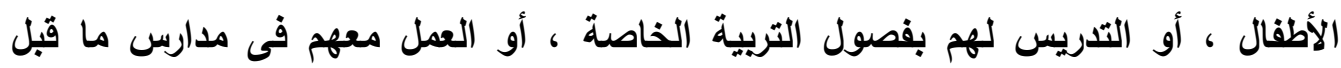

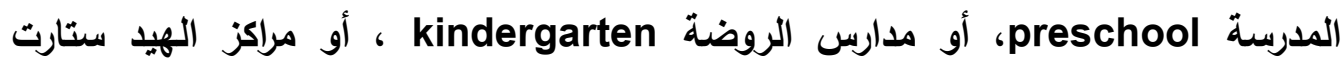
headstart أستخدام الألعاب ، وأجهزة الكمبيوتز والأدوات الأخرى لتقديم البيئة المدرسية للأطفال فضلاً عن تلريس المهارات الأساسية لهم كالتلوين، والتثكيل ، والعد ، والتعرف على الحروف ، والنظافة الشخصية ، والمهارات الأجتماعية ،وعلى المعلم أن يجعل الطلاب أكثر راحة داخل

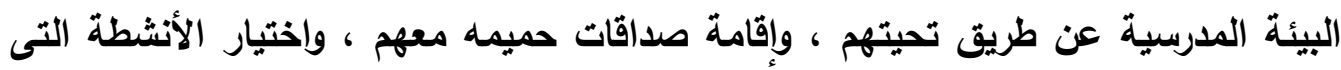
تناسب أهتماماتهم ، مع قيادة المعلم بعمليات التوجيه ونصح الطلاب عندما تصدر عنهم مشكلات أكاديمية معينة، ويشترط للعمل فى مدارس رياض الأطفال بالولايات المتحدة أن 
يحصل المعلم على ترخيص لمزاولة المهنة ، ويعد حصول المعلم على درجة البكالوريوس

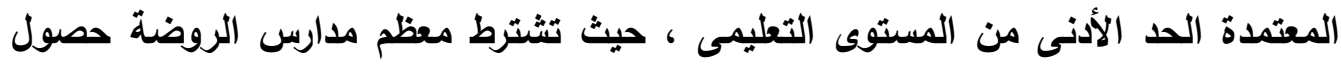
معلم رياض الأطفال على درجة الماجستير سواء فى الطفولة المبكرة أو التربية الخاصة.

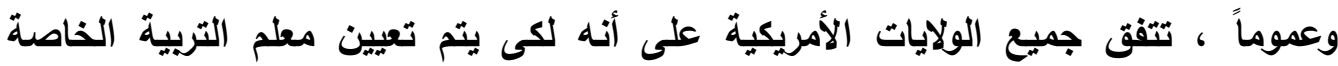
بالمدارس الرسمية للعمل مع الأطفال ذوى الاحتياجات الخاصة بأن يكون مؤهلاً تأهيلاً عالياً ،

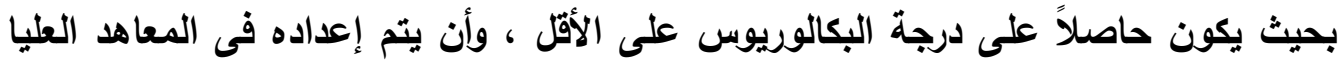

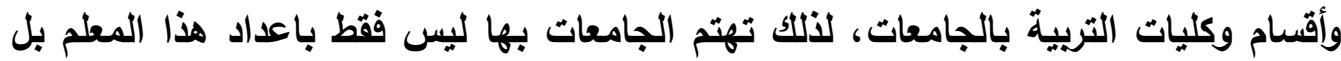

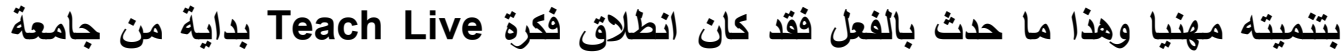

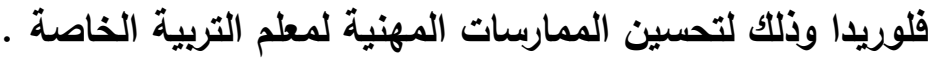
يُعد أسلوبTeach Live أحد أنواع الدحاكاة بالكمبيوتر ، والذي يرتكز العمل فيه على نظرية الإدراك الذاتى ، ويؤكد هذا النمط من الأساليب المتطورة في ميدان التعليم علي

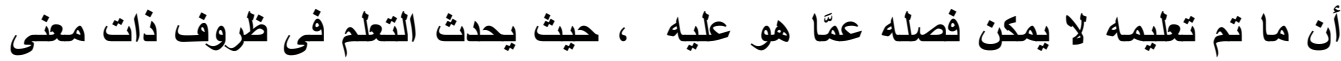

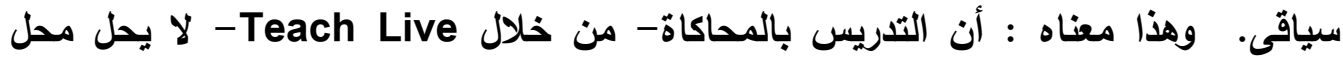
التدريس فى الحقيقة، ولكن يسمح بإجراء التجرية بأمان ومرح ، من دون التعرض التهاه

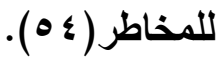
ويحاول Teach LiveTm إعادة إنتاج فصل دراسى بالكامل ، باستخدام بيئة الواقع

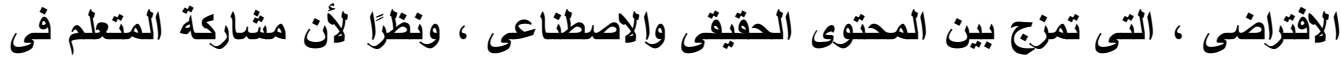

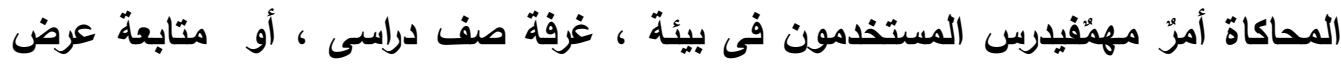
على شاثة التلفزيون ؛ مع محاكاة تجسيد الطلاب ، بوصفهم دمى ، بواسطة إنسان مدرب. اولا : خبرة حامعة فلوريليا:

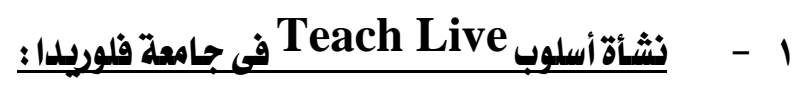

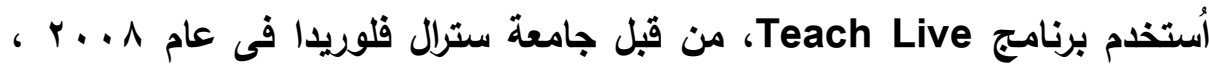

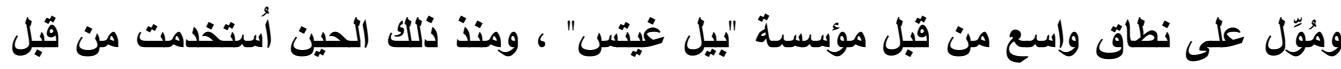

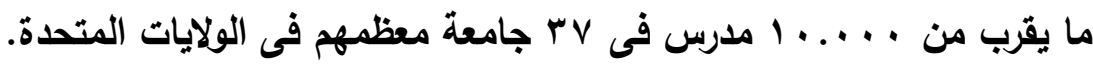

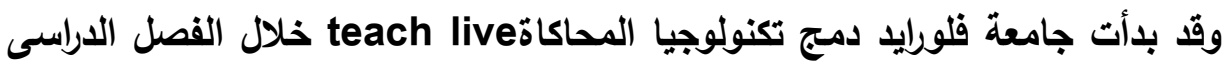

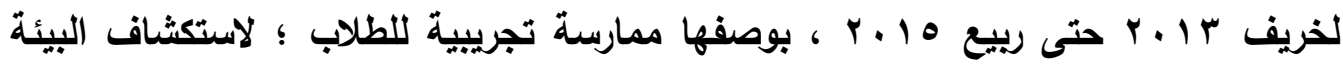


المحيطة بدون مخاطر ، بالنظر إليها علي أنها ممارسة حقيقية للتعليم في العالم الافتراضى ،

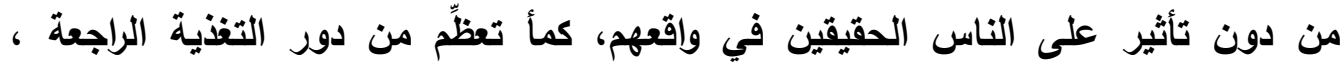
والتدريبات والممارسة العاكسة ، و تسهم في اكتساب المعلمين العديد من مهارات الاتصال

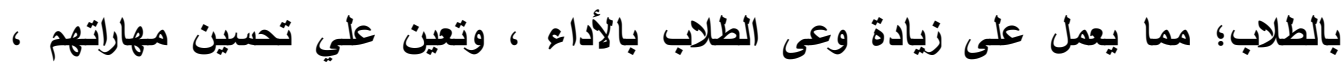

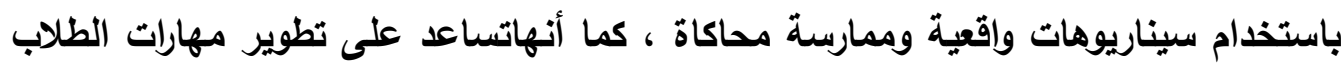
فى التواصل ، وزيادة التفاعل بين أولياء الامور والمعلمين . ويدار برنامج Teach Live بواسطة شركة mursioninc، حيث إنها شركة توفر بيئات تدريب افتراضية ، يمارس المهنيون - فيها - المهارات الشخصية التى يحتاجون إليها ، ويتقنونها؛ لتكون فعالة فى حياتهم المهنية. تاريخ TeachLive: يعد استخدام البيئات الافتراضية وطرق الوسائط المتعددة جزيًا من العديد من برامج الإعداد التعليمية مثل: البرامج الطبية الجراحية، وأجهزة محاكاة الطيران، وحالات التدريب على القتال العسكرى يعتقد الباحثون أن هذه التقتيات أصبحت جزعًا من

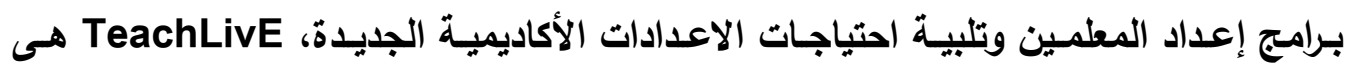
واحدة من تقتيات محاكاة التعليم الافتراضى هذه المصممة أصلاً لمحاكاة تعليم المعلمين. TeachLive الدراسية والتربية والمحتوى، تم تطويره فى جامعة سنترال فلوريدا بالولايات المتحدة الأمريكية ويتم تنفيذه حاليًا فى أكثر من أريعين حرمًا جامعيًا فى الولايات المتحدة وينمو ليشمل منـاطق مدرسية متعددة وشركاء دوليين يستخدم كل شريك أسلوب TeachLivE بطريقة فريدة بنـاءعًا

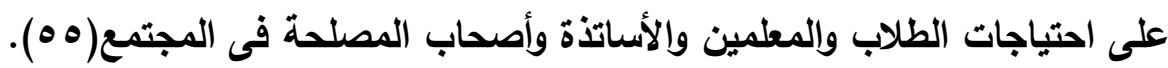
سوف يركز البرنامج على المعلم قبل الخدمة على تدريبه على إدارة الفصل، ودراسـة أسـاليب وأنشـطة التــريس، وتقديم المحتوى المناسـب، سيسـاعد النظـام الــى تـم تطـويره المعلمين الحساليين والمدرسين المحتملين فى أن يكونـوا قـادرين على تعلـم مهارات جديدة والتعمق فى المهارات التى ريما نسوها باستخدام TeachLivE الذى يمثل التعليم والتعلم فى بيئة افتراضية، يتيح برنامج TeachLivE تعيين المعلم فى فصل دراسى افتراضسى للطلاب، حيث يعمل كل أفاتار كطالب نموذجى مع امتلاك كل شخصية سمات شخصية خاصة بـه، بأن 
كل طالب افتراضى سيكون له قصة خلفية خاصة بـه ويتضمن سلوكيات نموذجية للطالب فى المدرسة المتوسطة أو الثانوية.

وللتحقق مس فاعليـة نظام TeachLivE فى تقديم تصحيح الأخطاء لمعلمى التعليم

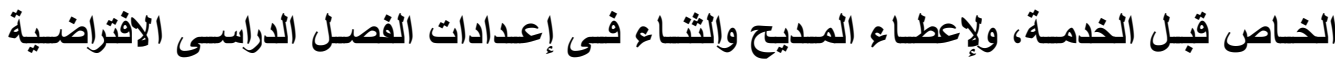
والحقيقية، شارك أربعة معلمين خاصين قبل الخدمة فى هذه الاراسة الأساسية متعددة الأوجه عبر مهارات أهداف محددة حضر المشاركون جلسات TeachLivE الأسبوعية كمجموعة، ثم شـاركوا فـى ثلاثـة أجـزاء قصـيرة مـن التـدريس تلاهــا ردود فعـل منظمـة، ثـم تعليـل كفــاءة المشاركين فى أهداف وهى الأهداف المحددة فى تقييماتهم الأسبوعية الثلاثة، وأعقب ذلك تقييم لكفاءة المشـاركين فى جميع المهارات بما فى ذلك تلكك التى لـم يتم تقييمها بعد وتم قياسها فورًا TeachLivE تقييم شـامل كانت المرحلة الأخيرة من التقييم هى تقديم تسجيل

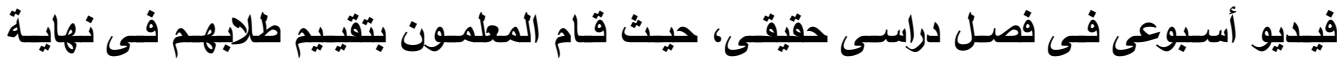

الأسبوع( أ ه).

ثم وجدت ممارسة متكررة وتعليقات فى إعداد TeachLivE عززت إتقان المشـاركين لمهارات الأهداف المحددة جميع المشاركين الأربعة كانوا بارعين فى تصحيح الأخطاء، والثناء المحدد، وإلثاء على كل من أداة تقييم التدريب TeachLivE ، والتقييم الأكثر تعقيدًا فى TeachLivE

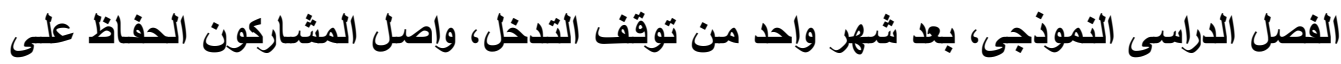
الكفاءة مع غالبية المهارات المستهدفة فى إعداد TeachLivE والفصول الدراسية العاديـة، وجدت نتائج الاراسـة فعالية الممارسـة المتثـابكة فى TeachLivE وكيف يمكن أن يتأثر التعميم والصيانة بدرجة التوافق فى الإعدادات الحقيقية والظاهرية.

\section{ب- -مفهوم أسلوب Teach Live في حامعة فلوريلدا:}

وهو فصل دراسى مختلط مع طلاب محاكين ، يوفِّر للمعلمين فرصة تطوير العملية التعليمية فى بيئة آمنة ، لا تعرِّ الطلاب الحقيقيين للخطر.وهو بيئة تعليمية افتراضية مبتكرة تستخدمها الجامعات - فى جميع أنحاء الولايات المتحدة - لاعم المعلمين المستقبليين فى العديد من الجوانب ، نحو : معرفة المحتوى ، و سلوكيات المعلم الفعالة ؛ بما فى ذلك الإدارة. 
وهو بيئة افتراضية واحدة ذات قيمة لبناء المهارات الاجتماعية للأفراد ذوى الاحتياجات الخاصة ،وقد طُوِرت فى جامعة فلوريدا (UCF) ، حيث أُشئت بيئة الواقع الافتراضى TLE لتوفير فرص التديب لمعلى ما قبل الخدمة، وتجد هذه البيئة الشخصيات والسمات والسلوكيات القائمة، ولكن التفاعلات مخصصة من خلال الامج ، ولقد تبين أن استخدام هذه التقتيةTLEمما يشكل السلوك بشكل إيجابى ، و بطريقة تنتقل من بيئة افتراضية إلى أخري واقعية . وقد أكتثفت هذه التقتية مع الأطفال والأفراد الأسوياء ن وذوى الاحتياجات الخاصة ، وخاصة حين يواجه الأفراد ذوو الإعاقة حواجزً اجتماعية منخفضة ، عند التواصل مع الصورة الرمزية ؛ مقارنة بالتواصل مع أقرانهم(ov).

\section{ج -استخلام أسلوب Teach Live في حامعة فلوريلدا:}

يُستخدم برنامجTeach Live فيها ، بحيث يُسمح للطلاب بممارسة أساليب التريس

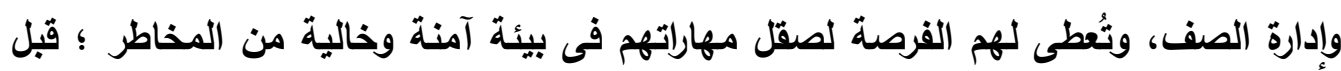
التوجه للعمل مع الأطفال بوصفهم معلمين، كما يمكن استخدامه من قبل المعلمين أثناء

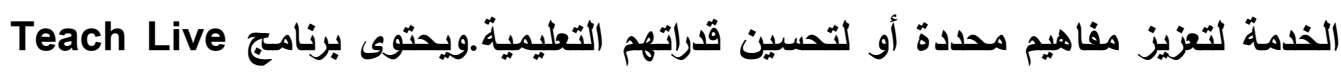
على خمس صور شخصية للطلاب ، ويمكن ضبط البرنامج وتكيفه؛ ليتناسب مع مجموعة

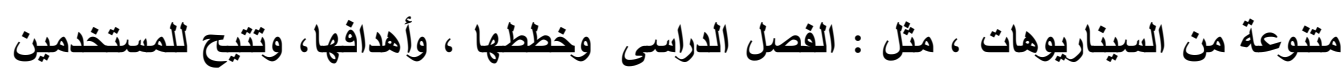

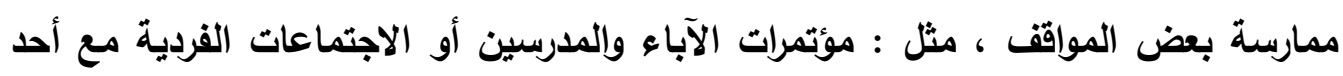
الوالدين ، فيما يتعلق بسلوك الطلاب. ويتيح Teach Live

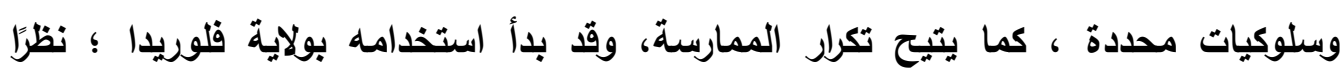

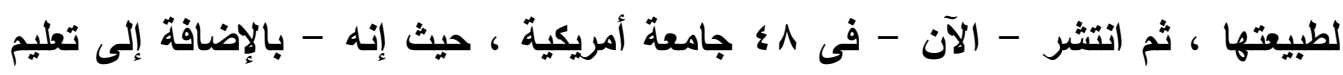

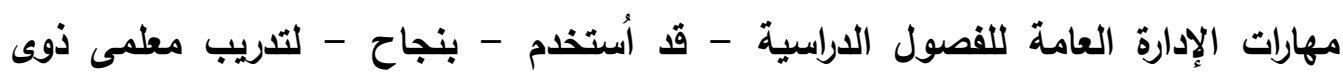
الاحتياجات الخاصة ؛ بما فى ذلك ذوى التوحد الثديد، وسنقوم بعرض Teach Live بشكل

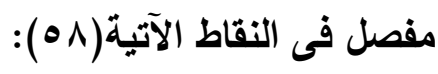

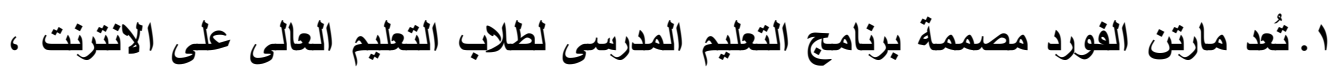
فى جامعة فلوريدا وهي شخصية تعليمية تتمتع بخبرة كبيرة ، ولقد حصلت على الدكتوراه 
فى التعليم الخاص ، وفي القيادة الأساسية فى التنمية المهنية للمعلم ، ولقد أثرفت على تلى

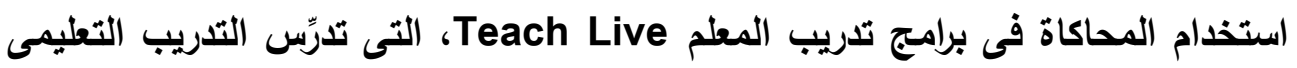
للطلاب ، للتعامل مع الطلاب ذوى الاحتياجات الخاصة. r. ويمكنتا وصف مختبر Teach Live؛ بأن نتخيل أننا نسير فى غرفة ، حيث يبدو كل شيء وكأته فصل دراسى فى المدرسة ، بما فى ذلك اللوحات البيضاء والطلاب ، وهو إعداد افتراضى والطلاب - فى الفصل الدراسى - هم من الشخصيات الرمزية ، ويمكن أن يتصرف الطلاب الظاهرين ، بوصفهم طالبًا نموذجيَّا، بناءً على أهداف التجرية، ويمكن للمشاركين التفاعل مع الطلاب ، ومراجعة العمل السابق ، وتقديم محتوى جديد للطلاب ، وتوفير الممارسة الإرشادية فى مجموعة متنوعة من مجالات المحتوى ، ومراقبة الطلاب . وفي هذا النمط يكتسب المعلمون المهارات اللازمة ليصبحوا محترفين فعالين ، في أثناء ممارسة مهاراتهم ، أو تنقيحها فى بيئة مخصصة لمراكز الطلاب. r. يستخدم المعلم في هذا النمط شاشة كبيرة تعرض لجميع الطلاب، من خلال التحرك نحو الشاشة ، والميل نحو الطقل ، ويمكن للمعلم التقاعل - بشكل فردى - مع كل طالب ، أو الوقوف أمام الغرفة لمخاطبة المجموعة. توفِّر المحاكاة الواقعية المختلطة Teach Live بيئة جليدة ، لتدريب معلمي التربية الخاصة ؛ مما يتيح لهم فرصًا جديدة لتطلم المهارات التريوية، بالتدريب على استخدام شخصيات افتراضية، بدلَامن الطلاب الحقيقيين ، حيث تستتد المحاكاةٍإلى تجربة الإدراك الموضعى ، التى تؤِّد على أن ما تم تعلمه لا يمكن فصله عن كيفيه تعلمه ، ولا عن كيفية استخدامه.

ونظرًاً لان تطوير المعرفة التريوية بالمحتوى مما بشكل تحديًا للمعمين ،فقدأستخدمت المحاكاة بطريقة تستثمرالتعلم التجريبى - ما أمكن - ويحدث هذا في بيئات واقعية وافتراضية مبنية ، بحيث تتيح للمتعلمين فرصه للتدريب والتعلم من الأخطاء فى بيئة آمنة، ويالتالى تتحقق خبرة المعلمين بسهولة التفاعل ، من دون أن يتعرض الطلاب المحاكين للأذى.

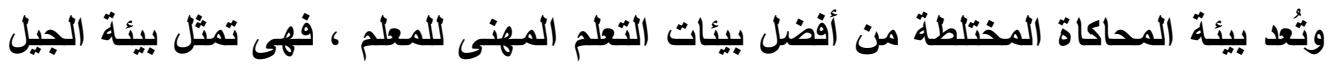
القادم للمعلم المحترف لتعلم المهارات التريوية والمحتوى وتحسين ممارسة المعلم ، في فصول محاكاة وواقع مختلط ، حيث توفر البيئات في آلية المحاكاة مكانًآمنًا للممارسة ، وتجمسيّد 
بروفة للمهارات المتعددة ، حتى إتقانها ، حيث تحسّن سلوكيات التدريس ، وتجعلها تسير

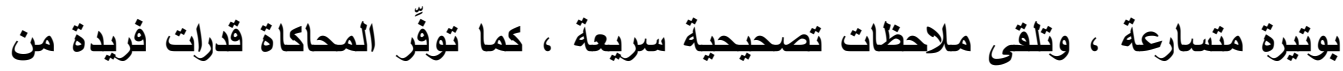

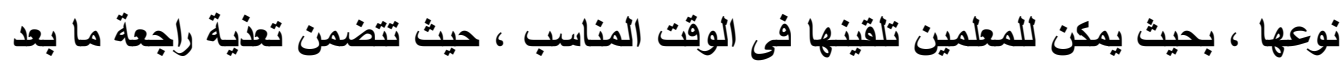

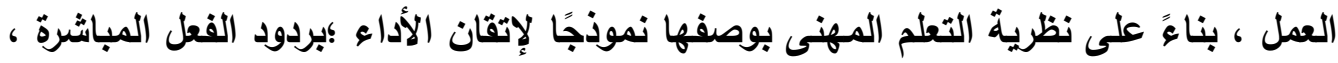
ويالقرة على تقليل التناقضات بين الآداء الحالى و المتوقع من التعلم المهنى بالمحاكاة.

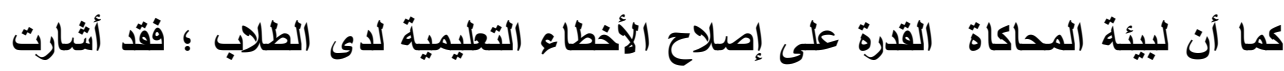
إحدى الاراسات - التى تتحدث عن "الحد من المشاكل بين الطلاب ، الذين يعانون من اضطراب طيف التوحد- إلي ضرورة تدريب المطلمين فى وضع واقع مختلط، ويالتالى هدفت المحاكاة إلي التطوير المهنى للمعلم لاعم الطلاب بشكل أفضل، لذا استهدفت هذه الداراسة تطوير مهارات المعلمين لتعزيز النتائج الإيجابية للطلاب الذين يعانون من اضطراب التوحداب

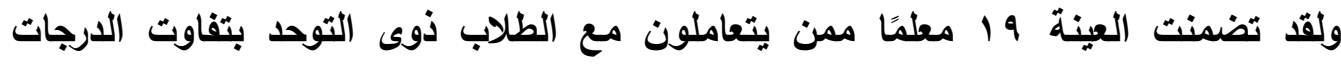

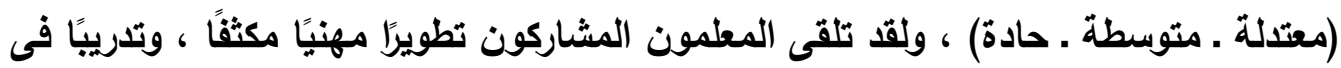

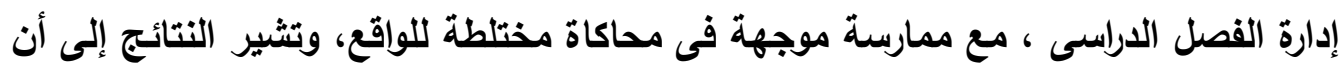

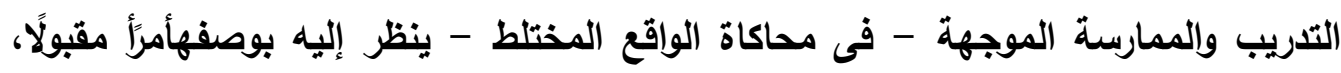

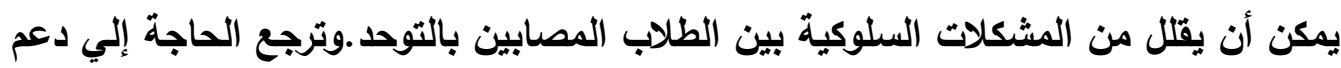
معلمي طلاب التوحد إلى الأسباب التالية (9ه):

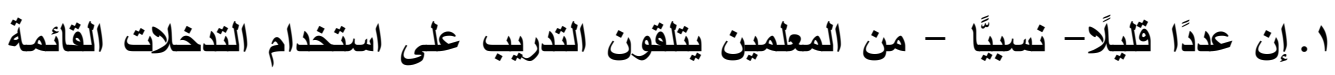

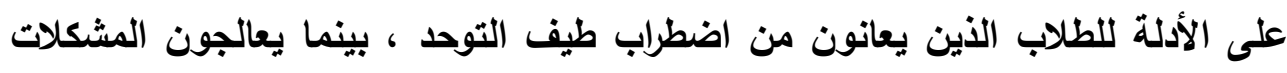
السلوكية فى الفصل الدراسى. r. . هناك نقص فى المؤلفات والأسس حول كيفية دعم تطوير مهارات المعلمين أثناء الخدمة.

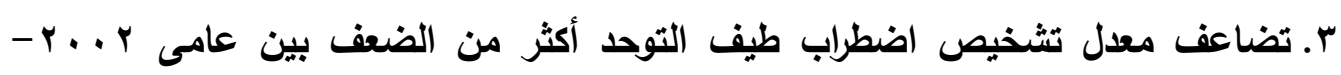

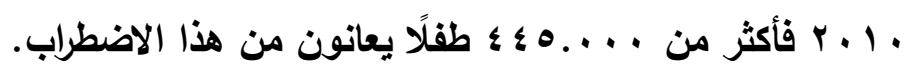

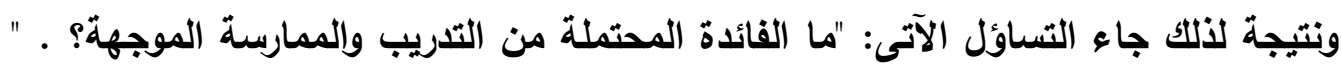

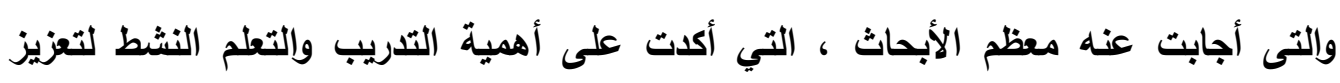

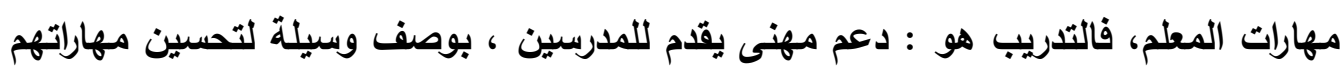


، حيث تسمح للمعلمين باستهداف مجالات المهارات التى يكافح فيها طلابهم ، في أثناء تلقى التغذية الراجعة المستمرة القائمة على الأداء. وقد تزايد الاهتمام باستخدام التكنولوجيا - بوصفها أداة لتوجيه المعلمين فى تعلم مهارات جديدة ، ومن هذه الأدوات التقتية المحاكاة ، التى توفر الفرصة للمشاركة فى الممارسة الموجهة ، التى قد لا تتاح فى الفصل الدراسى، وتمكن المحاكاة الأنظمة التعليمية من التفرغ لاحتياجات المعلم ، وتجنب تعرض الطلاب الحقيقيين لأنى المعلمين ، ويُعد Teach Live

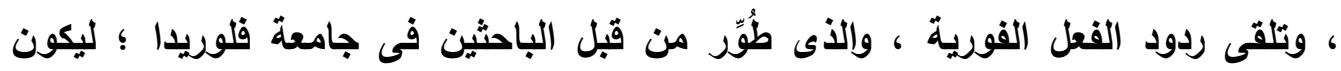
نموذجًا محاكيًا ومختلطًا ، حيث يتعامل المعلم مع خمس صور تجسيدية متحركة بواسطة الكمبيوتر

ولقد خلصت تلك الدراسة إلى أن المحاكاة مفيدة فى رسم الواقع؛ بوصف وسيلة لتدريب المعلمين، فيمكن من خلالها توفير العديد من فرص بناء المهارات للمدرسين ، وكذلك

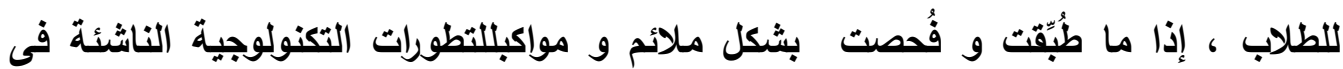
التعليم. وقد قدمت تلك الدراسة دليلًا على التأثيرات المحتملة لنموذج التدريب الذى يركز على المعلم لاعم الطلاب المصابين بالتوحد ، وعلى وجه التحديد أوضحت النتائج التى توصلت الدراسة إليها أن نموذج التدريب على الممارسة المحاكية للواقع المختلط قد يكون منهجًا فعالًا

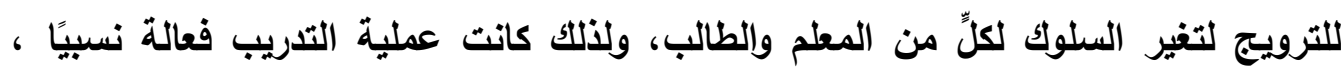
حيث تطلب حوالى ؛ ساعات من المشاركة للمعلمين ، واستقبلوها بشكل جيد ؛ علاوة على ذلك ، تشير البيانات إلى أن هذا التدخل مقبول لاي المعلمين ، وهو نهج محتمل الاستخدام - خاصة إذا تم إيلاؤه مزيدًا من الاهتمام لكيفية تقديم المحاكاة للمعلمين ، ولكيفية الوصول إليها. وهناك أمثلة أخري في هذا الصدد ، مثل : تدريس مهارات تناول الطعام للطلاب الذين يعانون من الاضطرابات العاطفية والسلوكية .

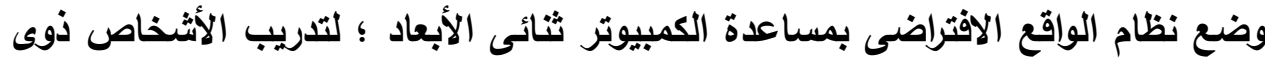
الإعاقة الأهنية على كيفية التسوق - مادة علم النفس التأهيلى. 
كما أنه قد أمكن لمحاكاة الكمبيوتر أن توفر بديلا، بتوفير التدريب على مهارات وكفاءات محددة، فى بيئة خاضعة للرقابة دون التعرض للخطر ، ودون التسبب فى ضرر للطلاب أو العملاء الفعليين ، لذا تعد المحاكاة معيار الصناعة فى مجالات الطيران ، وطب لهب لهابه الأسنان ، والطب ، والدفاع ، و هي بيئة تعليمية دامجة ، ويتعلم فيها الطلاب المهارات الأساسية ، ويمارسونهافى بيئة| منة، تخضع للإثراف ، وتسمح بالأخطاء والكعلاج ، من دون التأثير على العملاء الفعليين . التعائ.

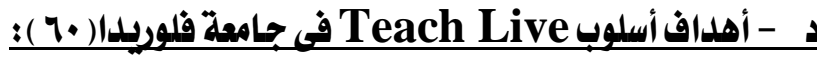

1. تشكيل السلوك من خلال مراقبة الأداء والتوجيه .

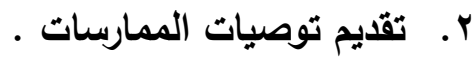

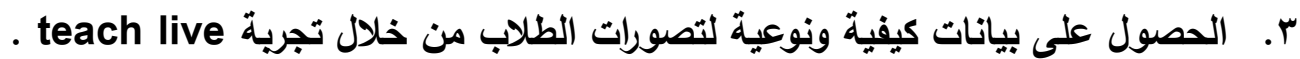

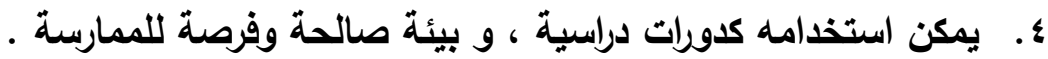
ه. ـ دعم مهارات الاتصال لاى الطلاب من خلال المحاكاة . צ. الاستفادة من خبرات الآخرين من خلال تبادل الأماكن بينهما . ل.

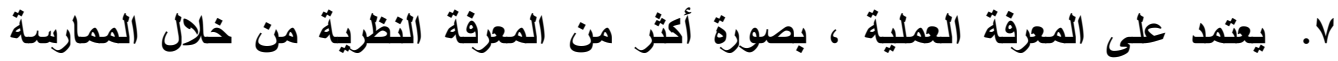

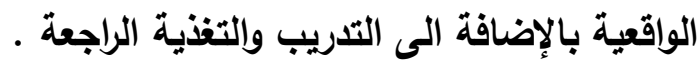

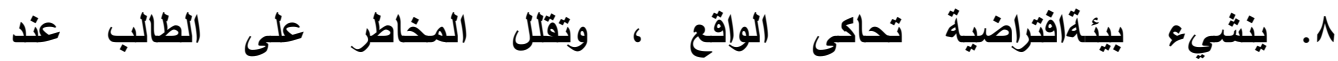

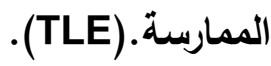

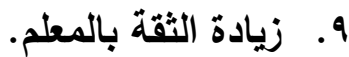

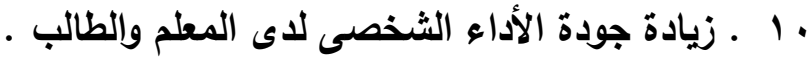
11

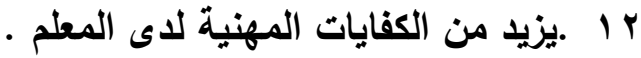

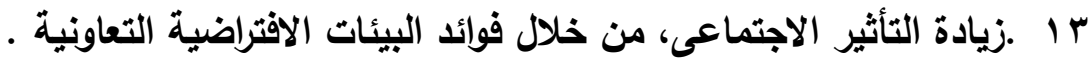

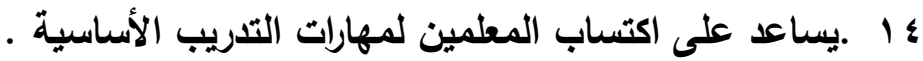

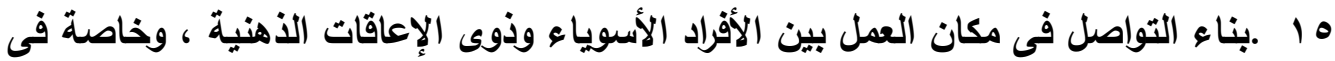
المهارات المتعلقة بالوظيفة ، وحل المشكلات الاجتماعية. 17 ـ ـ يقدم برنامج الاستعداد الوظيفى . 
IV يُككن من عمل توجيه الأفراد فى بيئة TEACH LIVE لحل المشكلات فى مكان

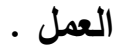

11 ، ـالوصول إلي فرص عمل لذوى الاحتياجات الخاصة ، والتدريب على التوظيف من خلال

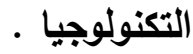

9 ، إعدادأعضاء منتجين و تخريجهم فى المجتمع بنجاح .

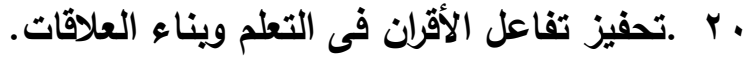

القوى والعوامل المؤثرة في استخلام Teach Live في جامعة فلوريدا بـالولايـات التتحلة

|لأمريكية:

تتكون الولايات المتحدة الأمريكية من العديد من الولايات ، التى تختلف - فى التى

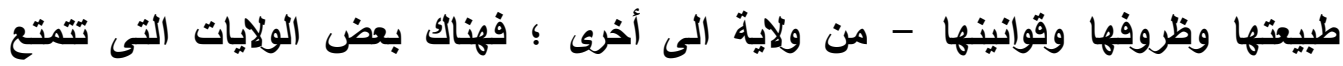

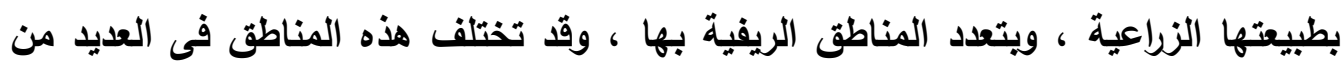
النواحى الاقتصادية والثثافية والتعليمية ومشاكلها الاجتماعية وصعوياتها ومدارسيها والمستويات المختلفة لطلابها . كما أن من صور الاختلافات بين الولايات المختلفة إنما تتمثل فى اختلاف طبيعة الطلاب فى هذه المدارس وفي تباين احتياجاتهم ، وما يعانون منه من صعويات واختلافات

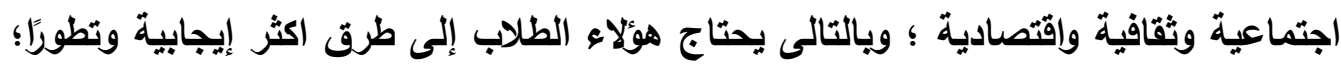

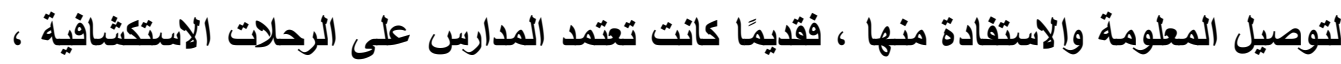

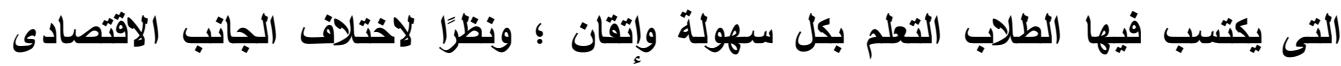
وصور التمويل للمدارس بالمناطق المختلفة ، فقد دعا ذلك إلي البحث عن سبل أخرى للتطلم

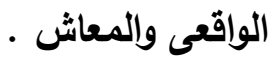
ونظرًا للتطور التكنولوجى ، الذى اجتاح العالم بآسره ، ومن ثم أُستخدم فى التعليم ؛

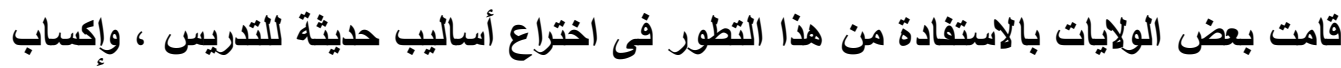
المعلومة ، و نسوق بعض الأمثلة للاستثهاد لا للحصر ، و ذللك علي النحو التالي( لآل) :

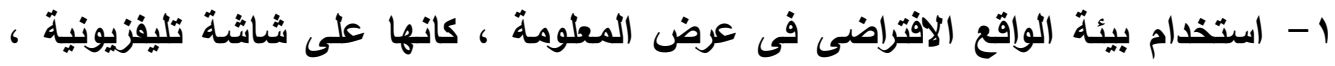
يعيش فى أحداثها الطالب ، بوصفه جزيًا منها ، إلى جاتب استخدامه للخرائط ، التى التى توضح له الأماكن وطبيعتها. 
r- استثمار الصور المتحركة فى عرض المعلومة بصورة تفصيلية ، فهى تساعد الأطفال

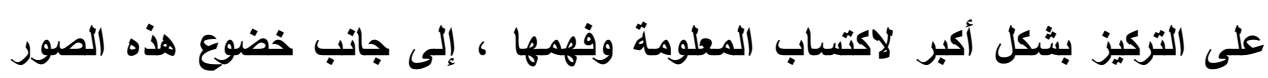

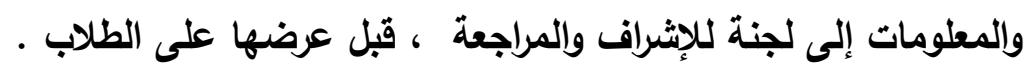

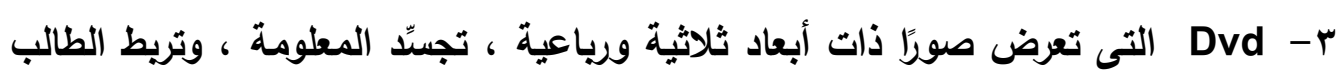

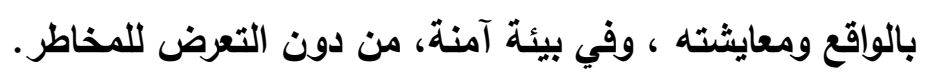

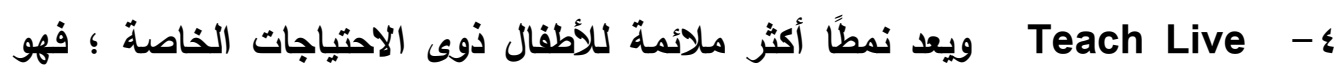

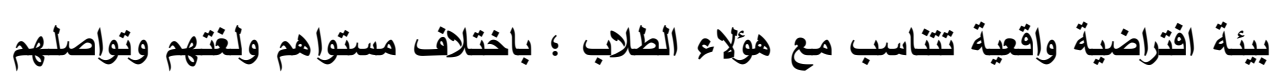

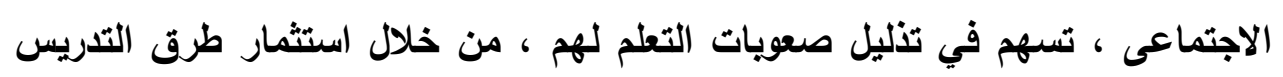
الدختلفة و مناسبتها لكل فئة منهم.

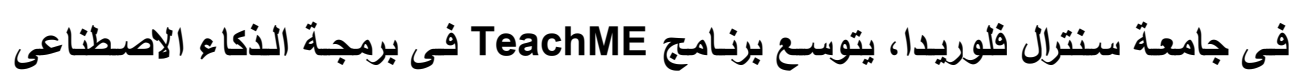

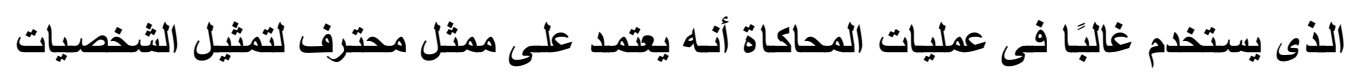
الخمسة التى تم إنثاؤها للمشروع.

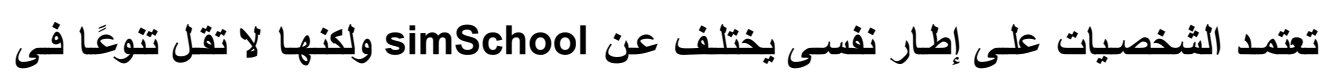

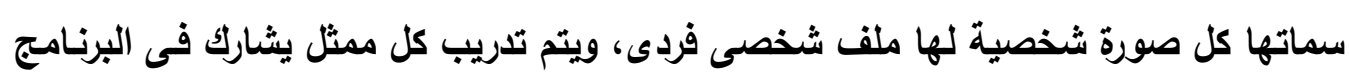

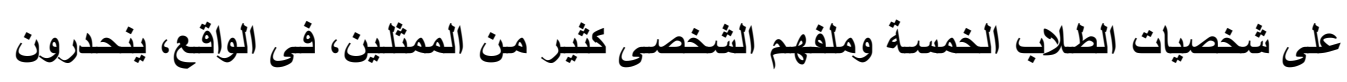
من برنامج للفنون الجميلة فى جامعة كاليفورنيا، يجمعون بين جوانب علم الثمن النفس والارتجال والأداء والفلسفة.

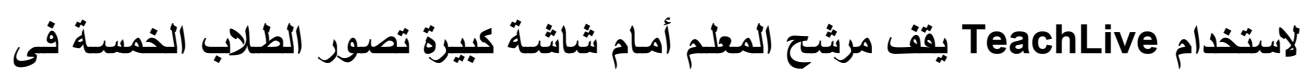

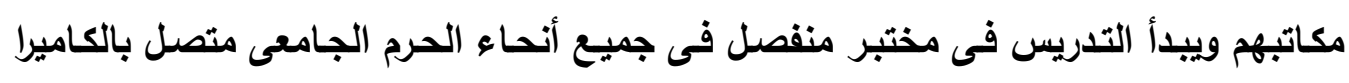

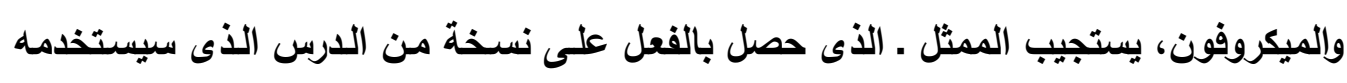

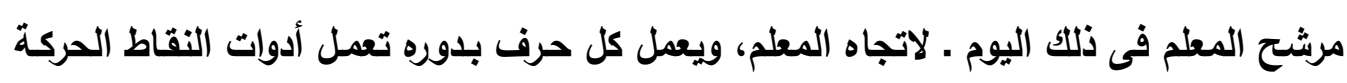

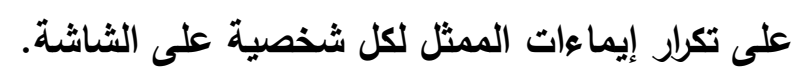

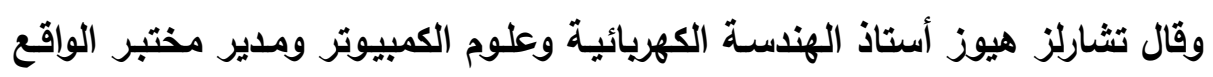

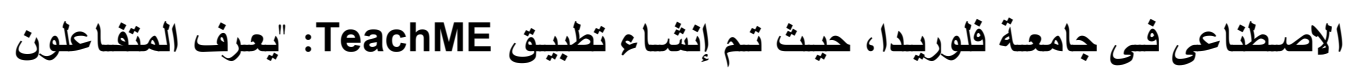

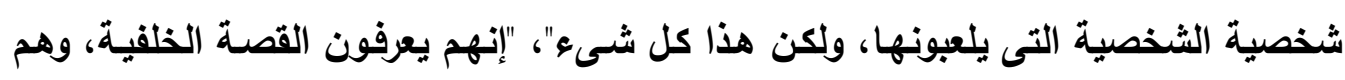


يعرفون الحياة الأسرية، لكن ليس لديهم نصوص مرتبطة بما يقوله ذلك الشخص؛ مـا يفطلونـه مدفوع بالكامل بالظروف".

كانت جاكلين أ. رودريغير، مديرة برنامج TeachME وطالب الدكتوراه فى جامعة فلوريدا، من بين المتشككين فى البداية فى أن الطلاب الأفاتار يمكن أن يشبهوا الطلاب فى الفصل الاراسى الحضرى، وقالت إن الأمر استغرق بضع دقائق فى المحاكاة لتغيير لأيها. لقد كان سؤالى، هل كانوا سيجييون مثل الطلاب الذين قمت بتدريسهم من قبل، ام كانوا

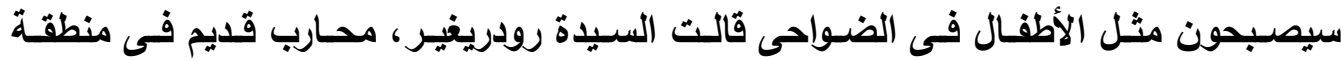
كولومبيا التعليمية من مقاطعة كولومبيا المدارس العامة لم يكونوا كذلك. قال السيد جيبسون إن مشروعًا مثل simSchool يفتقر إلى الممثلين المباشرين، لكن يمكن توسيع البرنامج الأساسى ليشمل ملفات شخصية عاطفية أكثر تعقيدًا للشخصيات كما أنه يود أن يرى المتغيرات المعرفية في البرامج تتضاعف للسماح بأنماط التحصيل أكثر دقة بين الطلاب الظاهرى.

غالبًا مـا يتم استخدام طرق تعليمية متعددة لإعداد طـلاب مـا قبل الخدمـة بفعاليـة للمهن كمدرسين، تتضمن بيئات تـريب المعلمين في كثير من الأحيان الخبرات الميدانيـة،

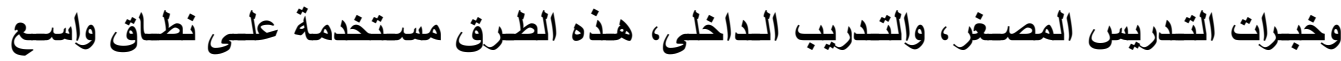
ومقبولة لتدريب المعلمين المنظرين للصف، ولكن المعلمين فى سنواتهم الأولى من التعليم غالبًا ما يواجهوه صعويات تتعلق بإدارة الفصول الدراسية TMTeachLivE هو بيئة تعليمية

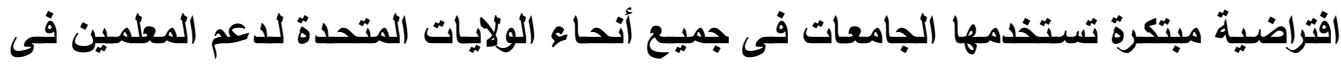
لامستقبل فى كل من المعرفة المحتوى والسلوكيات المعلم الفعال بما فى ذلك. وقدعملت مجموعة من أعضـاء هيئة التدريس فى جامعة سنترال فلوريدا (UCF) بشكل تعاونى لتطوير مفهوم TeachLive ردًا على سؤال طرح فى قسم تعليم المعلمين الخاص بهـم، كيـف يمكنتـا إعداد المعلمسين لإدارة الفصـول الدراسية وسـلوك الطالب دون تعـريض

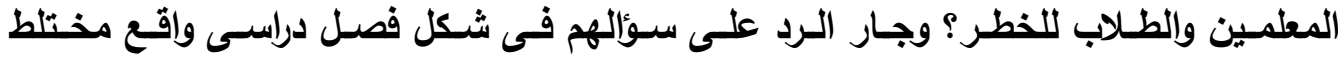
باستخدام التكنولوجيا فى شكل الآلة كما الطلاب والمتفاعلين الإنسان. وصف مختبر TeachLivE 
تخيل المشى فى غرفة يبدو فيها كل شىء وكأنسه فصل دراسى بالمدرسـة المتوسطة،

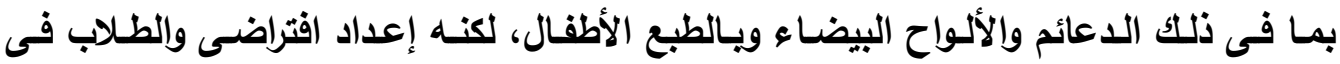
الفصل هم أفاتار قا يتصرف الطلاب الظاهريون مثل الطلاب الذين يتم تطويرهم عادة، اعتمـادًا على أهداف التجربـة يمكن للمشـاركين التفاعل مـع الطلاب ومراجعة العمل السـابق، وتقديم محتوى جديد للطلاب وتوفير سقالات أو ممارسـة موجهة فى مجموعة متنوعة من مجالات

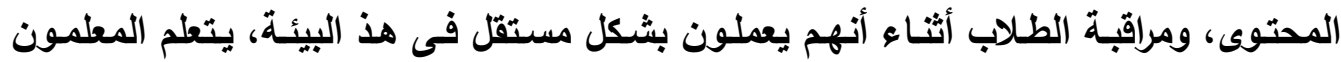

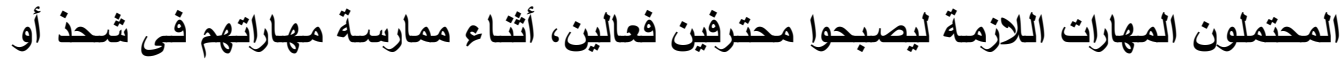
صقلها فى بيئة مخصصة لمراكز الطلاب، إذا فشل المعلمون أو المبتدئون أو المتمرسون فى مصن تلبية احتياجاتهم، هدف الجلسة، يمكنهم إعادة إدخال الفصل الدراسى الافتراضس بخطة جيدة والمحاولة مرة أخرى لتعليم الطلاب نفس المفهوم أو المهارة، اعتمدت منهجية تطوير النموذج

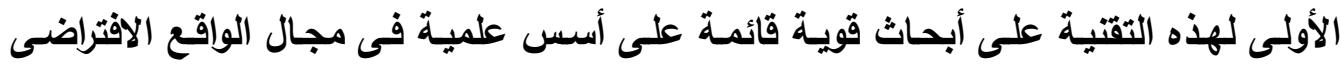
والمختلط.

إمكانـات المسـاعدة فى تدريس وتطوير سلوكيات التدريس الفعالـة لمعلمى مـا قبل الخدمة من خلال فى كلا المجالين من المعرفة بالمحتوى وإدارة السلوك، والاستفادة بالجهود

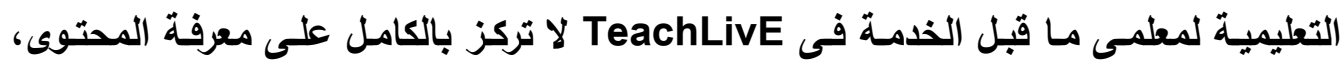
ولكن تتطلب أيضًا من معلم مـا قبل الخدمـة التركيز على إيصـالهم للتعليم وإدارة سـلوكيات الطلاب تعد TeachLivE واحدة من التقنيات التى تلدعم برامج تعليم المعلمين التى تضع مناهج أكثر تركيزًا على اللمارسة تريط المعلمين قبل الخدمة بالتوجيه المباشر لتعزيز مجموعة

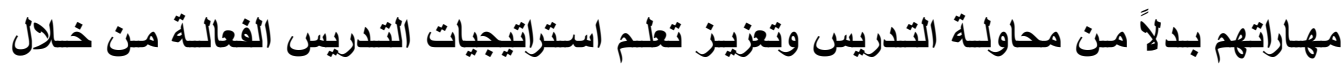
المحاضـرة أو المناقشــة لمعلمس مـا قبـل الخدمـة، تتيح هذه التكنولوجيـا للمتعلمسين تطبيتق المعرفة للمشـاركة فى تجارب ذات معنى فى TeachLivE يجب أن يعتمد المعلمون على أنفسـهم لتحفيز الطـلاب الظـاهريين الذذين لوحظوا فـى بعض الأحيـان عدم الاحترام وغير لهير المتحمسين وغير المتحمسين، ويعبارة أخرى حقيقية. 
- جامعة ماريلاند:

\section{-}

من المفيد الإثارة إلي أن تكوين بيئات افتراضية للمحاكاة، لتعزيز إعداد المعلم

بواسطةTeach Live، وهو وسيلة مبتكرة لتزويد المعلمين الممارسين - وماقبل الخدمة بطرق مختلفة لتلبية متطلبات الطلاب ذوى الاحتياجات المتنوعة، بتوفير مهارات القرن الحادى والعشرين ، ولابد أن تعظم الجامعات من القول : إن التدريس لا يحتاج إلى معرفة متخصصة، بطلب القليل من التدريب التريوى لأعضاء هيئة التدريس والفصول الدراسية، التى إنى إنى تسهل الدورات الكبيرة ، التى تركز على المعلمين ، وغالبًا ما يؤدِّي المساعدون فى التدريس دولًا مهمًا فى دعم أعضاء هيئة التدريس فى تحويل المقررات الدراسيةإلى مزيد من التركيز على الطالب ، وإدماج التعلم النشط في بيئة التعلم ، وذلك من خلال نموذج كولوراد للتعلم المساعد (LA) ) ، لإعداد الطلاب الجامعيين لتريس عالي الجودة ، وذلك من خلال استخدام

Teach Live.

Teach لذلك تم عقد شراكة بين جامعة ماريلاند وجامعة فلوريدا على استخدام

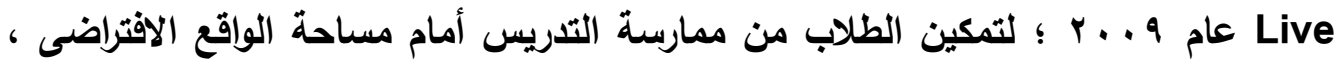
ومنذ ذلك الحين ازادت ممارسة هذا الأسلوب - بشكل كبير - داخل جامعة ماريلاند(r T). تم تطبيق برنـامـ TeachLive فـ الجامعـة مـع بعض المعلمـات قبل الخدمـة

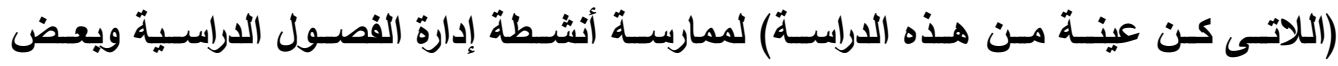
الاستراتيجيات التريوية قبل الذهاب إلى المدارس دون التعرض لخطر فى مواقف حقيقية، قام

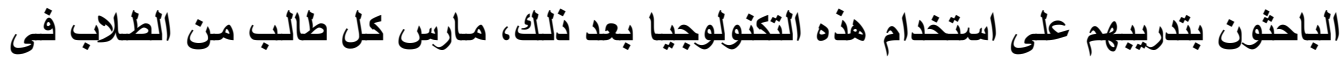
هذه العينة جلستين، واستغرق كل جلسة عشر دقائق، باستخدام TeachLive قام الباحثون أيضًا بتحليل تصورات هؤلاء الطلاب حول TeachLive وفوائدها للطلاب، كشفت النتائج أن بان جميع الطلاب فى العينة رحبوا بتكنولوجيا المحاكاة هذه وأعريوا عن تصوراتهم الإيجابية تجاه استخدام TeachLive ليس فقط فى إدارة الفصول الدراسية، ولكن أيضًا فى الجواتب التربويـة والمحتوى.

فى دراسة أخرى أظهرت النتائج أنه من المتوقع أن يقوم المعلمون بتعليم مجموعة مـن الطـلاب مـع مجموعـة واسـعة مـن الاحتياجـات الأكاديميـة، يجب أن تـوفر بـرامج إعداد 
المعلمين فرصيًا تعليميـة لهم ليصبحوا خبراء فى صنع القرار المعتمد على قواعد البيانـات والبراعة فى استخدام التذخلات القائمة على البحوث لتحسين النتائج النهائية للطلاب، أظهرت الأبحاث أن إخلاص المعلمين فى التتفيذ عند استخدام التدخلات يتأثر بعدد من العناصر بمـا فى ذلك: التطوير المهنى، دعم التدريب، التواصل التفاعلى، استخدام التكنولوجيا، والتفاعل مع مجتمع افتراضى من المتعلمين. يعـ الفصـل الاراسـى الافتراضس TLE (بيئة التعليم والتتعلم) المنصـة الافتراضية دلـ TeachLive نموذجيًا للطلاب فى هذا الإعداد، تتاح الفرصة لمعلمى مـا قبل الخدمة للتعلم دون أى آثاء سلبية على الطلاب "الحقيقيين"، وتلقى التعلم الشخصى ووقت للتفكير والتحسين. وقد جـرب البرنـامج على بعض المعلمـات قبـل الخدمـة على أنشـطة إدارة الفصل ويعض الاستراتيجيات التريويـة قبـل الذهاب إلـى المـارس دون التعرض لخطر الوقهوع فـى مواقف "حقيقيـة" قـام البـاحثون بتـدريب الطـلاب فـى عينـة الدراسـة علـى اسـتخدام تقتيـة TeachLive بعد ذلـك، مـارس كل طالب فى العينـة جلستين، واستغزق كل جلسـة عشـر دقائق، باستخدام TeachLive قام الباحثون أيضًا بتحليل المفاهيم المكتويسة لهؤلاء الطلاب حول TeachLive وفوائدها لكل طالب على حدة. كثفت النتائج أن جميع الطلاب فى هذه العينة رحبوا بتكنولوجيا المحاكاة وعبروا عن تصوراتهم الإيجابية تجاه استخدام TeachLive ليس فقط فى إدارة الفصول الدراسية، ولكن أيضًا فى الجواتب التعليمية والمحتوى، كان الثـاغل الرئيسى هو إدارة الفصول الدراسية التى استعرضـها الباحثون داخل الفصـول الافتراضية، تعدث الباحثون إلسى المحاكـاة لهم لتعليم الطلاب كيفية التحكم فى الأساليب المميزة لطلابهم.

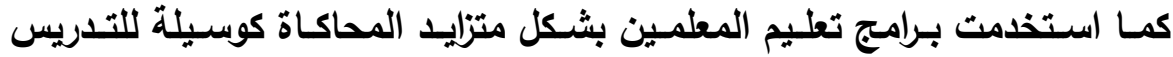

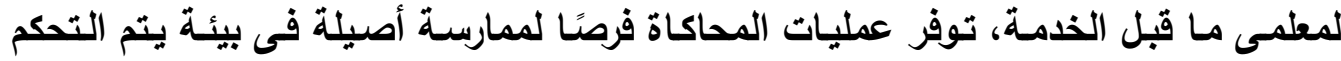
فيها مـع تقليل مخاطر حدوث ضرر، تبحث دراسـة الحالة المفيدة هذه تجارب سا I من معلمى

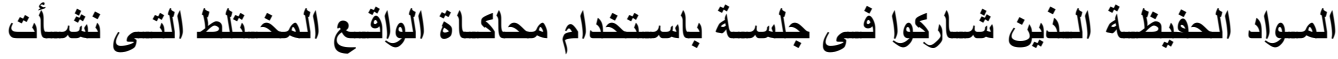

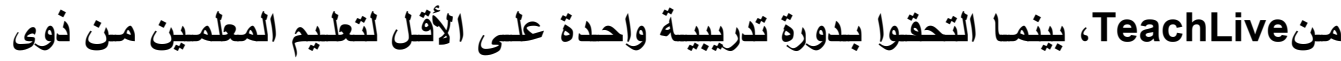
الخبرة الميدانية، قام الباحثون بتحليل بيانات المقابلة باستخدام مجموعة متنوعة من تقتيات 
الترميز ثم استخلصوا التأكيدات من الأكواد والمواضيع المشتقة من تحليل البيانـات، برزت أربعة محاور: فرصـة لممارسـة أصيلة، والنقل المتصور للتعلم، والثقة المتصورة، وتحديات استخدام محاكاة الواقع المختلط استخلص الباحثون الاستنتاجات التالية من هذه الموضوعات اعتبر المشاركون محاكاة الواقع المختلط شكلاً من أشكال الممارسة أكثر أصالة من ما قدمته ملاحظاتهم خلال التجارب الميدانية، تصور المشاركون نقل التعلم من ملاحظات الزملاء خلال الجلسات مع محاكاة الواقع المختلط إلى الأداء خلال جلساتهم الخاصة، رأى بعض المشـاركين زيادة الثقة فى تطبيق المهارات التى تمارس أثناء المحاكاة للعمل مـع الطلاب وأولياء الأمور

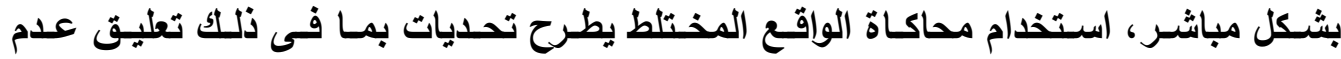
التصديق، وتلبيـة احتياجـات المرشحين، ووجود جمهور من الأقران، هذه الاراسـة لها آثار على الاستخدام المستقبلى لمحاكاة الواقع المختلط لإعداد المعلم. ب ب - مفهوم أسلوب Teach Live في حامعة ماريلاند: عبارة عن فصل دراسى محاكى بالكمبيوتز وغامض ومختلط يوفر TeachLivE للمعلمين الفرصـة لتطوير ممارستهم التريويـة في بيئة آمنـة لا تعرض الطـلاب الحقيقيسين للخطر. يخطو المعلمون إلى الفصول الدراسية الافتراضية لـ TeachLivE وفهى غضسون دقيقة واحدة من تجريـة الانغمـاس، ممـا يسمح لهم بتدريب على ممارسـات التدريس عالية الفعالية المتعلقة بإنجاز الطلاب. يشبه TM TeachLivE محاكاة الطيران للطيارين، وهو يحاكى تجربـة الفصول الدراسية للمعلمين لصقل مهاراتهم. وهو : مشروع "يعلم التدريس الحى فى الفصول الاقتراضية ، وقدعُقد الجامعة - من خلاله -شراكة مع جامعة فلوريدا ، لتمكين الطلاب من ممارسة التدريس أمام مساحة الواقع الافتراضى. وهو تقنية محاكاة للواقع المختلط ، حيث يقوم المعلمون المبتدئون بتدريس دروس مع فئة افتراضية ، تتكون من خمسة طلاب رمزيين مبرمجين بأنماط شخصية مميزة ،

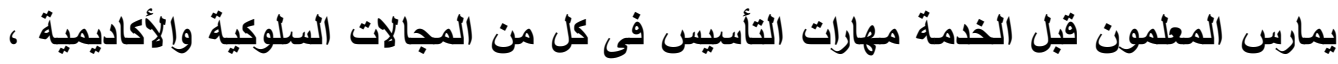
بوصفها أساس لتطوير أدوات تعليمية أكثر تعقيدًا للاستخدام مع الأطفال الحقيقيين( T 7). 
ج - استخدام أسلوب Teach Live في جامعة ماريلاند

تم استخدام TeachLive Lab فى العديـد مـن المشــاريع البحثيـة وقد شــلت هذهاه المشـاريع تحسـين مهارات الانتقـال للطـلاب ذوى الاعاقـات الكبيـرة، وتـوفير التغذيـة المرتـدة الفورية من خلال التكنولوجيا فى الأنن للمعلمين قبل الخدمة، وتطوير مهارات التجريـة السرية فى المعلمسين قبـل الخدمـة وفى الخدمسة، وإعداد المعلمسين ليصبحوا محترفين فـى استخدام

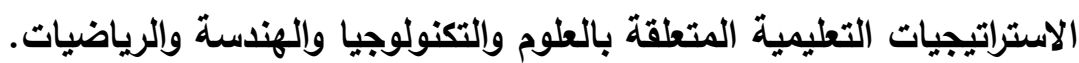
تعد جامعة ماريلاند وإحدة من ابرز جامعات ولايـة وإثنطن تستخدم حاليًا بيئة الواقع المختلطة الفريدة هذه لإعداد أو إعادة تـدريب المعلمين قبل الخدمسة أو أثنـاء الخدمسة مسن

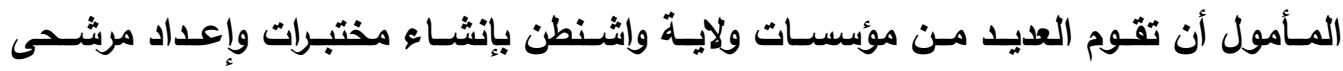
المعلمين وإلمهنيين بشكل أفضل فى مجال التعليم.

Uعلم تقريبًا مع UCF مثلما يتدرب الطيارون على أجهزة محاكاة الطيران، يمكن لمعلمى الفيزياء صقل مهاراتهم فى أجهزة محاكاة الفصول الدراسية بطبيعة الحال، فغن شرح قوانين نيوتن للمراهقين أقل صـوية من هبوط V V ومـع ذلك تظهر دراسـة جديدة ان مسـاعدى التدريس فى المرحلـة الجامعيـة الأولـى يمكنهم اكتســاب خبـرة قيمـة في ممارسـة دروسـهم أمسام "الصـور الرمزيـة"

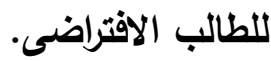

أظهرت العديد مـن الاراسـات أنـه يمكن للمهنيين التريـويين تحسين تعليمهم من خـلال التمرين أمام محاكى الفصل الدراسى أراد الأستاذ المساعد جاكلين تثنينى، دكتوراه، وزملاؤها، كارى إل ستراوب، وكيفن توماس، تقييم مـا إذا كان يمكن الاستفادة من نفس المزايـا من قبل مساعدى التعلم، والطلاب الجامعيين الذين يقدمون تعليمـة إضـافية لزملائهم زميل الصف فى الصى الدراسـة، يمسارس مســاعدوا التتعلم علـم أصسول التــريس فـى الفيزيـاء فـى محساكى الفصـول الدراسية، استكثف الدكتور تشينى استخدام محاكى الفصول الاراسية الواقع المختلط، ودعا TLE TeachLivE للسماح LAs الجامعيـة لممارسـة المهارات التريويـة، بينمـا بـأت مـع التخصصـات التعليميـة، أثناء الدراسة، بحثوا أيضًا فى توسيع استخدام TeachLivE إلى STEM الرئيسية. 
شـينى وزملاؤهـا جنـدوا LAs 14 لإعطـاء دروس مـدتها خمس دقــائق فـى محساكى

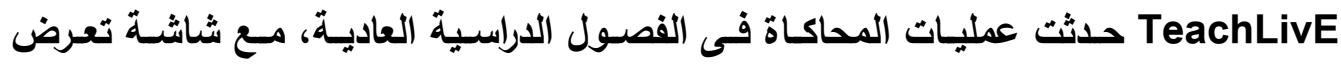
مجموعة من الصور الرمزيـة للطالب في سن المدرسـة الثانويـة، والذين يمكنهم التحدث مـع المعلم والرد عليه.

صنف معظم LAs التجربـة بأنها "واقعيـة" مما يشير إلى أنهم يتصرفون كما لو كانوا مـع

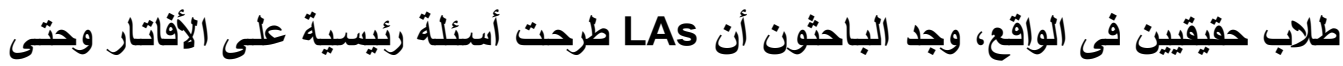

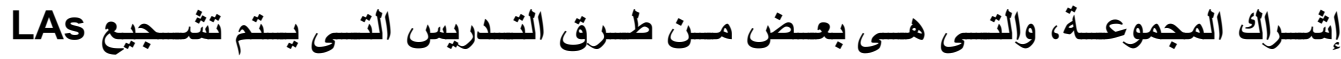

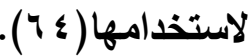

تـم تطوير محساكى UCF فC بواسطة الأستاذ ليزا ديكر، دكتوراه، مدير المدرسة مايك هاينز، دكتواه، فى كلية التربية والأداء البشرى وأستاذ بيغاسوس تثـارلى هيوز

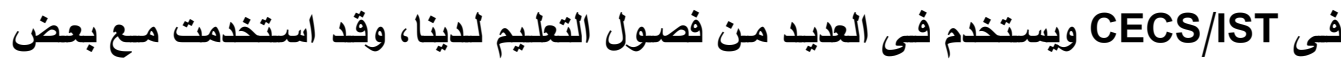
المعلمين K-12 المحلية.

يتم التحكم فى إبداعات Teach Live، من خلال مجموعة من البرامج الآلية ، وإحداث تفاعل متدرب يتحمم عن بعد فى سلوكيات واستجابات الطلاب أثناء محاكاة الدرس، وتبلغ تكلفة ذلك ـ r ا دولاًًا فى الساعة أثناء تثغيل المحاكاة. ويطبق على المعلمين قبل الخدمة المسجلين فى ماجستير التربية والغرض منه الحصول على وجهات نظر المعلمين قبل الخدمة حول كيفية تأثير تجريتهم فى الفصول الدراسية على تنمية المهارات ، وتصحيح الأخطاء ، وإدارة الفصل.ويمكن أن يُستخدم - مع الأسلوب - طريقة لعب الأدوار ، عندما يتم وصف الموقف لشخص ما ، ويطلب منه أن يعمل أو يصف الاستجابة ، وهذا تلخل آخر لزيادة التواصل فى حل المشكلات ، وتضمن تمثيل الأدوار النموذجية المباشرة ، ومثال ذلك : in for force برنامج

وهو: برنامج لله قوة خاصة فى حل مشكلات مكان العمل ، وهو توليفة من العناصر

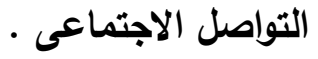

تفاعل الأفراد . لعب الأدوار . 


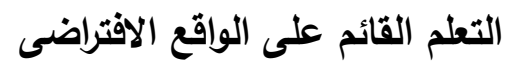

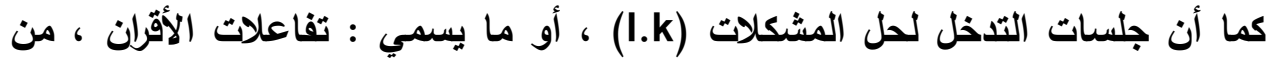
الطلاب ذوى الإعاقات الذهنية أو التوحد هي خريطة لأدبيات التذخل البحثي والممارسة التانة ل للأشخاص ذوى الاعاقات الثديدة .

إمانة الخاصة ، وهي خاصة بموضوعات ذات باضطراب اللفة ، لزيادة أداء مهارات حل المشكلات

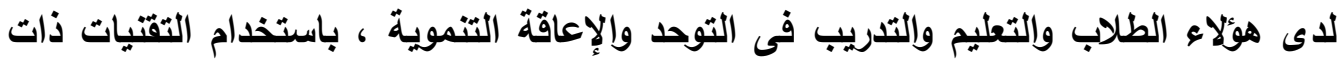
التحكم الذاتى لاعم تحقيق المهارات لاى الأشخاص الذين يعانون من اضطراب التوحد أو الو

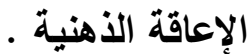

يتتمد مركز UCF للأبحاث فى تكنولوجيا المحاكاة التعليمية (crest) على قيادة UCF

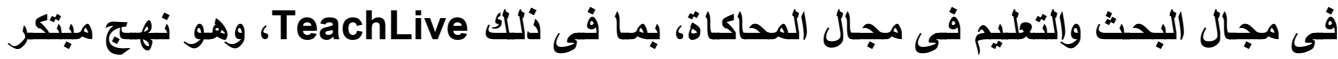
يسمح للناس بممارسة مهارات التفاعل بين الإنسان والإنسان، بما فى ذلتك المهارات المرتبطة بالتدريس، الغرض من المركز هو توفير بنية متكاملة تسمح باستخذام التقتيات والنماذج التى

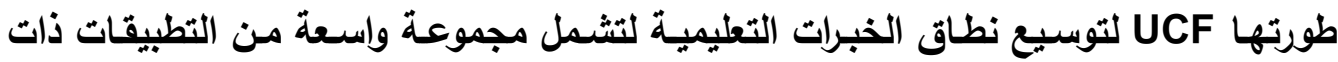

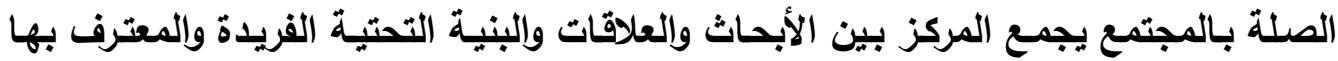
دويًًا والتى نمت عضويًا من الجهود التعاونية لأعضاء هيئة التدريس الفردية، وتتمثل مهنتها

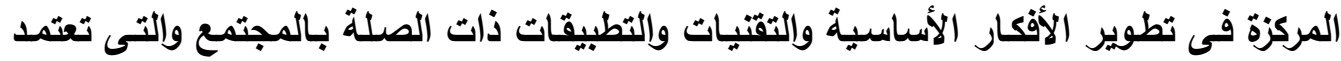
على نقاط القوة الحالية للأعضاء المؤسسين من كلية الهندسة وعلوم الكمبيوتر (CECS)

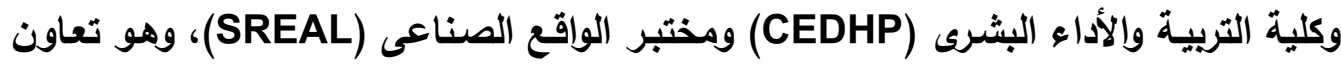
متعدد التخصصات يقع فى معهذ المحاكاة والتدريب (IST) يقوم المركز بتوسيع نطاق العمل الأولى لـ TeachLive لتوسيع هذا العمل ليشمل البحث فى مجالات جديدة ومبتكرة، يوفر هذا المركز الخدمات التكنولوجية للمواقع النى تستخدم TeachLive وكذلك المنتجات الأخرى

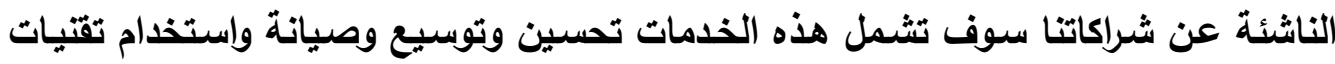

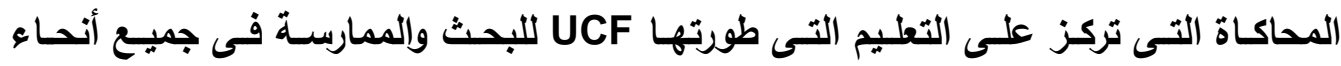

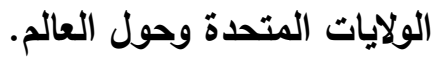




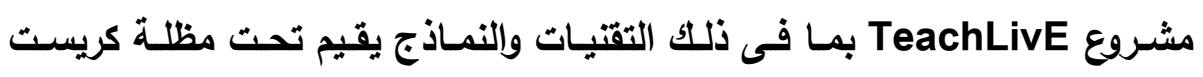
هeachLivE TLE

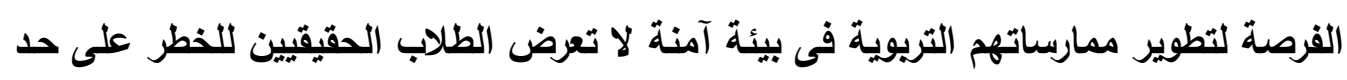

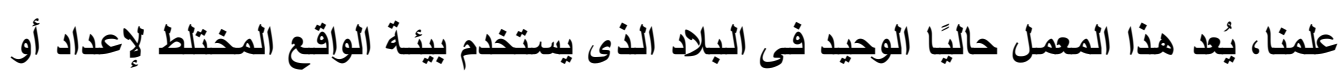

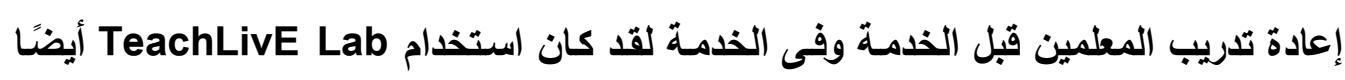

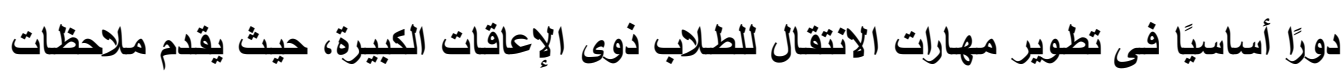

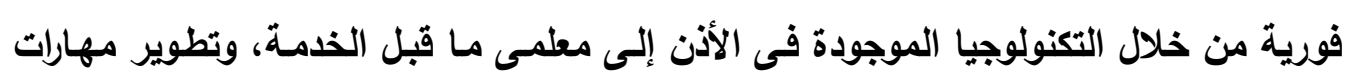

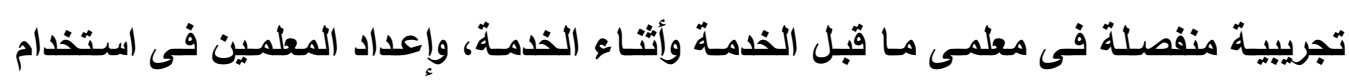
الاستراتيجيات التعليمية STEM ذات الصلة.

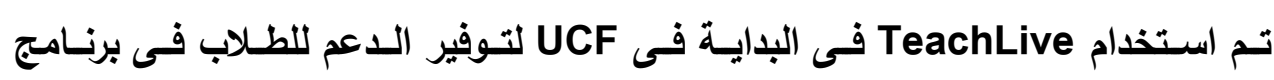
الانتقال إلى تدريس الرياضيات والعلوم هؤلاء الطلاب هم مغيرون وظيفيون فى الرياضيات

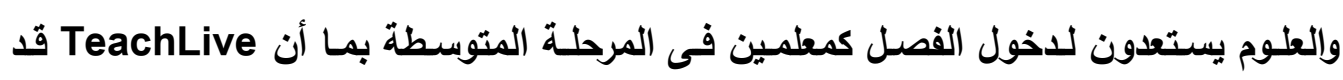
نضجت، فقد زار ممثلون من أربعة بلدان بيئة TeachLivE.

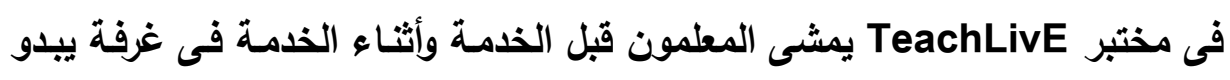

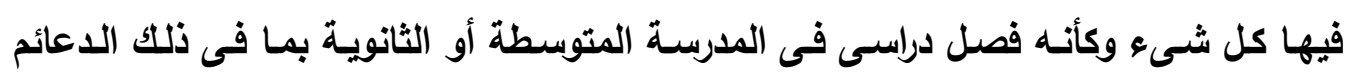

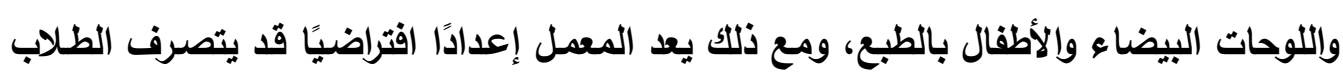

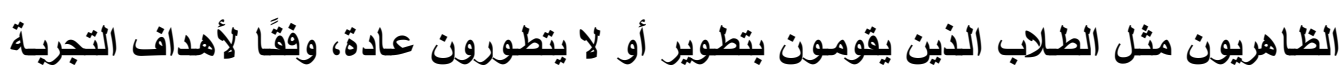

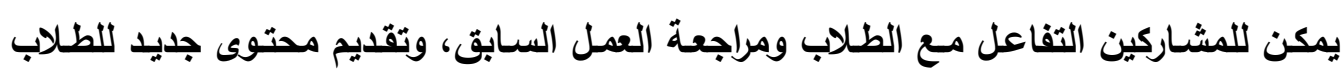

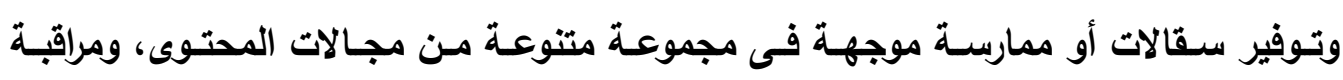

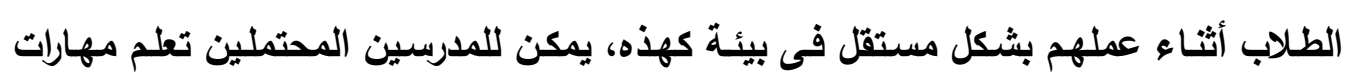

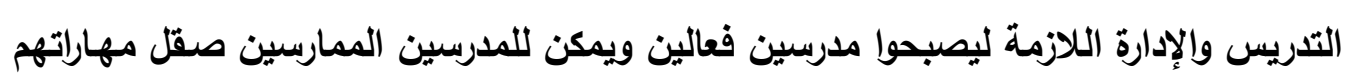

وصقتها.

\section{هـ - أهداف أسلوب Teach Live في جامعة ماريلاند:}

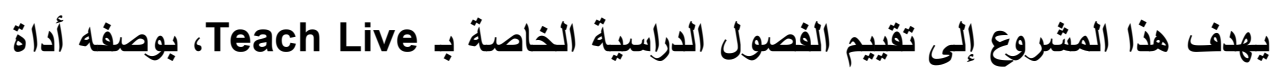
لتطوير مهارات التدريس لمعلمين التربية الخاصة قبل الخدمة. ا. توفير أداة تعليم الواقع الافتراضى للطلاب ، لاكتساب خبرات تعليمية فى بيئة محاكاة. 
r. سيقوم الطلاب بتدريس الدروس المصغرة ، التى يخططون لها ، بوصفهم جزعًا من

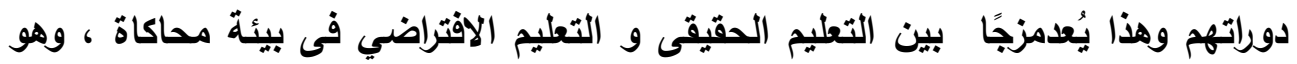
امتداد لممارسة (70)micro teaching).

r. تلك الاروس تسمح بإجراء تجارب تعليمية سابقة للتدريس ، وتوفِّر تعليمًا رائعًا حول التدريس داخل شبكة من الأمان.

فى الفصول الاراسية الحقيقية، قد يشعر الطلاب بالملل ويصبح من الصسب إدارته

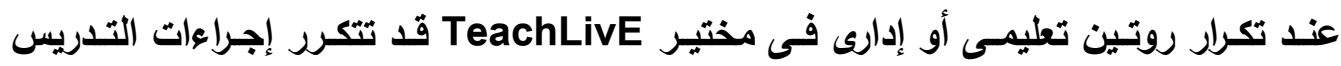
والإدارة مع معلم فردى أو عبر العديد من المعلمين باستخدام نفس السياق التعليمى حيى يتم إتقان الروتين يمكن بعد ذلك تغيير سياق التعليمـات أو الإدارة بشكل منهجى لاراسـة كيفية

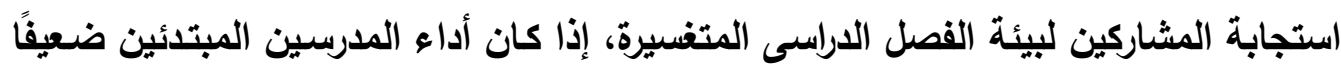

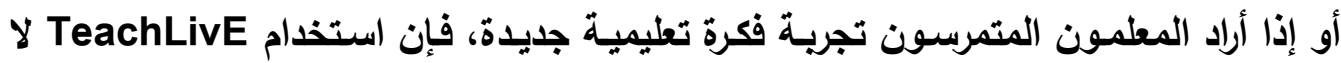
يشكل أى خطر على تعلم أى طالب حقيقى، علاوة على ذلك، فى الفصول الدراسية الحقيقية،

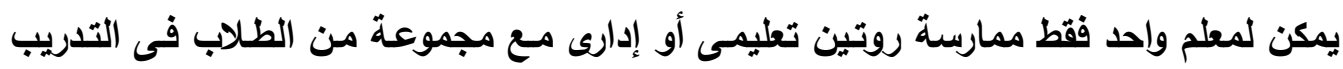
العملى التقليدى أو التدريب العملى فى TeachLivE Lab، يمكن للعديد مـن المعلمين توجيه الفصول الدراسية الافتراضية على مدار سـاعة واحدة، علاوة على ذلك إذا كان للى

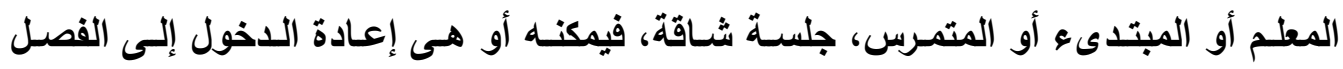

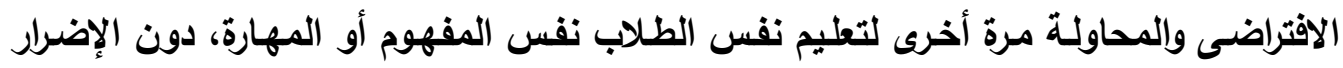
بأى طالب فى الفصل الافتراضى. القوى والعوامل المؤثرة فى استخدام Teach Live بحامعة ماريلاند بـالولايـات المتحدة الامريكية: تم استخدام نظام TeachLive لأغراض متعددة فى التعليم من قبل حس كلية للتعليم

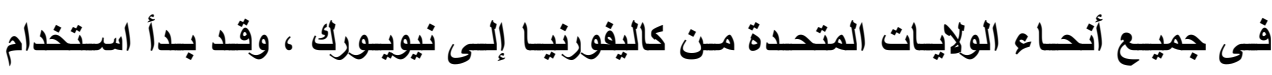
كeachLive

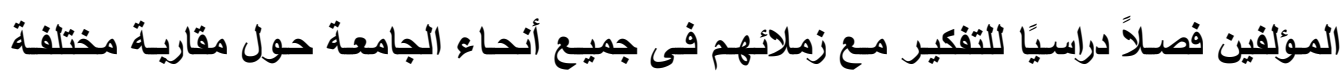

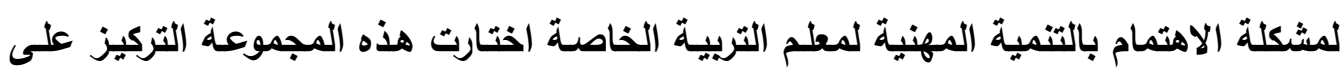

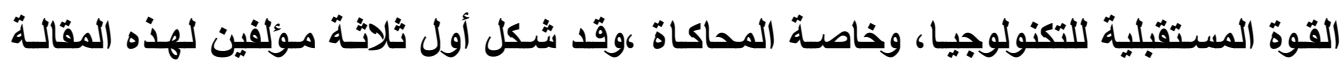
إطارًا أساسيًا للتعاون على مر السنين، ويمساهمات من العديد من الباحثين من أعضاء هيئة 
التذريس والطلاب فى مجموعة متنوعة من التخصصات، بما فى ذلك التعليم الخاص، وتعليم

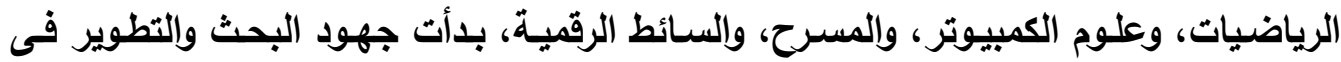
الظهور فيما يتعلق بما كان، فى ذلك الوقت، ممكن فى البيئات المحاكاة التى يمكن أن تؤثثر

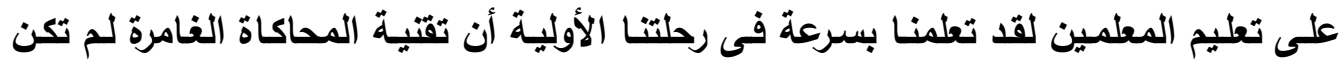
مناسبة جدًا للتطبيق المطلوب فى تعليم المعلمين، كانت التكنولوجيا الحالية إمـا مكلفة للغاية أو غير قادرة على إنشاء أى شىع أكثر من مجرد لعبة على الإنترنت، لم يكن أى من العلول التكنولوجية قريبًا مما يواجهه المعلم يوميًا بعد أكثر من نصف عقد من المناقشات المستمرة

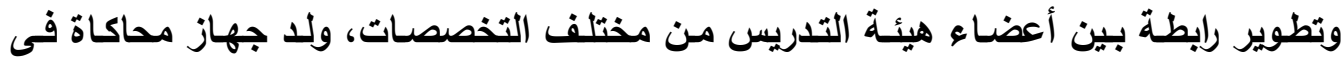
تعليم المعلمين يتطلب تطوير مثل هذه المحاكاة المعقدة العديد من التجارب التى تم فيها إعادة تصور النظام وإعادة بنائه وإعادة تحويله تستمر أعمال التطوير بوتيرة اكبر اليوم، على ملى الرغم من وجود نظام مستقر وقابل للاستخدام ومفيد بالفعل يستمر إنشاء ميزات جديدة فى TeachLive بمـا فـى ذلك نمـاذج التفاعل الجديدة والبنيـة التحتيـة التقنيـة المحسـنة، بـلا هواده، ومواكبة التطورات فى التكنولوجيا وعلوم الكمبيوتر والعمليات التعليمية تطورت هذه الحركة متعددة التخصصات إلى عدد من الاكتثافات والأخطاء والتجارب والأخطاء والنجاحات

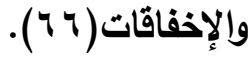

الى ان تم التوصل لمختبر الذى من خلاله أنشأوا بنية تحتية لتوفير التفاعل بواسطة

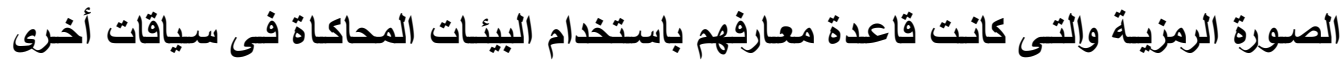
مهرهة فى بناء محاكى تعليم المعلمين، وقد قادت الدكاترة تطوير ممثل تجسدات الآلَة وهو مختبر Teach Live لطلاب المدارس المتوسطة فى أى نظام مدرسى وسيناريوهات تلدريس

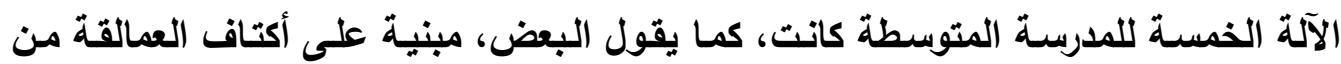

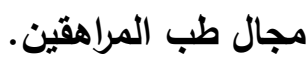

ومن هنا قام فريق خبراء فى أداء المعلمين من علم نفس النمو والطفل بتصميم جهاز

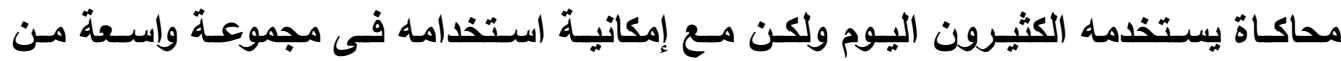
التطبيقـات فـى البيئـات الريفيـة ؛ حيـث يـوفر TeachLive أداة مخلصـة للفصـل الدراسـى الحقيقى، مما يسمح لمستخدميه بمعالجة كل شىع فى التدريس من التنوع إلى إدارة السلوك إلى تدريس الصف الأول حتى تدريس الفيزياء الى ان أصبحت أفكاراستخدام فى المحاكساة 
تتجاوز مجال التعليم الخاص، حيث تصل إلى جميع مجالات التعليم للمعلمين وأولياء الأمور

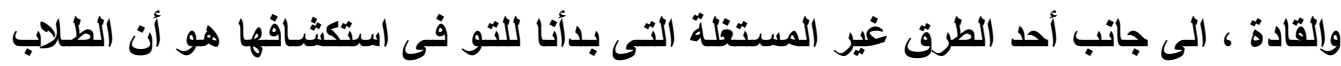

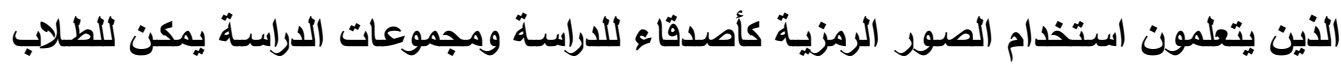

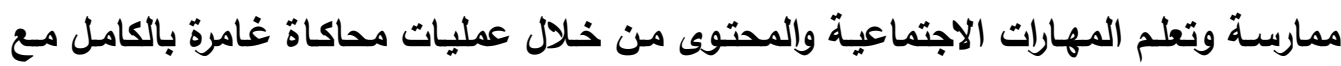
تجسدات الآلة.

هeachLive باللعب مع عمليات المحاكاة المطورة باستخدام الكود الأساسى يستخدم Thesy stem حاليًا الصور الرمزية للطالب أو أولياء الأمور/ المعلمين التى تم انشاؤها باستخدام تقتيات النمذجة باهن

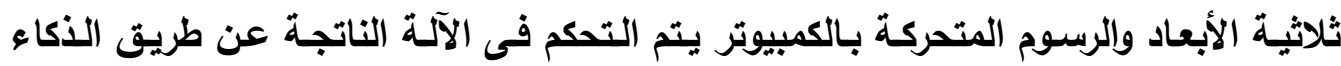
الاصطناعى وإلمشغل البشرى الذى يجسد الآلة ، تبدو الصور الرمزية، وتتحدث، وتتثفاعل مثنل

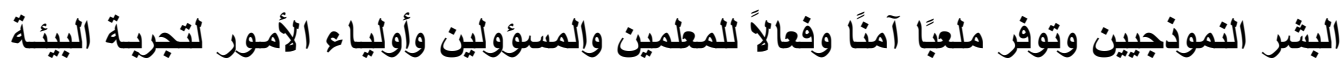

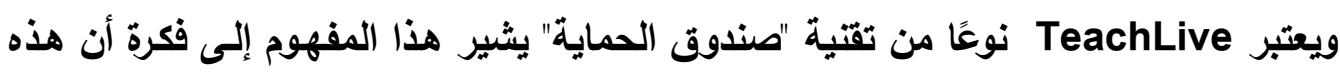
التكنولوجيا تثبه اللعب فى صندوق رمل: بمجرد إعطائك حبيبات الرمال، يمكنك اللعب بها بطرق عديدة لبناء أى بنية، هناك قيود مبنية حول الوقت والموارد المتاحة للعب (أى مقدار

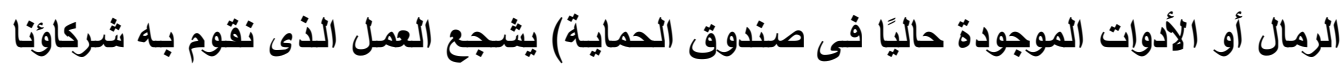
على إنشـاء أدوات، أفكار وإضـافتها إلى صندوق الحمايـة بحيث يمكن لكل موقع اللعب معًا

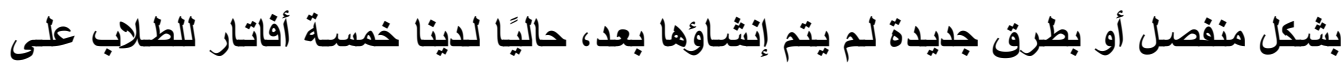

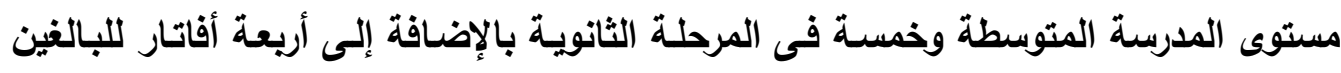

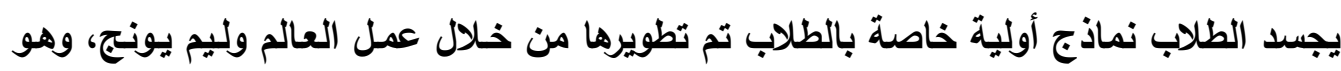

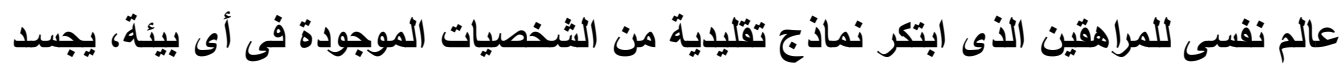

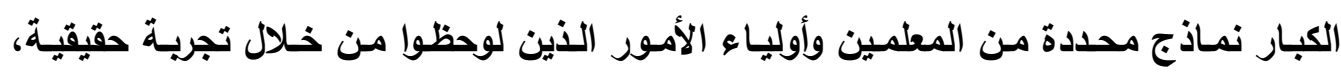
يمكن للمعلمين الممارسين والإداريين والمرشحين المعلمين التفاعل مـع الطلاب أو البالغين

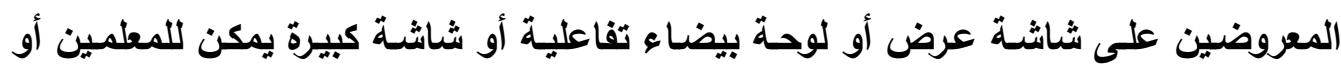

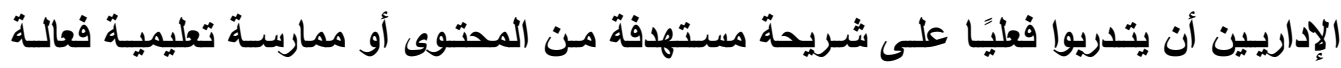

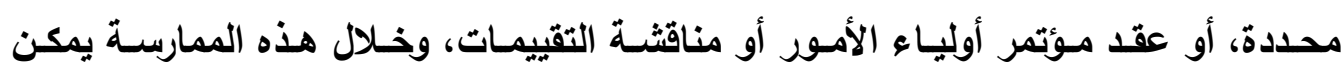

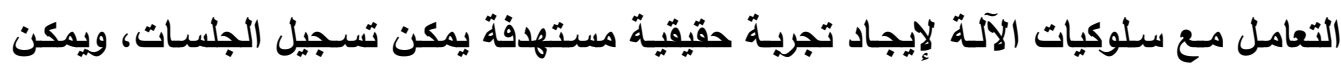


ترميز المعلم فى أداء المحاكى بناءً على مهارة محددة لتسـهيل التدريب/ التغذيـة الراجعة بعد

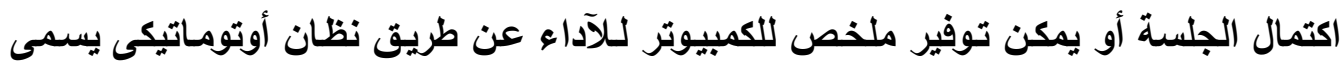
"التدريس بعد العمل" علم AAPs. كان هذا التطور للأفكار الممكنة فى TM TLE TeachLivE واضحًا في مؤتمر أقيم

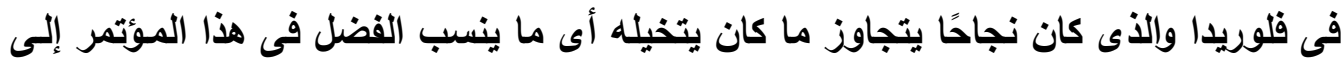
روئيسة طـالبين مسن طـلاب الــكتوراه (يعملـون فـى مختلف التخصصـات فـى مجـال النمذجـة

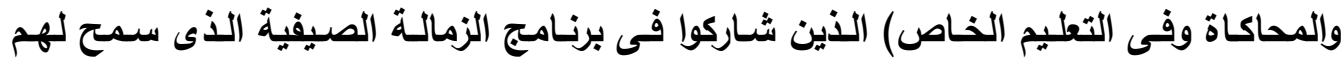

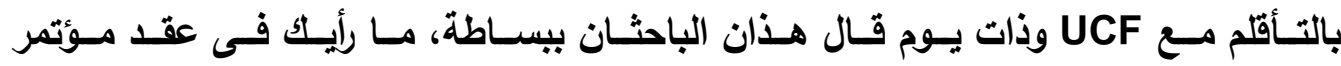
TeachLive ه 11 مشـاركًا، مسن بينهم ممثلـون عن دولتين و بr جامعـة ركزوا جميعهم على موضـوع وروئة تبنى تعاون متعدد التخصصات باستخدام المحاكاة ومـع ذلك فإن روح TeachLive ليست فى التقتية ولا فى الآلة ولا فى براءات الاختراع أو حقوق النشر أو العلامـات التجاريـة فى المستقبل، ولكن الروح الحقيقية لـ TeachLivE هى فى قوة هذه الأداة التى تتيح للناس الته

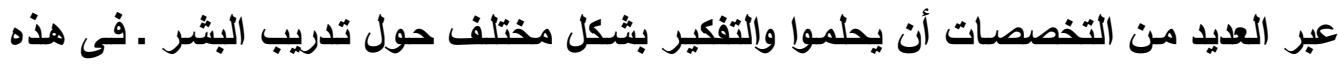

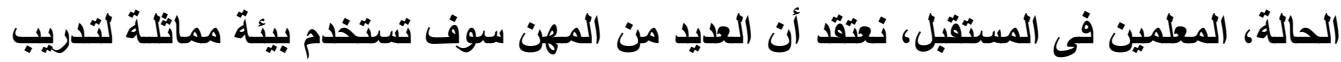
البشر الذين يستخدمون بانتظام التواصل بين الأشخاص مع أناس حقيقيين كل يوم.

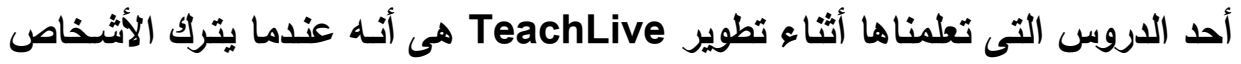
تخصصـاتهم ويتعاونون فى مجالات المحتوى أو التخصصـات أو الجامعات أو حتى القـارات فإن النتيجة يمكن أن تحول المشهر التعليمى باكمله . اليوم نظرًا لعملنا المتعدد التخصصـات، لـينا بحث واضـح يُظهر التحسن في مهارات تعليم المعلمين التى تحققت فى بيئة TeachLive التى تنقل مرة أخرى إلى فصول المعلمين كان هذا الانتقال للمهارة قد توقف أو لم يكن أبدًا ثريًا أو قويًا دون التعاون الحقيقى والتفكير هئي

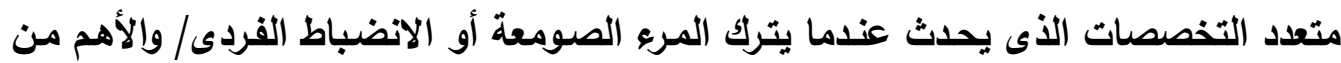

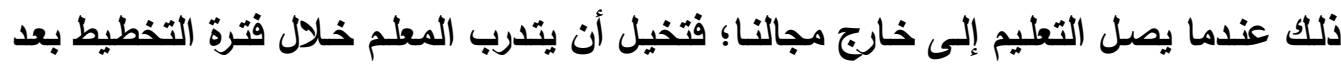
المدرسة يمكن التفكير فى كيفية تعاملهم مـع موقف مـع طالب معاق أثناء النهار في جلسة بعد الظهر حيث تتوفر صورة تجريبيـة مـع إعاقـات مماثلـة فى TeachLive ، كمـا يمكن 
للمدرسين أيضًا العمل مـع طالب ذى أنماط خطً لضمان تعلمهم مهارة محتوى مستهذفة قبل تجرية الدرس مع طالب حقيقى، وريما يمكن للمدير أن يتدرب على التحدث مـع أحد الوالدين الذى يعانى ابنـه من مشكلة، ولكنـهـه هو على لوحسة المدرسـة أو يمـارس تدريبًا على إقنـاع عضو مجلس محافظ بالمدرسة بدعم الحاجة فى مدرسته الكل ممكن، وهكذا. خامسًا :التحليل المقارن لاستخدام أسلوب Teach Live في كل من حامعتى فلوريدا وماريلاند

بـالولايـات المتحلدة الأمريكية:

أوجه الشبه:

تشابهت كلٌّ من الجامعتين فى تحديد مفهوم teach live ، بالإضافة الى أهدافه فى عملية التدريس للأطفال ذوى الاحتياجات الخاصة ، وهذه هى نقاط التشابه بين

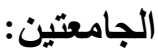

\section{مفهوم Teach live}

وهو: بيئة محاكاة للفصول الدراسية مقلدة ، تجسِّد الموقف المراد تعلمه ، وتجمع

بين الأكاء البشرى والرسوم والصور المتحركة بالكمبيوتر .

teach live أهداف

ا ـ اشتراك جميع الطلاب فى المناقشة .

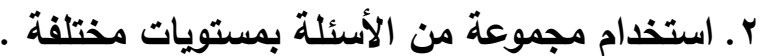
r. توصية الطلاب إلى الفكرة الأساسية بشكل كبير. ـ ـ يتيح تعليم الاقران.

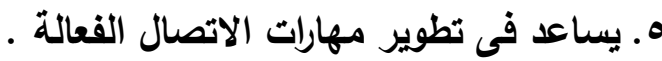
7 . يساعد على اكتساب المعلمين رؤى جديدة فى العمل مع الزملاء . V . بمنح بعض المعلمين تغذية راجعة عن التذريس .

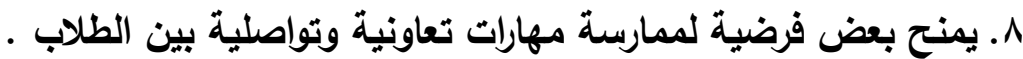
9. تقليل انشغال الطلاب بمواضيع التدريس . ـ 1 ـ الحد من السلوكيات غير المحبية للطلاب .

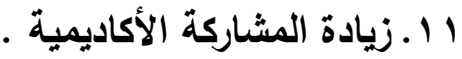
r ا. زيادة الحافز لدى الطلاب . 
با ا. زيادة احترام الطلاب لذواتهم.

ـ ا. إنشاء مساحة تعلم أكثر إنتاجية ، وكثر فاعلية لتحسينالعلاقات بين المعلم والطالب. ه 1 ـ تساعد المعلمين على زيادة مهارات إدارة الفصل.

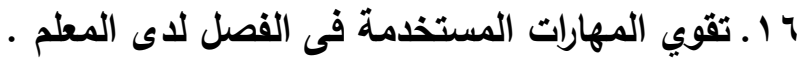

\section{أوحه الاختلاف :}

اختلفت كل من الجامعتين فى بداية نشأة teach live ، بالإضافة إلى استخداماته فى عملية التدريس للأطفال ذوى الاحتياجات الخاصة ، وهذه هى نقاط الاختلاف بين الجامعتين:

\section{teach live شأة}

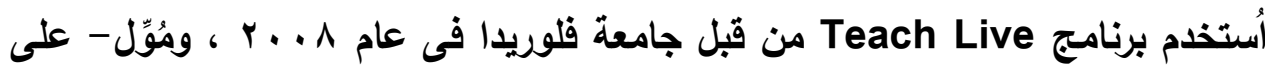
نطاق واسع -من قبل مؤسسة "بيل غيتس"، في حين ابتدات جامعة ماريلاند بعد جامعة

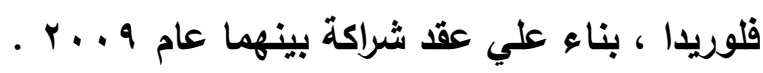

teach live استخدامات

اختلفت جامعة ماريلاند عن جامعة فلويدا فى الامج بين أسلوب Teach Live

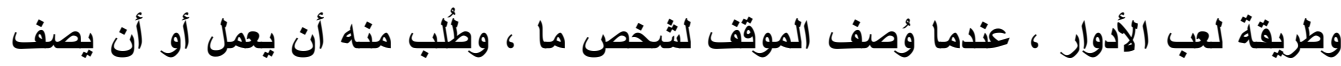
الاستجابة ، وهذا تلخل آخر لزيادة التواصل فى حل المشكلات ، وتضمن تمثيل الأدوار النموذجية المباشرة ، وذلك من خلال النقاط التالية: برنامج in for force ، وهو : برنامج له قوة فى حل مشكلات مكان العمل وهو توليفه من النقاط التالية (10):

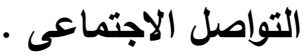

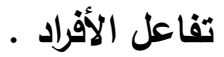

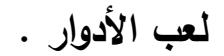
التعلم القائم على الواقع الافتراضى •

كما أن جلسات التذخل لحل المشكلات (I.k) ، أو ما يسمي : تقاعلات الأقران ، من الطلاب ذوى الإعاقات الذهنية أو التوحد هي خريطة لأدبيات التدخل البحثي والممارسة للأشخاص ذوى الاعاقات الثديدة . 
من خبرة الجامعتين السابقتين نجد انه يتم استخدام مختبر TeachLivE، حاليًا فى أكثر من هم فرعًا فى الولايات المتحدة وينمو ليشمل مناطق تعليمية متعددة وشركاء دوليين، حيث

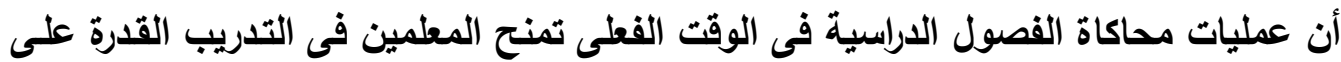
التجرية ـ وارتكاب الأخطاء ـ دون القلق من إلحاق ضر بتعلم الطقل الفعلى. على الرغم من أنه لم ينتشر بعد فى تعليم المعلمين، إلا أن فكرة محاكاة الفصول الدئه الدراسية

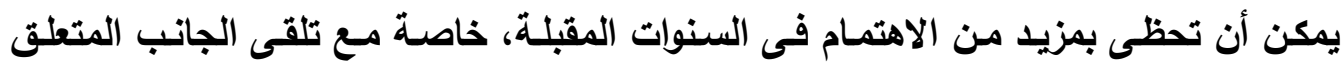
بتدريس الطلاب لإعداد المعلم الآن للتدقيق، تقوم مجموعات مثل المجلس الوطنى لاعتمـاد تعليم المعلمين أو NCATE بالضـط مـن أجل بـرامج تعليم المعلمين لزيـادة تنـوع تجـاريهم الميد|نية وطولها ونوعيتها. فيعد كل من simSchool \& TeachME نتاج شـراكات غير عاديـة تريط المعلمين والباحثين والخبراء فى عمليات المحاكاة أو الوسـائط الغامرة، على الرغم من استخدامها على نطاق واسع لتدريب المتخصصين فى الطب والتمريض والطيران، إلا أن عمليات المحاكاة غير شائعة فى إعداد المعلمين، يحصل العديد من المعلمين الطامحين على حوالى · 1 إلى ؟ 1 ألى أسبوعًا من التدريس للطلاب فى المدارس المحلية. لا تكمن الفكرة وراء عمليات المحاكاة فى استبدال تدريس الطلاب التقليدى وجهًا لوجهه، ولكن لمنح المعلمين والمعلمات القدرة على تجربة دروس محددة فى بناء المهارات، يوضح ديفيد

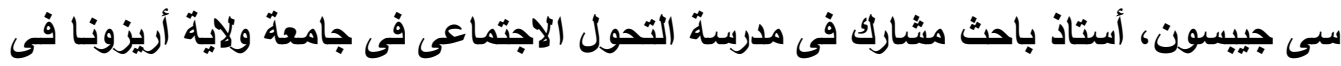
تيمبس، فقد كـان السيل جيبسـون، المصـمم الرئيسـى لمدرسـة SimSchool، مصدر إلهام للقيام بالمشروع من خلال عمل الباحثين فى جامعة ماريلاند هناك، أنشـأ الباحثّن برنـامج كمبيوتر تحصيل الطلاب، والتفكير فيها، مثل لعبة الألواح، كانت تعتمد على الدوران، وهى هـى

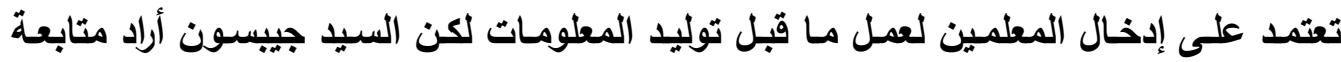
برنـامج تعمق فى ممارسـة الفصل ـ كيف يستجيب المعلمون دقيقة تلو الأخرى في بيئة ديناميكية. مـاذا يحدث عندما تظلق الباب وتدرسـه؟ مـا الذى ستقوله؟ مـا ستفعل؟ مـاذا يحدث

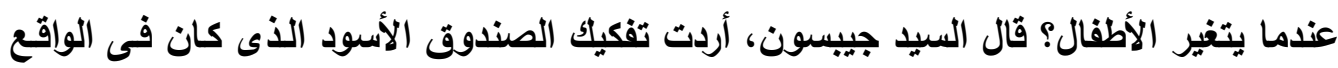
الفصول الدراسية. 


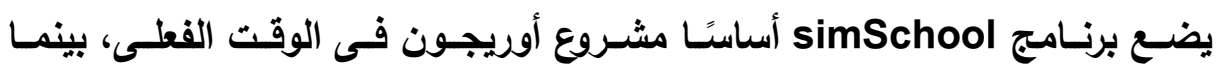
يستخدم مرشتح المعلم هذا النظام، فإنـه يتببع كيفية ارتفاع أداء الطالب وسقوطه يعتمد هذا

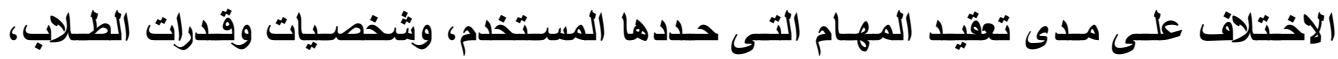
ومشاركة الطلاب فى كل نشاط. كما هو الحال فى الفصل الدراسى الحقيقى، لا يجلس هوّلاء الأطفال فى مكان ثابت بناء على مدى ارتباطهم بأفعال المعلم، سوف يولى الطلاب اهتمامًا وثُيقًا، أو يصرف انتباه أقرانهم يقول السيد جيبسون، ان هذا الجانب يعطى نظرة واضحة إلى المعلمين حول ميزات

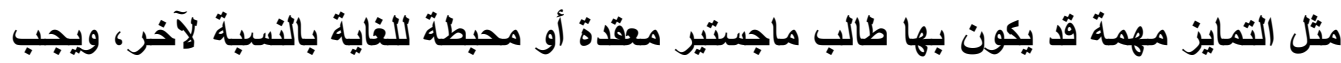
على المعلمين تحليل بيانات الطلاب للاستجابة بشكل مناسب. على الرغم من أن استخدام المحاكـاة كوسيلة تـدريب أصبح أداة شـائعة لتوفير ممارسـة المهارات فى مجالات مثل الطب والطيران، فقد ظهرت هذه التكنولوجيا مؤخرًا فى مجال التعليم كوسيلة لإعداد المعلم يشارك المعلمون قبل الخدمة عادة فى الملاحظات الميدانية قبل إكمال التدريب العملى، لكن هذه المشـاركة قد توفر أو لا توفر تجربـة نشطة فى الفصل مـع فرص

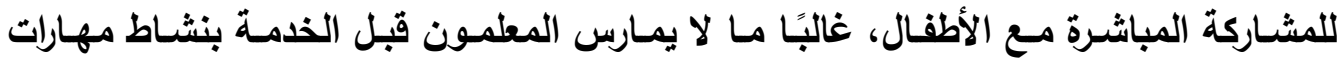
التدريس فى بيئة الفصل الدراسى حتى يصبحوا معلمين طلاب معينين لفئة من الطلاب فى الفي فصل دراسى فعلى فى المدرسة. كما تواجها جودة التدريس التدقيق والانتقاد فى كثير من الأحيان، هذه الحقائق تتحدى برامج تعليم المعلمين لإيجاد طرق جليدة لضمان أن خريجيهم سيكونون فعالين فى ظروف المعلم الشاقة للغايـة لتسليط الضوء على الطرق التى يمكن أن تعزز بها عمليات المحاكاة الجوانب الأساسية لإعداد المعلم حيث تبحث برامج تعليم المعلمين عن طرق لتجهيز خريجيها بثكل أفضل لمواجهة التحديات المستقبلية تُظهر التجرية أن عمليات المحاكاة يمكن أن تدعم برات الفحص للقبـول فـ البرنـامج، وممارسـة لتحسين مهـارات التـدريس وإدارة الصـف وتطوير مهـارات التدريس تزداد إمكانـاتهم مـع التقدم التكنولـوجى الذّى يـوفر قدرً أكبر مـن الواقعيـة والوصول الموزع وتطبيقات المحاكاة للأجهزة المحمولة. إلى جانب زيادة الممارسة والملاحظة والتغذية الراجعة أثناء تدريب المعلمين، مهارات الفصـول الدراسية الجديدة للمعلمين واتجاهـات التـريس، وتحسين نتـائج تعلم الطـلاب فـى 
المستقبل، توفر عدة أنواع من المحاكاة فرصًا لتوسيع وتعزيز هذه الممارسـة والتعليقات فى

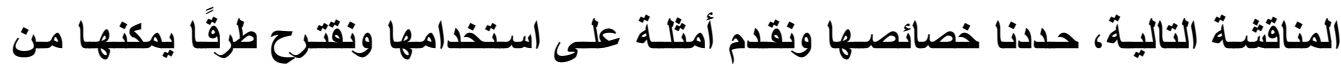
خلالها تحسين جوانب تعليم المعلمين المتعلقة بتحقيق الطلاب.

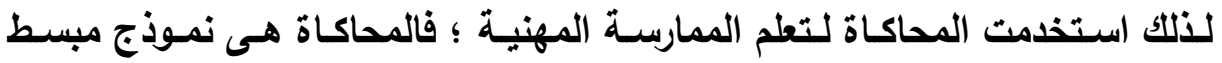
ولكنه دقيق وصحيح وديناميكى للواقع يتم تنفيذه كنظام، تتميز المحاكاة عن الألعاب لأنها لا تنظوى على منافسة تسمح المحاكاة للمستخدمين بمواجهة مواقف المشـاكل وتجربـة القرارات والإجـراءات وتجربـة النتـائج وتعديل سـلوكهم دون المخـاطرة بالإضــرار تم اسـتخدام عمليـات المحاكاة على نطاق واسع لسنوات عديدة فى أماكن مثل الطيران والطب، حيث تمثل ممارسـة

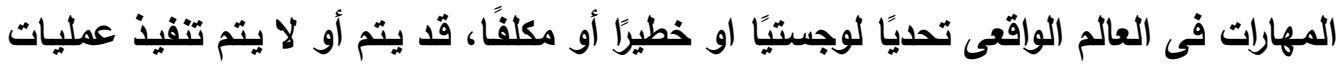
المحاكاة باستخدام التقتيـات الرقمية، ولكن الاستفادة منها بشكل متزايد لتوفير المزيــ من الواقعية والمرونة والوصول والتعليقات المفصلة. تتمتـع عمليـات المحاكـاة بمزايـا عديدة للتعلم والممارسـة، بمـا فى ذلك القدرة على تكرار السيناريوهات بأهداف تعليميـة محددة، والممارسـة لفترات أطول ممـا هو متـاح فى الحيـاة

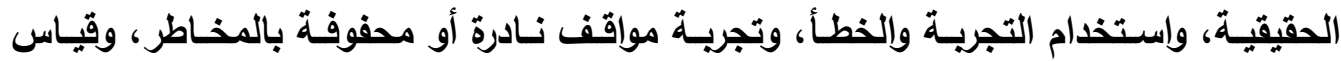
النتائج بوضوح باستخدام أنظمة تسجيل معتمدة، بالنسبة لتنمية المهارات، تعد مقاييس نتائج المحاكاة، بالإضـافة إلى استخلاص المعلومـات والتأمل بمثابة ردود فعل لدورة تقييم تكوينية لممارسة وتحسين الأداء المتكرر. وأصبحت عمليـات المحاكـاة أكثر شـيوعًا فـى تعليم المعلمين قبـل الخدمـة، ممـا يتيح الممارسـة والتغذية المرتدة للمهارات مثل تخطيط الدروس وتتفيذها، وإدارة الفصول الدراسية وتعليم الطلاب ذوى الاحتياجات والتحديات التعليمية المختلفة على سبيل المثال يمكن لمعلمى ما قبل الخدمة الانتقال من النظرية إلى العمل، مع مزيد من الوقت والتنوع التدريبى أكثر مما سيكون متاحًا فى جلسات التدريب العملى المباشرة المحدودة، دون التأثير سلبًا على الطلاب المستضعفين كما فى المجالات الأخرى، يعتمد التعلم من عمليات المحاكاة فى التدريس على التفكير والممارسة المتكررة، يبدو تقييم المعلم باستخدام المحاكاة أقل شيوعًا، لكن الأمثلة من فئل المجالات الأخرى تشير إلى هذه الإمكانات. 
ليست محاكاة السيناريو/ لعب الأدوار جديدة فى تعليم المعلمين، ولكنها تكتسب أهمية حيث

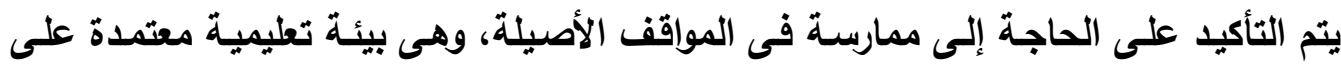
الويب تستخدم نهجًا منظمًا لمساعدة المعلمين على تطوير مهاراتهم وتصرفاتهم اللازمـة لحل معضلات الفصل الدراسى غير الواقعية فى العالم الواقعى أدوار قصيرة تركز على مهام الفصل

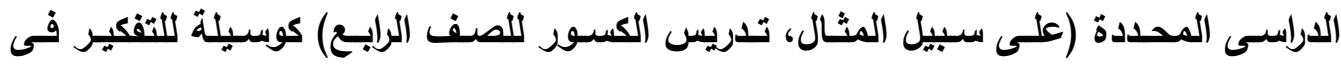
الممارسات المعرفية وإلعلاقاتية المحدة التى تسهم فى التعلم وتحسينها، وصف محاكاة قام بها مدرسو اللغة الثانية بدور طلابهم وتم تعليمهم بلغة لم يعرفوها جيدًا إن التفكير فى تجربـة عدم الارتياح والارتباك دفعهم إلى فهم أفضل لتقتيات التدريس الفعالة والتعاطف مـع تحديات تعلـم طلابهـم، محساكلاة مماثلـة لعب فيهـا معلمو العلوم قبـل الخدمـة دورهم لطلابهم وكـانوا قادرين على روية أفضل كيف يمكن لممارسات التدريس المحددة أن تلبى احتياجات طلابهم. حيث يحاول TeachLivE إعادة إنتاج الفصل الدراسـى بالكامل باستخدام "بيئة واقع مختلطة" تمزج المحتوى الحقيقى والاصطناعى نظرًا (الى الاعتقاد بأن البيئة المحاكاة "حقيقية"

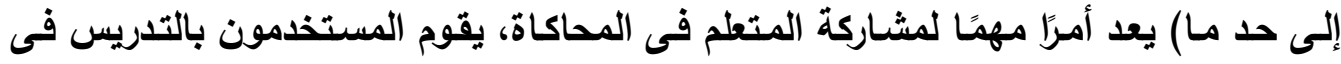

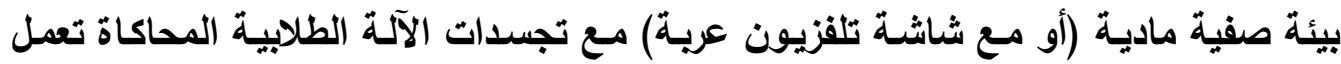
كدمى من قبل إنسان مدرب.

\section{خامسيًا : واقع التنمية المهنية لمعلم التربية الخاصة في مصر}

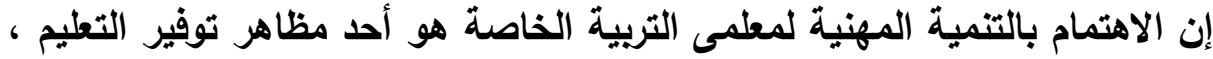
بوصفه حقًّ لذوى الاحتياجات الخاصة ، والتى تهدف إلى تحقيق الرعاية التعليمية والتريوية لهم بتوفير فرص تعليمية تتناسب مع إعاقاتهم، ويتوفير معلمين على مستوى متميز ومدريين تدريبًا جيدًا لهم، ويقوم تدريب معلم التربية الخاصة على مبدأين رئيسين: المبدأ الأول: إنه

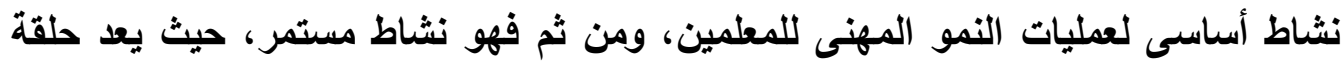
حيوية، ضمن منظومة التنمية المهنية للمعلم، أما المبدأ الثانى: فهو التدريب بنظام متكامل لله صفة التكامل والترابط فى مدخلاته وأنشطته ونتائجه. وتعد هذه المبادى أساس لقلسفة التنمية المهنية - بصفة عامة - كما أنها تتضمن فلسفة مهنة كافة البرامج، وفى ضوء القلسفة السائدة فى مصر يمكن تحديد أهداف تدريب معلمى التربية الخاصة أثناء الخدمة إلى( آج): 
- رفع مستوى أداء المعلمين بتحسين اتجاهاتهم وتطوير مهاراتهم التعليمية ومعارفهم، وزيادة مقدرتهم على الإبداع والابتكار فى مجالات التخصص ، مما يؤدى إلى تحفيزهم على النمو المهنى وذلك بتهيئة الظروف التى تمكنهم من الحصول على مزيل من الخبرات الثقافية وإلسلوكية.

- تقديم العون الضرورى للمعلمين الجدد ، أو من يمارس منهم لأول مرة مسئولية جديدة ، أو ياخل ميدانًا جديدًا من ميادين العمل بالتريبة الخاصة. - تأهيل المعلمين غير المؤهلين علميًا وتريويًا لتعليم ذوى الاحتياجات الخاصة. - إعداد بعض المعلمين لتدريس مقررات مطورة عن الفئة التى يتعاملون معها. - زيادة إلمام المعلمين بالطرق والأساليب الحديثة فى تعليم الاحتياجات الخاصة ، وتعزيز خبراتهم فى مجالات التخصص العلمية والثقافية. وفى ضوء تلك الأهمية البالغة التى اكتسبتها التنمية المهنية، فقد تعددت وظائفها

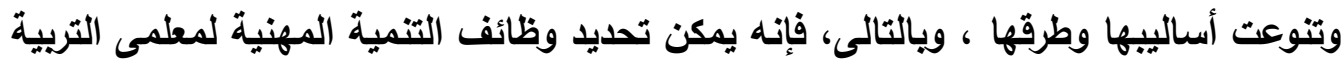

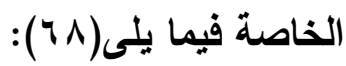
- تلافى أوجه النقص أو القصور فى برامج إعداد معلم التربية الخاصة قبل التحاقهم بالخدمة. - رفع الكفاءة الإنتاجية لمعلم التربية الخاصة بزيادة كفاءته الفنية ، وصقل مهاراته التدريبية أثناء الخدمة. - مساعدة المدرسين الجدد بصفة خاصة - على التأقلم مع النظام المدرسى، والاطلاع على المبادى ع والدساتير والقوانين التى تحكم الإدارة التعليمية والمدرسية فى رسم سياستها فى في تنظيم النشاط التدريبى أثناء الخدمة كما يلى(9 9 (7): - يكون التدريب متطورًا فى أساليبه. - يشترك المتدريون فى تخطيط إعداد برامج التدريب. - تنوع برامج التدريب أثناء الخدمة ، حيث تبعد النمطية وإلتكرار. - يتم تقييم كل البرامج لمعرفة أوجه الضعف بهرف تعديلها أو تطويرها. 
- تدريب معلم التربية الخاصة أثناء خدمته ، بصورة تؤدى إلى نجاحه فى عمله، وتحقق الرضا النفسى له ، وتعزز ثقته بنفسه ، الأمر الأى ينعكس بالإيجاب على آدائه فى العمل

، ويالتالى تحقيق أهداف العملية التعليمية.

- - تغيير الأفكار الخاطئة التى قد يكتسبوها أثناء خدمتهم مع ذوى الاحتياجات الخاصة. - إعطاء أنواع من التغذية الراجعة لمعاهد إعداد المعلمين وكلياته، لكى تقوم بمراجعة خطط الإعداد ويرامجه.

وتتعدد برامج التنمية المهنية لمعلمى التربية الخاصة ، حسب الهرف المنشود منها ، فهنالك

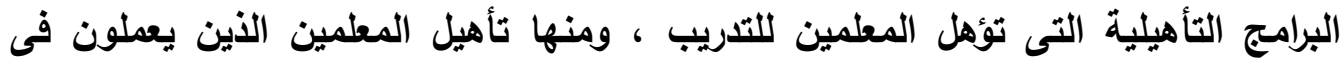
التدريس ، من دون تأهيل تريوى سابق، ومنها البرامج التجديدية التى تهدف إلى تجديد

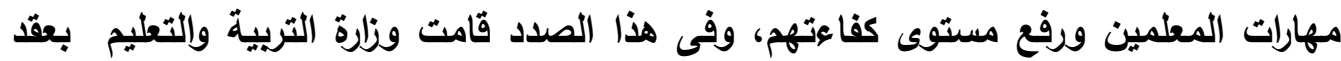
دورات تدريبية عن طريق الإدارات العامة للتربية الخاصة من وقت لآخر للمعلمين. وفى هذا الصدد فإن التنمية المهنية - التى تقوم بتنظيمها الإدارة العامة للتربية الخاصة لماصدية بوزارة التربية والتعليم بالاشتراكك مع الإدارة العامة للتدريب سواء كانت (ترقية ـ مناهج جديدة ومتطورة . تحويلى معينين جدد . تجديدى . إعداد بعثات) - تسعى لتحقيق الأهداف

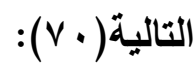
- كيفية التعامل مع ذوى الاحتياجات الخاصة. - - التدريب على الطرق العلاجية. - كيفية مشاركة الأسرة فى تربية ذوى الاحتياجات الخاصةوتعليمهم. - كيفية توظيف اللعب فى توصيل الخبرات لذوى الاحتياجات الخاصة. - فلسفة المنهج المقدم والاعتبارات التى يجب الأخذ بها. ويلاحظ - من أهداف هذه البرامج والتى تتثابه فى كل البرامج- أنها تركز - بنسبة كبيرة - على الناحية الفنية فى العملية التعليمية ، وعلى اكتساب المعارف - بنسبة أكبر من التركيز على الناحية المهارية والناحية الوجداتية، كما لم تذكر هذه الأهداف قياس أثر التدريب ومتابعة معلمى التربية الخاصة بعد تدريبهم.

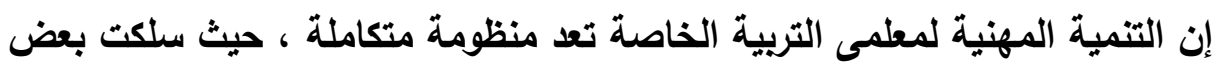
الدول المتقدمة أساليب أسهمت فى تكيفها مع متطلبات الدارسين وحاجاتهم، من خلال 
تضمينها المهارات والمعارف الطبية والنفسية والاجتماعية والأخلاقية والتتريب على الأساليب المعاصرة فى الإشراف التربوى ومشاركة المعلمين فى التوجه إلى المدارس ومستثفيات ذوى الاحتياجات الخاصة لجذبهم ونقل البرامج التدريبية إلى مواقع العمل ، لتكون أكثر واقعية ، وقد أخذت بعض الدول بأهمية توفير عضوية مهنية من خلال تأهيل الخريجين فى برامج خاصة تسمح لهم بالحصول على شهادة الممارسة العملية ، ووضع معايير علمية وأخلاقية كلالتزام بها مهنيًا.

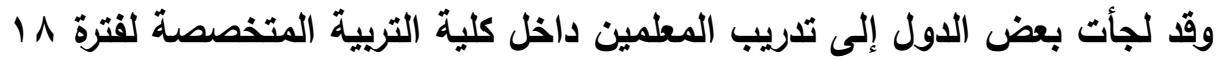
شهرًا؛ للتأكد من الصلاحية والاستعداد والتدريب وفق احتياجاتهم الحقيقية ؛ من واقع مشكلات العمل بالمؤسسات ميع استحداث بعض الاستراتيجيات التدريسية الجديدة ، كالتعلم التعاونى والتخطيط للأنشطة الصيفية بين أولياء الأمور واللارسين على تنفيذ الدرس، وتدريب المعلمين على القدرة التصنيفية لذوى الاحتياجات الخاصة، وتحديد درجة الإعاقة بالتعاون مع القائمين وأفراد الأسرة، وتبادل الخبرات والمعلومات وإجراء البحوث المشتركة للتحسين المستمر لتتك البرامج، وفى خبرات أخرى لبعض الدول عملت على تأسيس شبكة الكترونية لربط المدارس بعضها البعض ، والاستفادة من النماذج الناجحة، وتضمين التدريب برامج للتوعية الوالدية والاتصال عبر الجامعات الإلكترونية لمناقشة مشكلاتهم وطرح الحلول بأسلوب تعاونى بينهم ، وتؤكد بعض الخبرات على أهمية المشاركة الفعالة لكل من الوالدين والتلاميذ أنفسهم فى ورش العمل وأساليب التواصل فى البيئة الصيفية ، والتدريب على إدارة الوقت والتنظيم والرعاية الذاتية، كما أكلد على استخدام التكنولوجيا الحديثة فى التدريب عن بعد والتعلم الذاتى. وتعد التنمية المهنية محاولة لتغيير سلوك المعلمين وتنميتهم ، بحيث تجعلهم يستخدمون طرقًا وأساليب مختلفة فى أداء أعمالهم ، ولا يقتصر على مجرد إلقاء معلومات كمية أو كيفية ؛ مهما بلغت قيمتها وأهميتها ، بل يقترن بالممارسة الفعلية لأساليب الأداء الجديدة، والعمل على تنمية المعارف والمعلومات والمهارات والقدرات وتنمية الاتجاهات، ويرى البعض أن التنمية المهنية ، بوصفها نظامًا فرعيًا ضمن نظام أساسى للتربية المستمرة ، بحيث يتضمن كل أنشطة الأفراد فى المدرسة والتى تسهم فى نموهم المهنى المستمر ونمو 
قدراتهم ، وإذا كانت التربية المهنية على هذا القدر من الأهمية فإنها تزداد أهمية فى التربية الخاصة.

ومن هنا يتفق كثير من التريويين على أهمية دور المعلم ومكانته فى العملية التعليمية داخل الفصل وخارجه، حيث إن العامل الرئيس لتجاح أى برنامج تعليمى؛ سواء كان لتلاميذ عاديين أم لذوى الاحتياجات الخاصة، حيث يساعد على تنمية قدراتهم فى التحصيل والإنجاز فى مختلف جوانب شخصيتهم ، ويشجع على تنمية اهتمامهم وقدراتهم، وإذا كان معلم التلاميذ العاديين له مهام وأدوار ومسئوليات داخل الفصل وخارجه ، فمثل هذه الأدوار تزداد تعقيًًا وصعوية مع معلم التربية الخاصة وذلك لطبيعة شخصياتهم وقدراتهم ، التى ولى تتطلب من المعلم جهذا كبيرًا على المستوى التريوى (إدارى أو فنى) حتى يحقى أهداف العملية التعليمية، ومن خلال ذلك على المعلم أن يتعرف على أدواره ومسئولياته وواجباته ، حتى يصل إلى أعلى درجة من الكفاءة التريوية ، بقدرته علي التخطيط للاروس وتقويم تلاميذه وإتخدام التكنولوجيا وادارة الفصل وإدارة الوقت والاتصال بالبيئة المحيطة به. فى ضوء ما سبق ، ويعد التعرف على طبيعة ذوى الاحتياجات الخاصة، ومعرفة نظم تدريب معلم هذه الفئة وتتميته مهنيًا ؛ يمكن إدخال بعض التحديثات والتطويرات الجزئية على منظومة تدريب وتنمية معلمى التربية فى جمهورية مصر العربية، ومن خلال إجراء إصلاح جوهرى وجذرى شامل لمعلمى التربية الخاصة عن طريق الشراكة فى التدريب ؛ سواء من قبل المؤسسات الأجنبية المعنية بالتربية والتعليم أو المعنية بذوى الاحتياجات الخاصة أم الجمعيات غير الحكومية ، ويتطلب تطبيق هذا الإصلاح إجراء تغييرات جذرية فى إعداد معلى التربية الخاصة وتنميتهم، من حيث التظيم والهيكل والسلطات المتاحة، وإجراء تغييرات فى الهيكل التنظيسى للإدارات التعليمية وفى المديريات ، وكذلك المدارس ، ويتطلب أيضًا - تغيرات تشريعية، ومع ذلك فقد أكلت بعض الدراسات - لواقع تنفيذ منظومة إعداد معلمى التربية الخاصة وتتميته، إلى وجود عدد من نقاط القوة التى ينبغى الإبقاء عليها والعمل على تلعيمها، وعدد من نقاط الضعف أو المشكلات التى تعوق تحقيق هذا الإعداد والتنمية المهنية لأهدافها ، والتى يمكن إنجازها فيما يلى، ويمكن تحديد جوانب القوة فى تنفيذ نظم الإعداد والتنمية المهنية لمعلمى التربية الخاصة فى النقاط التالية (V (V): 
ا. ـ حقق إعداد معلم التربية الخاصة أهداف التعريف بالمبادىء الأساسية للتربية الخاصة، وزوَّد المعلمين بمعلومات عن أهداف هذه المدارس، وكيفية التكيف مع العمل بها.

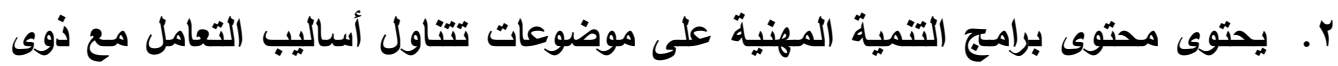
الاحتياجات الخاصة، والجوانب النفسية للتلاميذ، ويحتوى على جزء نظرى كبيز ومادة علمية غزيرة.

r. دعوة خبراء أجاتب للتنمية المهنية، وتوفير التمويل المناسب لبرامج التدريب. أما جواتب الضعف فى تنفيذ البرامج التدريبية فتتمثل فيما يلى(VY) 1. لم تحقق برامج التنمية المهنية هدف تنمية المعلمين على التعاون مع الأجهزة الفنية المختلفة المعنية بذوى الاحتياجات الخاصة. r. لا يؤخذ بآراء معلمى التربية الخاصة عند تصميم برامج التنمية المهنية، ولا يتضمن

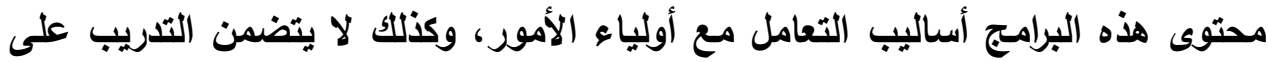

$$
\text { مهارات إدارية. }
$$

r. بستخدم أسلوب المحاضرة النظرية - غالبًا - كذلك حلقات المناقشة مع معلمى التربية الخاصة.

؛. لا تُشتخدم أساليب تدريبية حديثة ، مثل لعب الأدوار، وكذلك أسلوب نمذجة السلوك لمساعدة المعلمين على الأداء الجيد. لابله ه. المدريون المختارون متخصصون ، حسب موضوعات برامج التنمية المهنية، ومنهم أساتذة الجامعات، ولديهم مهارات تريوية خاصة، إلا أنهم يُففلون الجانب العملى، بران، ويهتمون بالجانب الأكاديمى.

ج. لا تعقد الدورات التدريبية فى وقت يناسب عمل المعلمين، وقاعات التدريس غير مجهزة بغرف إضافية تخصص لعقد ورش العمل. و لعل من معوقات التنمية المهنية لمعلمى التربية الخاصة: ا - معوقات حسب المستوى تصنف إلى(VT): 1. معوقات على مستوى الفرد. r. . معوقات على مستوى الوظيفة أو المهمة. r. معوقات على مستوى المؤسسة. 
ـ ـ مشكلات على مستوى السياسة العامة. r - معوقات حسب المصدر تنصف إلى:

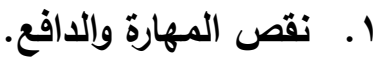

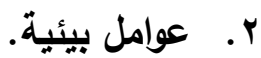

كما تُوجد معوقات أخرى تعترض العمل الجماعى ، وتعوق الالتزام بروح الفريق من أجل تحقيق التنمية المهنية أهمها ما يالى: 1. العلاقة بين المعلمين والمدير وصعوية تجاوز حاجز الفرق فى المركز الوظيفى بين الاثنين.

r. . العلاقة بين المعلمين ومعاونيهم فى المختبرات والمعامل والمكتبة. r. ضعف مواكبة التطورات الحديثة فى مجال إعداد المعلم. ء. اقتصار مجال البحث التريوى على مجال واحد ، وهو البحث الأكاديمى. r- المشكلات التى تواجه التنمية المهنية للمعلمين: 1. علم جدية مرحلة التدريب العملى فى اكتساب المهارات الأساسية فى مؤسسات ما قبل الخدمة ومعاهده، وعدم الجدية فى الإعداد ، لذا نجد ضعف فعالية برنامج التريية العملية. r. تدنى مستوى الطلبة الملتحقين بمؤسسات إعداد المعلمين ، وتلنى فعالية طرائق التدريس المستخدمة فى تلك المؤسسات. r. ض. ضعف الأجهزة التى تُشرف على تدريب المعلمين ، سواء قبل الخدمة أو أثنائها، وتحد من ندرة الكفايات المطلوية ذات المستوى الرفيع لتريب المعلمين و تسد الحاجة لعقد تدريب مسبق للقيام بعملها . ع. افتقار التدريب - أثناء الخدمة وقبأها - إلى التوثيق والبيانات والبرامج الحديثة ، بهدف تبادل المستحثثات التربوية الجديدة وتوزيعهابين المؤسسات المتخصصة داخل الدولة وخارجها ؛ مما أدى إلى التقليل من تبادل الاستفادة وتبادل الخبرات. ه. علم حصول البرامج التدريبية على قر كافٍ من التقويم الواسع الثامل، ولا على المتابعة المستمرة والتوجيه والإشراف الجدى من قبل المشرفين والمدربين فى مجال تلدريب المعلمين. 


\section{سادسا : تصور مقترح لتطبيق أسلوب Teach live في التنمية المهنية لمعلم التربية}

\section{الخحاصة في مصر في ضوي خيرة جامعتى فلوريلـا وماريلاند بـالولايـات التتحدة الأمريكية}

يبني التصور المقترح فى ضوء واقع التنمية المهنية لمعلم التربية الخاصة فى فئمائية

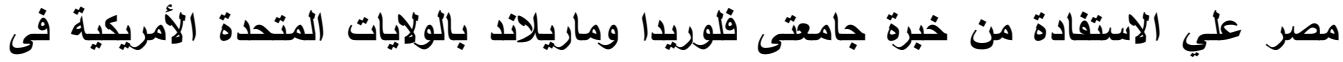
استخام أسلوب Teach Live فى تدريس معلم التربية الخاصةوتدريبه. أهداف التصور:

1. تطوير أساليب التنمية المهنية لمطلم التربية الخاصة. r. اكتساب المطلومات الخاصة بهذا النوع من التدريس بالمحاكاة، باستخدامه ، بوصفه التهائه

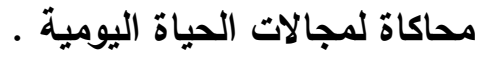
r. استخدام التكنولوجيا بدقة فى التدريس .

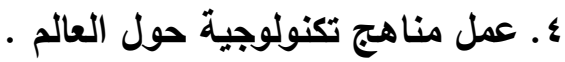
ه. معرفة احتياجات المجتمع المعاصر . ا. يكتسب معلم التربية الخاصة مهارات عصر جديد ومواكبلاتكنولوجيا

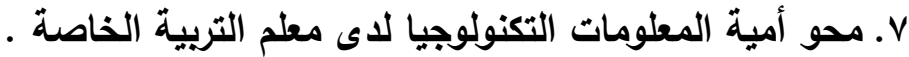
A. اكتساب مهاراتit وزيادة كفاءة معلم التربية الخاصة فى المجالات التالية : استخذام الميديا فى توضيح المطلومات .

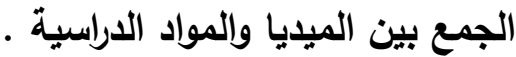

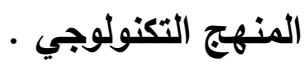$$
\text { محو أمية المطلومات . }
$$

9. يمثل هذا التصور متطلبًا مهمًًا جنًاً ، وخاصة للإعلام ، بكل ما هو مستحدث وجديد فى إنى

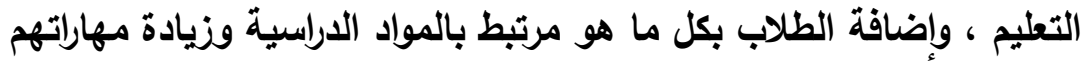

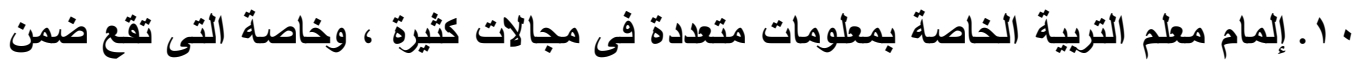

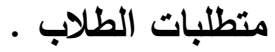


منطلقات التصور المقترح:

ا. لم تحقق برامج التنمية المهنية هدف تنمية المعلمين على التعاون مع الأجهزة الفنية المختلفة المعنية بذوى الاحتياجات الخاصة. r. لا يؤخذ بآراء معلمى التربية الخاصة عند تصميم برامج التتمية المهنية، ولا يتضمن باجن محتوى هذه البرامج أساليب التعامل مع أولياء الأمور، وكذلك لا يتضمن التدريب على برهي مهارات إدارية. r. بستخدم أسلوب المحاضرة النظرية -غالبًا - وكذلك حلقات المناقشة مع معلمى التربية الخاصة. ؛. لا تُستخدم أساليب تدريبية حديثة ، مثل لعب الأدوار، وكذلك لا يُستخدم أسلوب نمذجة

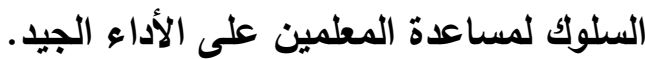
ه. المدريون المختارون متخصصون حسب موضوعات برامج التنمية المهنية، ومنهم أساتذة الجامعات، ولديهم مهارات تريوية خاصة، إلا أنهم يففلون الجاتب العملى، ويهتمون بالجانب الأكاديمى. צ. . لا تعقد الدورات التدريبية فى وقت يناسب عمل المعلمين، وقاعات التدريس غير مجهزة بغرف إضافية تخصص لعقد ورش العمل . V. تلافى أوجه النقص أو القصور فى برامج إعداد معلم التربية الخاصة قبل التحاقهم بالخدمة. ^. رفع الكفاءة الإنتاجية لمعلم التربية الخاصة عن طريق زيادة كفاعته الفنية ، وصقل مهاراته التدريبية أثناء الخدمة. 9. عدم جدية مرحلة التدريب العملى فى اكتساب المهارات الأساسية فى مؤسسات ما قبل الخدمة ومعاهده، وعدم الجدية فى الإعداد ، لذا نجد ضعف فعالية برنامج التربية العملية. • 1. تدنى مستوى الطلبة الملتحقين بمؤسسات إعداد المعلمين ، وتلنى فعالية طرائق التدريس المستخدمة فى تلك المؤسسات. 
1 ا. ضعف الأجهزة التى تُشرف على تدريب المعلمين ، سواء قبل الخدمة أو أثنائها، وتحد

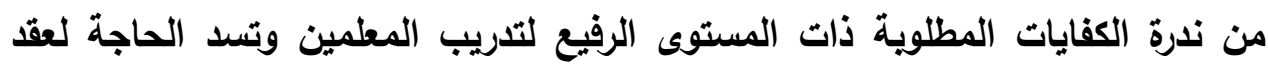
تدريب مسبق للقيام بعملها.

7. افتقار التدريب - أثناء الخدمة وقبلها - إلى التوثيق والبيانات والبرامج الحديثة ، بهدف تبادل المستحدثات التريوية الجديدة وتوزيعها بين المؤسسات المتخصصة داخل الدولة وخارجها ؛ مما أدى إلى التقليل من تبادل الاستفادة وتبادل الخبرات. V. علم حصول البرامج التدريبية على قر كافٍ من التقويم الواسع الثامل، ولا على هئ المتابعة المستمرة والتوجيه ، والإشراف الجدى من قبل المشرفين والمدربين فى مجال

$$
\text { تدريب المعلمين. }
$$

\section{احراءات التصور المقترح ؛}

ا ـ تقدير الاحتياجات وخريطة الموارد.

r. اعتماد التشريعات والسياسات والاستراتيجيات . r. توفير التمويل وزيادة القدرة على تحمل التكاليف. ع ـ إعداد أنظمة تقديم خدمات التكنولوجيا المساعدة. ه ض ضمان توفير منتجات مساعدة الجودة.

$$
\text { 7. ح. تدريب الموظفين. }
$$

ا.برامج إعداد معلم التربية الخاصة ، لكى تحقق أهداف التعريف بالمبادىء الأساسية

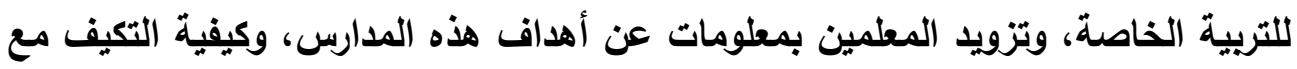
العمل بها. r.برامج التتمية المهنية ، لكى تحتوى على موضوعات تتناول أساليب التعامل مع ذوى الاحتياجات الخاصة، والجواتب النفسية للتلاميذ، ويحتوى على جزء نظرى كبير ومادة علمية غزيرة. r.دعوة خبراء أجاتب للتنمية المهنية، وتوفير التمويل المناسب لبرامج التدريب. 
1. هناك صعوية من ممارسة teach live عندما يكون المعلمين ليسوا على علاقة بالطلاب

r أهمية بناء علاقات قوية بين المعلمين والطلاب .

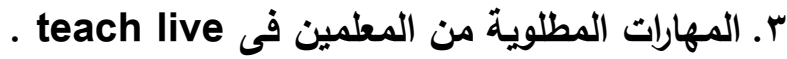
צ. لابد للمعلمأن يستخدم مهارات القرن اب ، والتحول من المعرفة والمنهج المركز والموحد إلى المنهج المفتوح ، واكتساب المعرفة بطرق مختلفة ، وهذا يتطلب النقاط التالية :

هـ محو أمية التكنولوجيا المعلوماتية . 7.

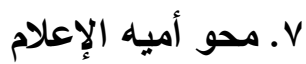

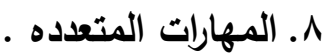

آليات التصورالمقتزح :

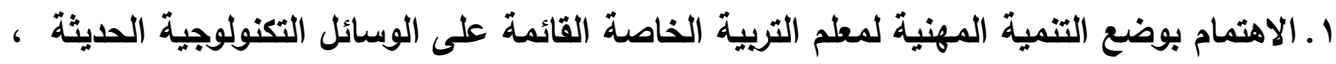

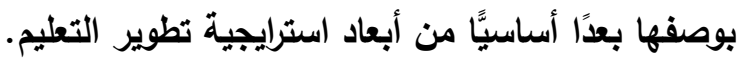
r. تفعيل دور المؤسسات المهنية المتخصصة لتدريب المعلمين كـ : الأكاديمية المهنية للمعلمين والنقابات والاتحادات ؛ لتطوير التنمية المهنية لمعلمى التربية الخاصة. r.نشر ثقافة البيئات الافتراضية ، بوصفها أحد اساليب التنمية المهنية لمعلم التربية الخاصة فى المجتمع المصرى . ؛ . البحث عن مصادر تمويل بديلة من خلال المؤسسات المختلفة المهتمة بالتعليم والمنح والهبات ؛ لجلب وسائل التكنولوجيا الحديثة ؛ ولتصميم البيئات الافتراضية فى الددارس.

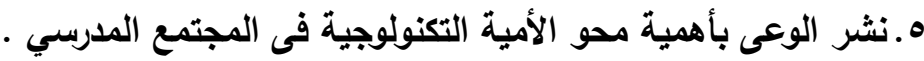

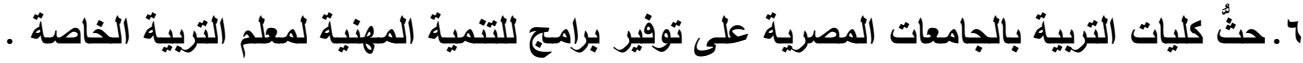

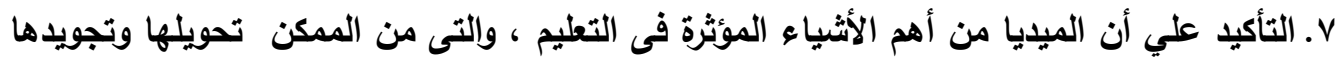

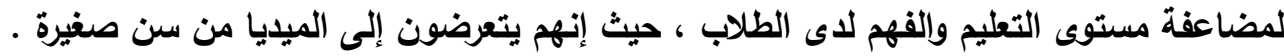
معوقات تنفيذ التصور المقترح: ا ـ نقص الخبرة فى استخدام التكنولوجيا .

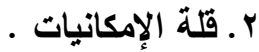


r. قالة التمويل لشراء الوسائل المساعدة والأجهزة . \&. بعض موضوعات المنهج يصعب معها استخلام المحاكاة للواقع المختلط ـ وكنلك الرسوم الصور

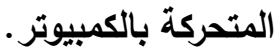

\section{الحلول المقتز حة للتفلب على معوقات تنفيذ التصور المقترح :}

ا ـ مساعدة المدرسين الجدد بصفة خاصة - على التأقلم مع النظام المدرسى، والاطلاع على المبادىء والدساتير والقوانين التى تحكم الإدارة التعليمية والمدرسية فى رسم سياستها فى في تنظيم النشاط التدريبى أثناء الخدمة ، كما يلى r. أن يكون التدريب متطورًا فى أساليبه. r. أن يشترك المتدريون فى تخطيط إعداد برامج التدريب.

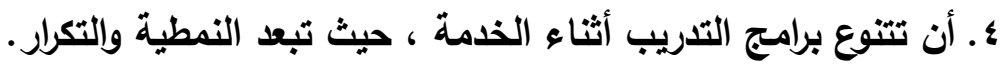
ه. يتم تقييم كل البرامج ؛ لمعرفة أوجه الضعف ، بهرف تعديلها أو تطويرها.

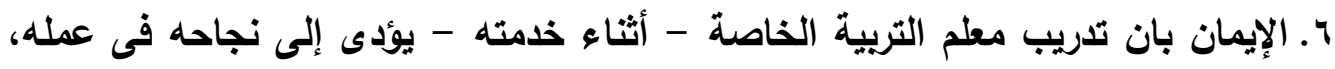
وإلي تحقيق الرضا النفسى له ، ويعزز ثقته بنفسه ؛ الأمر الأى ينعكس بالإيجاب على لإنى آدائه فى العمل ، ويالتالى تحقيق أهداف العملية التعليمية.

V. تغيير الأفكار الخاطئة التى قد يكتسبوها أثناء خدمتهم مع ذوى الاحتياجات الخاصة.

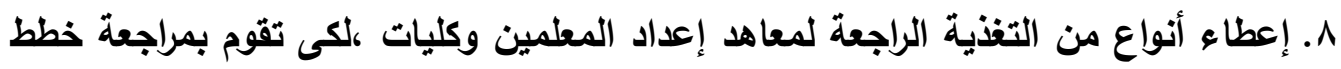
الإعداد والتتمية المهنية ويرامجهالمعلم الطلاب ذوى الاحتياجات الخاصة. 9. تدريب المعلم على كيفية توظيف اللعب فى توصيل الخبرات لذوى الاحتياجات الخاصة. • 1 ـ تدريب المعلمين على استخدام أساليب المحاكاة بكل صورها. 11 ـ الاستفادة من المنح والمؤسسات المختلفة فى التمويل لاستخدام الأساليب الحديثة. 


\section{قائمة المراجع:}

1. صموئيل أديب نظلة (99v ( ) ) ، إعداد معلم الأطفال ذوى الاحتياجات الخاصة فى ضوء الاتجاهات

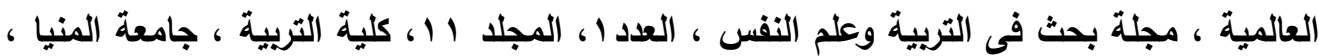

ص ص

r. فاروق شوقي البوهي(17 + (Y)،النظم التعليمية للتربية الخاصة وإعداد المعلم في بعض

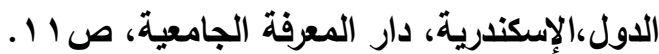

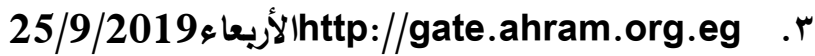

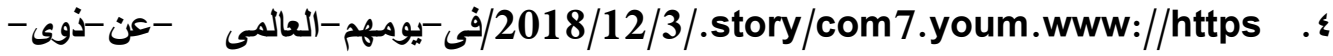
الاحتياجات-الخاصة-فى ه. مديرية التربية والتعليم بمحافظة الإسكندرية، إدارة التربية الخاصة، إحصائية بعدد طلاب الدمج

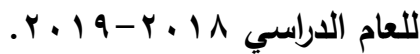
צا. البعد-الاجتماعي/التعليم

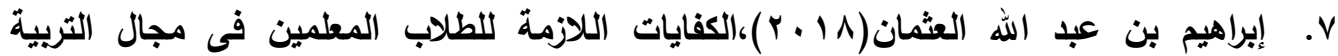

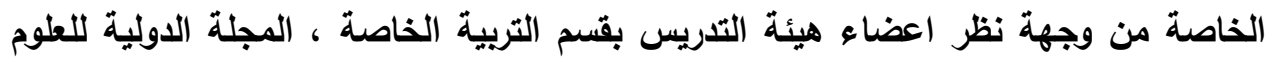
وتأهيل ذوى الاحتياجات الخاصة ، المؤسسة العربية للبحث العلمى والتنمية البثرية.

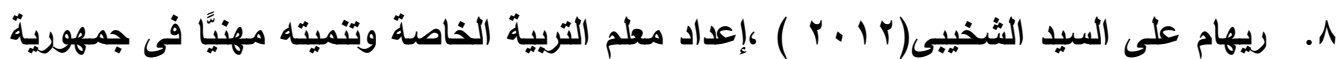
مصر العربية دراسة تحليلية ، جامعة عين شمس ، كلية البنات للآداب والعلوم وإلتربية.

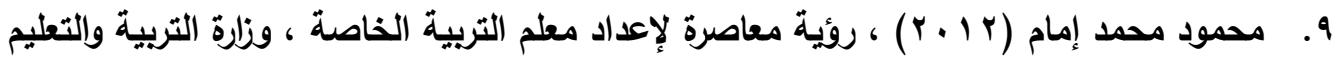

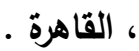

Micheal Hynes,Charles Hughes(2014). The Second National TLE .1. Teach Live Converance, university of Florida,USA.

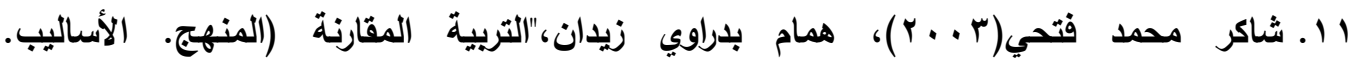

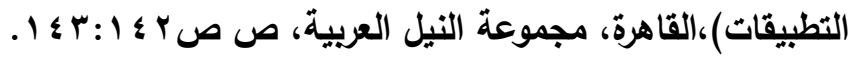

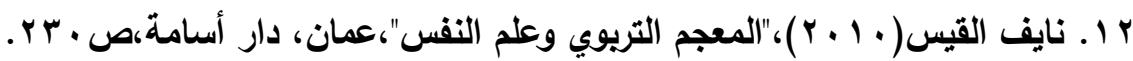

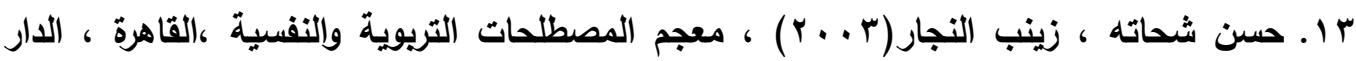
المصرية اللبنانية . مداتهان ؛ 1 ـ محمد على الخولى (919 191)، قاموس التربية ، القاهرة ، دار العلم للملايين . 15. Lisa A. Dieker, Michael C. Hynes- Charles E. Hughes Stacey Hardin( 2015), the teach live tm using technology to provide Quality 
استخدام اسلوب teach live فى التنمية المهنية لمعلم التربية الخاصة فى مصر

professional development in rurd schools, rural special education quarterly, volume 34, number 3, p. 11-15.

17 . عبد الفتاح صابر عبد الحميد(9 9 1 ) ، التربية الخاصة لمن ؟ لماذا ؟ كيف ؟ مؤسسة الصفوة

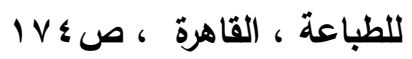

V ا ـ إبراهيم عبد الهادى المليجى(r . . r) ،الرعاية الطبية والتأهيلية المكتب الجامعى الحديث

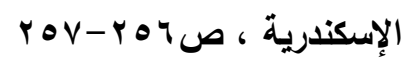

1 ا ـ ديان برادلى وآخرون( . . . †) ، الدمج الثامل لذوى الاحتياجات الخاصة وتطبيقاته التربوية ،

$$
\text { ترجمة عبد العزيز الثخص وآخرون ، دار الكتاب الجامعى ، الإمارات ، ص V V }
$$

9 1. سعيد حسنى العزة (r . . r)، صعويات التعلم ، مفهومة الثخصى - الأسباب - أساليب

التدريس واستراتيجيات العلاج ، الدار العلمية الدولية ودار التعاقد ، عمان ،ص اء

• r. منى صبحى الحديدى(1991) ، مقدمه فى الإعاقة البصرية ، دار الفكر للطباعة والنشر

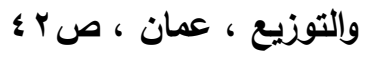

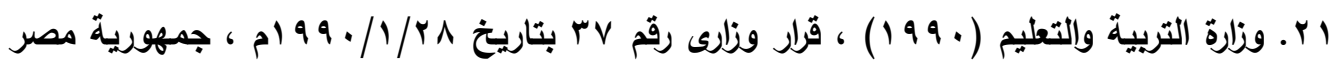

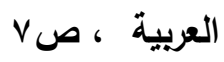

r r . مصطفى فهمى(99 199) ، سيكولوجيا الأطفال غير العاديين ، دار مصر للطباعة ، القاهرة ، 纟

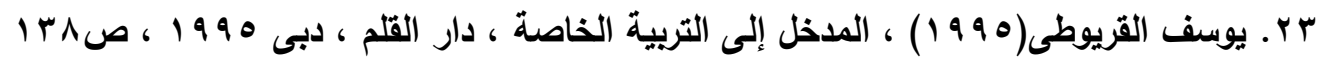

24. . American Psychiatric Association. (2013). Diagnostic and statistical manual of mental disorders (5th ed. Text revision). Washington, DC: Author .

25. American Psychiatric Association.(2013). Highlights of Changes from DSM-IV-TR to DSM-5 www.DSM5.org

26. Colleen M.Harker, M.S, \& Wendy L. Stone. (2014). Caparison of the Diagnostic Criteria for Autism Spectrum Disorder across DSM-5, DSM-IV-TR, and the Individuals with Disabilities Act (IDEA) 3 Definition of Autism. Early Autism Detection and Intervention. University of Washington.

27. Maenner M, Rice C, Arneson C, et al(2014). Potential Impact of DSM-5 Criteria on Autism Spectrum Disorder Prevalence Estimates. JAMA Psychiatry.

28. Kristine M. Kulage, Arlene M. Smaldone, Elizabeth G. Cohn(2014). How Will DSM-5 Affect Autism Diagnosis? A Systematic Literature Review and Meta-analysis.Journal of Autism and Developmental 
استخدام اسلوب teach live في التنمية المهنية لمعلم التربية الخاصة فى مصر .

Disorders,

DOI:

10.1007/s10803-014-2065-2

\section{Autism}

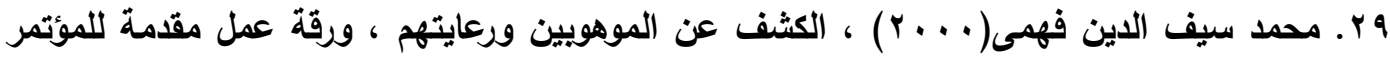

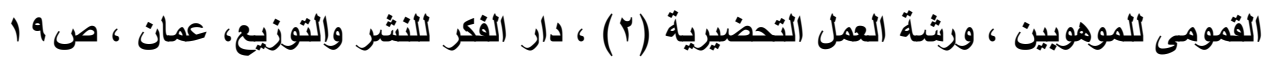

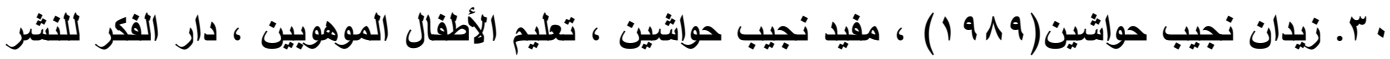

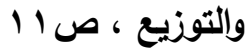

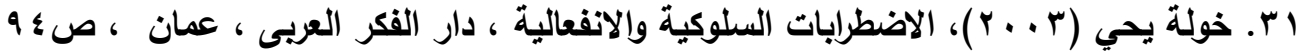

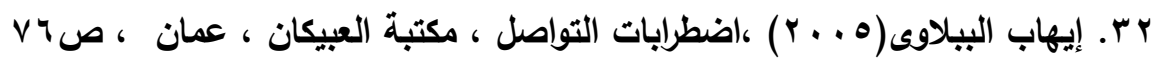
rr. عادل قورة وآخرون(999 199) ، واقع المعوقين فى مصر ، المركز القومى للبحوث الاجتماعية

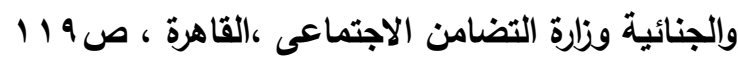

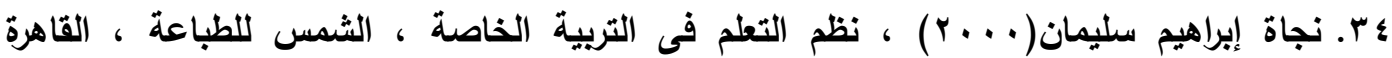
lor هr. وزارة التربية والتعليم(999 199) ، القرار الوزارى رقم (rv) استحداث وظيفة الموجة المحلى للإعاقة لكل من الفئات الثثلاث البصرية والسمعية والفكرى بكل مديرية تعليميه وأن يكون مقيمًا طوال الوقت ولته

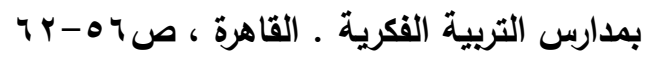

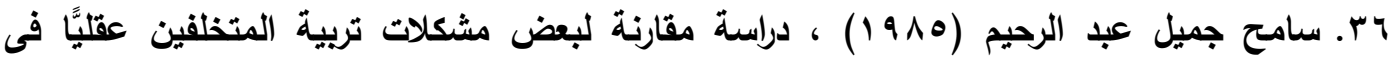

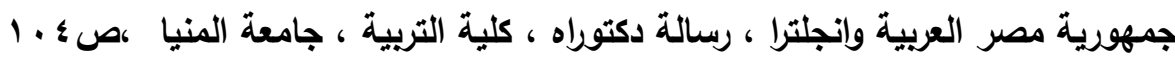

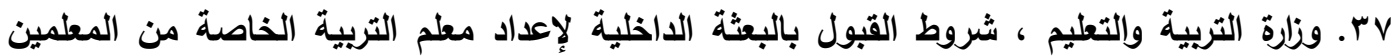

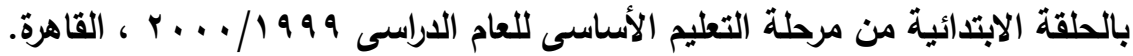

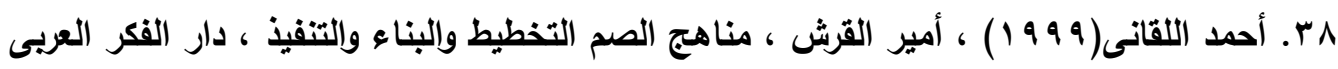

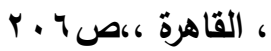

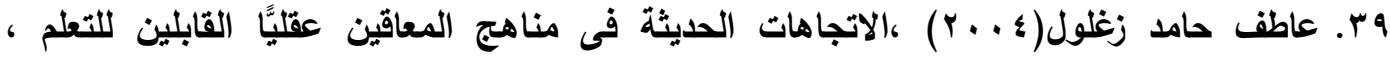
المؤتمر العلمى التانى " تربية الأطفال ذوى الاحتياجات الخاصة فى الوطن العربى - الواقع

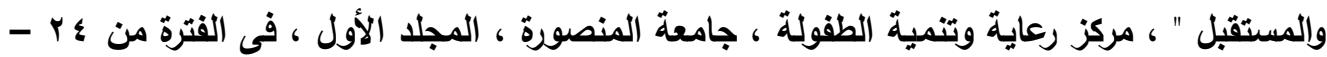

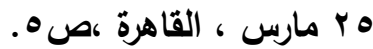

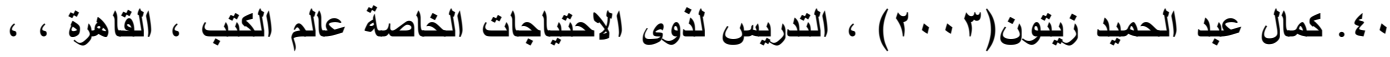
ص 


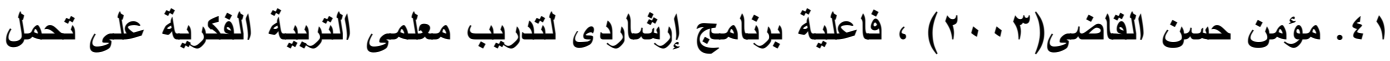

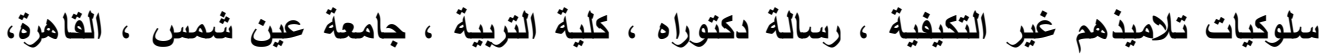

ص מ

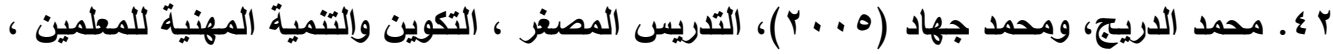

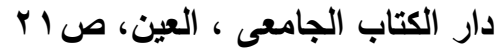

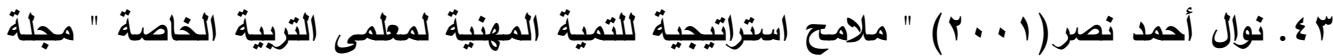

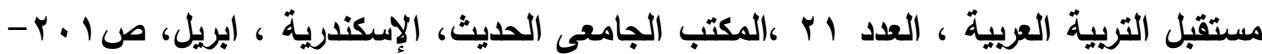

$$
\text { ros }
$$

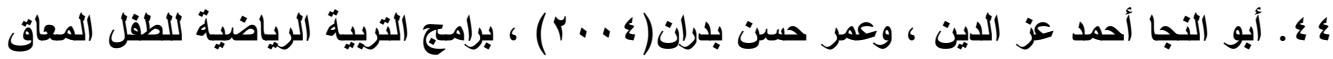
حركيًّا : تحديات الواقع - استثراف المستقبل ، المؤتمر العلمى التانى "تربية الأطفال ذوى الاحتياجات الخاصة فى الوطن العربى - الواقع والمستقبل " ، مركز رعاية وتنمية الطقولة ،

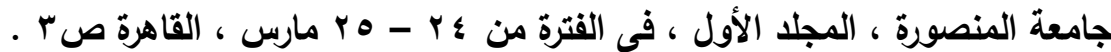

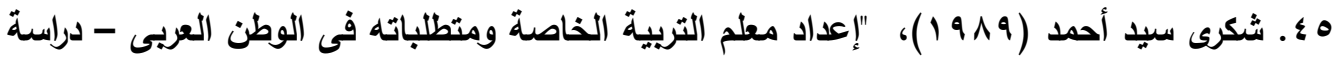

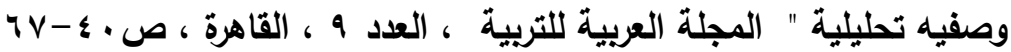

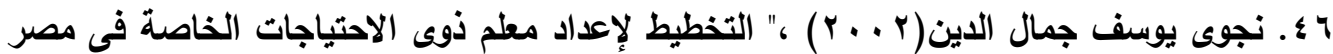
فى ضوء التطورات الحديثة والواقع الميدانى " ، مجلة التربية التنمية ، مكتب الاستشارات

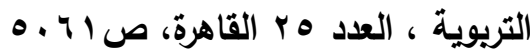

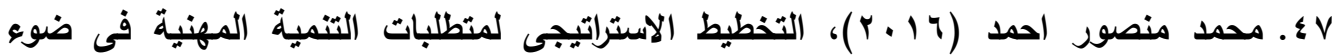

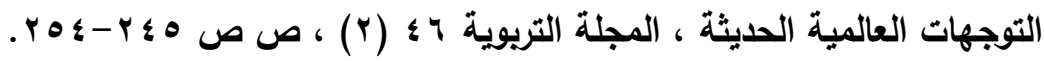

48. David Kaufman(2016), Enhancing Teacher Education with simulations, published online 9 march 2016 Association for Educational communications \& technology, p. 260-265.

49. Elise T. pas(2016), Reducing Behavior problems Among students with autism spectrum disorder: coaching teachers in mixed Reality setting. Published online: 2 September 2016, springing science + Business media new York, p 3640 - 3650.

50. Elise T(2016). pas, Reducing Behavior problems Among students with autism spectrum disorder: coaching teachers in mixed Reality setting. Published online: 2 September 2016, springing science + Business media new York, p 3640 - 3650

51. Mary P. Dingle(2011), Developing effective special education reading teachers: The influence of professional development, context, and 
استخدام اسلوب teach live فى التنمية المهنية لمعلم التربية الخاصة فى مصر

Individud Qualities, learning Disability Quartery, voL.. 34, No.1, p.87-103

52. Rob horowitz(2018), Every Arts for special education: Impact on student learning and teachen development, p.37-63

53. This research was supported by us department of Education I3 Grant U396C100275 awarded to district 75, New York City Department of education.

54. Cahill, K., Silva, R., \& Chappell, D. A. (2012). SANDI training manual. Riverside, CA: Riverside County Office of Education.

55. Horowitz, R., \& Horowitz, A. (2016, October). Demonstration of a hierarchical survey platform for program evaluation and student assessment. Demonstration presented at the American Evaluation Association Conference, Atlanta.

56. EVERYDAY ARTS FOR SPECIAL EDUCATION: IMPACT ON STUDENT... 64 New York State Education Department, Office of State Assessment. (2010). New York State Alternative Assessment: Administration manual 2010-11, pp. 1-31.

57. Albany, NY. Riverside County Office of Education, Special Education Unit. (2008). Student annual needs determination inventory (3rd ed.). Riverside, CA: Riverside County Office of Education. What Works Clearinghouse: Procedures and Standards

58. Handbook: Version 3.0. (2014). Washington, DC: U.S. Department of Education, Institute of Education Sciences.

59. Miller. M.D.. Brownell. M.T. \& Smith. S.W. (1999). Factors that predict teachers staying in leaving, or transferring from the special education classroom. Exceptional children. 65.-

60. Boe. E.E. Cook L.H.. Bobbitt. S.A. \& Terhanian. G. (1998). The shortage of fully certified teachers in special and general education. Teacher Education and Special Education.

61. Mastropieri. M. (2001). Is the glass half-full or half empty? challenges encountered by first year special education teachers. Journal of Special Education. 35(2). 66-75.

62. McNally. R. Cole. p. \&Waugh. R (2001). Regular teachers. Attitudes to the need for additional classroom support for the inclusion of. students with intellectual disability)'.Journal of Intellectual \& Developmental Disability. 26(3). 257-273.

63. Miller. M.D.. Brownell. M.T. \& Smith. S.W. (1999). Factors that predict teachers staying in leaving. or transferring from the special education class room. Exceptional children. 65 . 
استخدام اسلوب teach live فى التنمية المهنية لمعلم التربية الخاصة فى مصر

64. Riggs. C.(2001). Employment and utilization of par educators in inclusive settings Journal of Special Education. 35(1). 54-63

65. A American Psychiatric Association. (2013). Diagnostic and statistical manual of mental disorders (5th ed. Text revision). Washington, DC: Author .

66- Kristine M. Kulage, Arlene M. Smaldone, Elizabeth G. Cohn(2014). How Will DSM-5 Affect Autism Diagnosis? A Systematic Literature Review and Meta-analysis.Journal of Autism and Developmental Disorders,; DOI: 10.1007/s10803-014-2065-2

47. كلية التربية سرى محمد رشدى( • · ץ) ، إعداد معلم التربية الخاصة فى ضوء معايير الجودة ، المؤتمر العلىى العاشر " البحث التربوى فى الوطن العربى - رؤى مستقبلية " كلية التربية

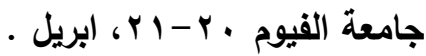

V. . محمد خميس(1991) ،فتحى عشيبة ،برنامج تدريبى مقترح لمعلم الصم أثناء الخدمة فى ضوء احتياجاتهم التدريبية ، المؤتمر السنوى الثالث التربية لذوى الاحتياجات الخاصة، كلية

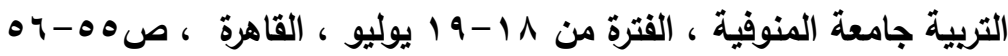

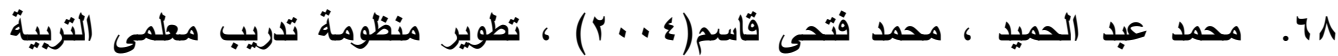
الخاصة فى مصر فى ضوء خبرات الاول ، مجلة التربية ، مجلة التربية ، الجمعية المصرية للتريبة المقارنة والإدارة التعليمية ، العدد I| ، السنهل ،مارس ،القاهرة . 97. وزارة التربية والتعليم (ع ا +ץ)، إحصائية بأعداد ذوى الاحتياجات الخاصة ، بوابة المعرفة . www.mog.gov.eg

• . . . الجهاز المركزى للتعبئة والإحصاء(11 + r) ، إعداد ذوى الاحتياجات الخاصة جمهورية مصر

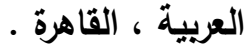

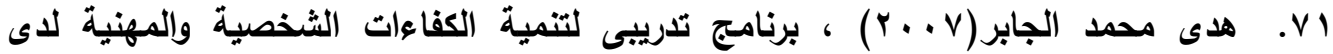
المعلمين فى تغيير اتجاهاتهم نحو دمج الأطفال ذوى الاحتياجات الخاصة ، رسالة دكتوراه ،،

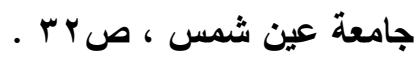

